Florida International University FIU Digital Commons

\title{
Corrosion Degradation Mechanism of CBPC Coating System for Highway Bridge Steel Components
}

\author{
Md Ahsan Sabbir \\ Florida International University, msabb004@fiu.edu
}

DOI: 10.25148 /etd.FIDC001797

Follow this and additional works at: https://digitalcommons.fiu.edu/etd

Part of the Civil Engineering Commons

\section{Recommended Citation}

Sabbir, Md Ahsan, "Corrosion Degradation Mechanism of CBPC Coating System for Highway Bridge Steel Components" (2017). FIU Electronic Theses and Dissertations. 3179.

https://digitalcommons.fiu.edu/etd/3179 
FLORIDA INTERNATIONAL UNIVERSITY

Miami, Florida

CORROSION DEGRADATION MECHANISM OF CBPC COATING SYSTEM FOR HIGHWAY BRIDGE STEEL COMPONENTS

A dissertation submitted in partial fulfillment of

the requirements for the degree of

DOCTOR OF PHILOSOPHY

in

CIVIL ENGINEERING

by

Md Ahsan Sabbir

2017 
To: Interim Dean Ranu Jung

College of Engineering and Computing

This dissertation, written by Md Ahsan Sabbir, and entitled Corrosion Degradation Mechanism of CBPC Coating System for Highway Bridge Steel Components, having been approved in respect to style and intellectual content, is referred to you for judgment.

We have read this dissertation and recommend that it be approved.

Norman D. H. Munroe

Ton-Lo Wang

Hesham Ali

Walter Tang

Dale DeFord

Kingsley Lau, Major Professor

Date of Defense: March 22, 2017

The dissertation of Md Ahsan Sabbir is approved.

Interim Dean Ranu Jung College of Engineering and Computing

Andrés G. Gil

Vice President for Research and Economic Development and Dean of the University Graduate School

Florida International University, 2017 
(C) Copyright 2017 by Md Ahsan Sabbir

All rights reserved. 


\section{DEDICATION}

I dedicate this dissertation to my beloved parents Md Abdul Hamid and Sakhina Khatun, and my lovely wife Saiada Fuadi Fancy. Their inspiration, support, and most of all love encouraged me to complete this work. 


\section{ACKNOWLEDGMENTS}

Research in this manuscript was supported by the State of Florida Department of Transportation (FDOT).

First and foremost, I would like to express my deepest gratitude to my major professor, Dr. Kingsley Lau, for his guidance, support, and encouragement at every stage of this dissertation. He encouraged playful and independent thinking and gave the freedom to try out new ways. With his very positive approach he assisted in boiling the essential out of results and helped to make the work converge to a thesis. I regard him as an outstandingly good scientific supervisor and a very nice person to work with.

My deepest appreciation is also extended to the examining committee members Dr. Norman D. H. Munroe, Dr. Ton-Lo Wang, Dr. Hesham Ali, Dr. Walter Tang and Dr. Dale DeFord for their invaluable contribution and reviewing my research work.

I experienced a great teamwork environment in the corrosion engineering laboratory and I am giving a countless number of thanks to many members of the laboratory specially Saiada Fuadi Fancy, Samanbar Permeh, Annie Barahona and Krishna Vigneshwaran Konda Krishnamurthy. 


\title{
ABSTRACT OF THE DISSERTATION \\ CORROSION DEGRADATION MECHANISM OF CBPC COATING SYSTEM FOR \\ HIGHWAY BRIDGE STEEL COMPONENTS
}

by

\author{
Md Ahsan Sabbir \\ Florida International University, 2017 \\ Miami, Florida \\ Professor Kingsley Lau, Major Professor
}

Coatings are widely used to mitigate corrosion of structural steel in aggressive humid environments. However, the service life is often diminished in aggressive environments. Repair of coatings can be costly due to materials, labor and environmental controls. So in search for novel coatings, Chemically Bonded Phosphate Ceramic (CBPC) coating was investigated for marine bridge application. The research on CBPC coating considered various exposure environments such as inland, beach, salt-fog, wet and alternate wet and dry exposure to identify the degradation mechanism of the CBPC coating for long-term application. To assess the corrosion damage due to exposure, the coating was evaluated by visual inspection, coating thickness, adhesion measurement, optical and electron microscopy and X-ray diffraction.

The CBPC coating degraded initially due to the alternate wet and dry environmental exposures. The unreacted coating constituent reacted further in moist environment to form magnesium phosphate hydrate and enhanced the coating porosity for bulk coating degradation. That facilitated excess moisture to the coating substrate and formed apparent protective iron phosphate hydrate by interaction with steel substrate to 
the CBPC coating constituents. Passive-like conditions were observed in wet test of chloride-free solutions for the formation of hydration product of magnesium but that type of hydrate was not identified in chloride solution for the apparent high solubility. The resolved impedance coating parameters (solution resistance, coating pore resistance and coating capacitance) were introduced to characterize the bulk ceramic degradation. The solution resistance did show a decrease for all samples in both salt and salt-free solutions due to the leaching of minerals from the bulk material during exposure to the solution. The resolved pore resistance did not show any distinct change, though there was an indication of bulk coating degradation by MIP testing. Water saturation level during exposure was also calculated from the resolved capacitance value. An approach was proposed to transfer the pre-exponential term, $\mathrm{Y}_{\mathrm{o}}$ to coating capacitance, $\mathrm{C}_{\mathrm{C}}$ for ceramic coating. The estimated value of the coating capacitance from the developed technique indicated early saturation with water during exposure due to the porous nature of the coating. So, the extent of CBPC coating permeability and degradation could not be resolved only by conventional approaches for data analysis for conventional coating. However, the formation of iron hydrogen phosphate hydrate and iron phosphate hydrate for the reaction of the unreacted coating constituents was thought to provide apparent protection from enhanced corrosion but there is a probability of steel substrate corrosion in extended exposure in humid environment. 


\section{TABLE OF CONTENTS}

CHAPTER

PAGE

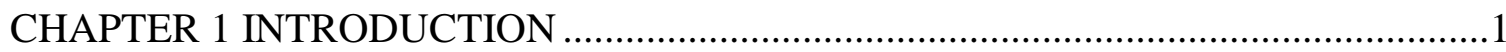

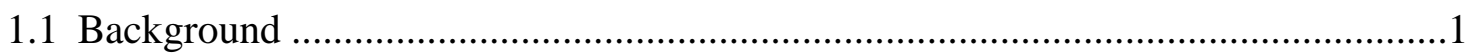

1.2 Chemically Bonded Phosphate Ceramic (CBPC) ................................................2

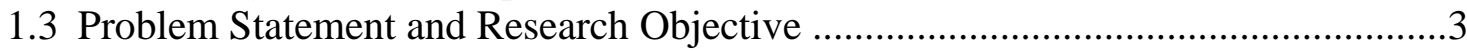

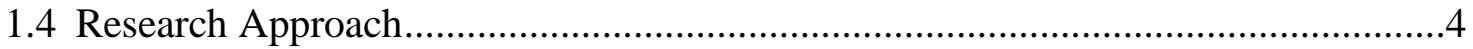

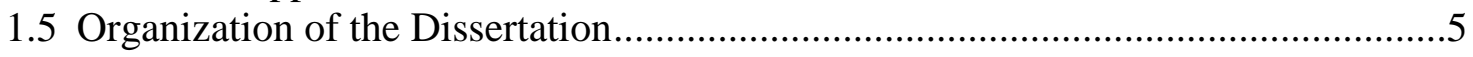

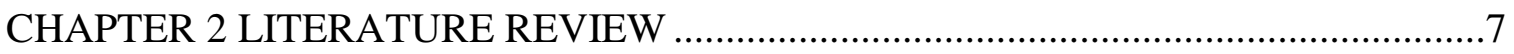

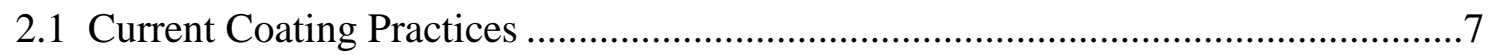

2.1.1 Three Coat Systems ……………………………........................................

2.1.2 Other Paint Coatings..................................................................................

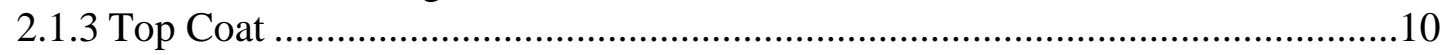

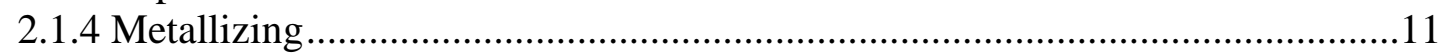

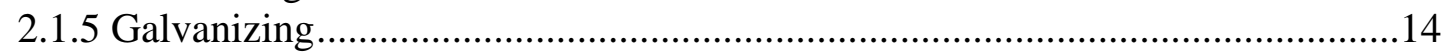

2.1.6 Galvanneal , Galvalume and Galfan..........................................................15

2.1.7 Thermal Diffusion Galvanizing (TDG) ......................................................16

2.1.8 Chemically Bonded Phosphate Coating …………..........................................17

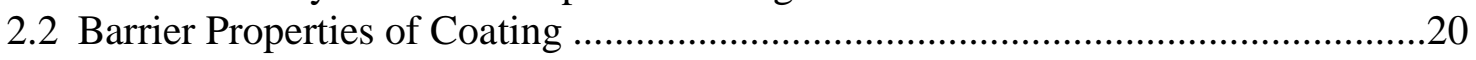

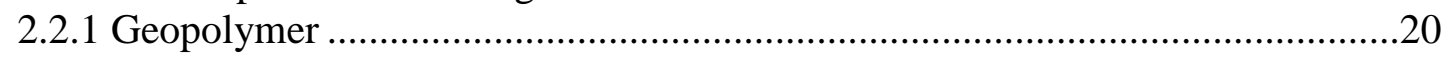

2.2.2 Zinc-Fe Alloy Layers...............................................................................21

2.3 Performance Evaluations for Structural Steel ...................................................23

2.3.1 Performance of Paint Coatings ......................................................................23

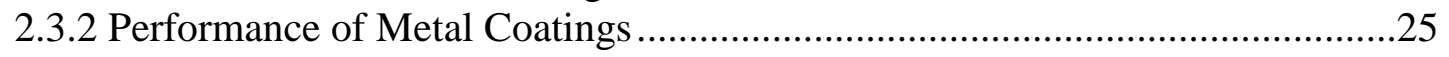

2.3.3 Performance of Ceramic Coatings ...............................................................26

2.5Electro Chemical Evaluation Basic Principles .......................................................27

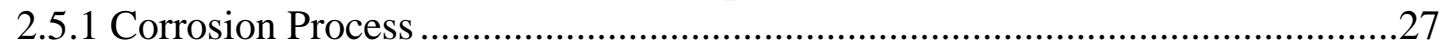

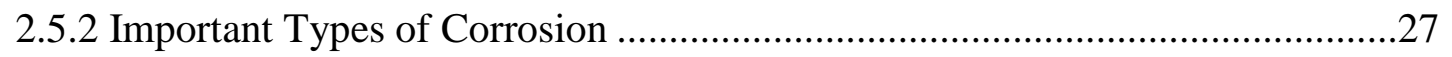

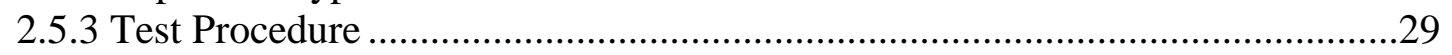

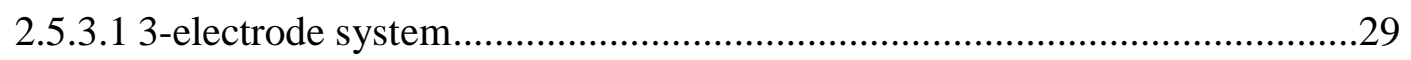

2.5.3.2 Open Circuit Potential..............................................................................29

2.5.3.3 Linear Polarization Resistance (LPR) .....................................................30

2.5.3.4 Electrochemical Impedance Spectroscopy ................................................... 31

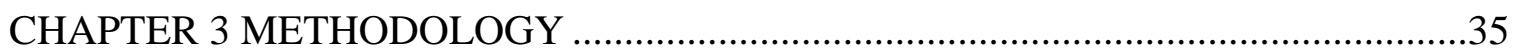

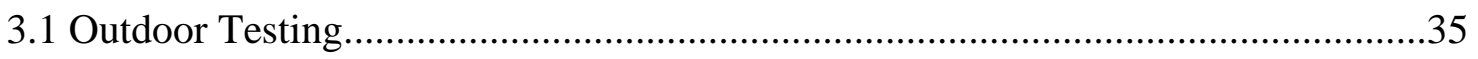

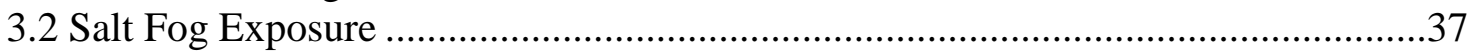

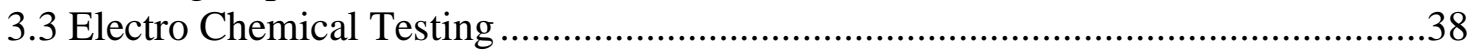

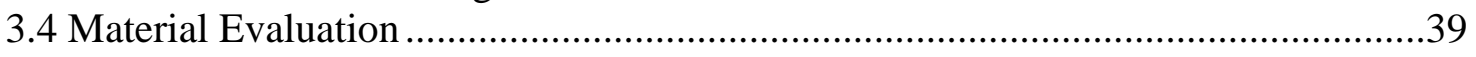




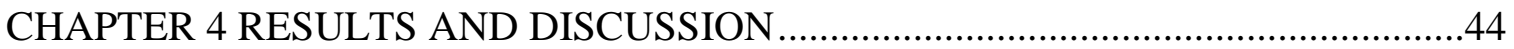

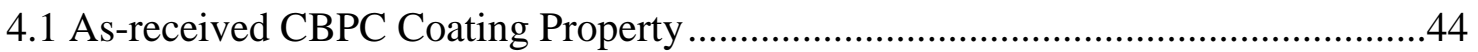

4.2 Coating Degradation after Out-door and Salt-fog Exposure.....................................46

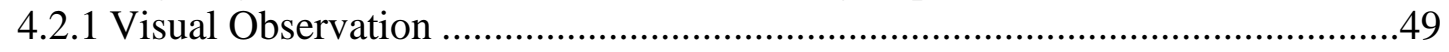

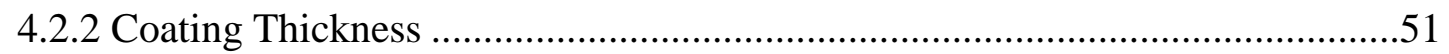

4.2.3 Pull-off Adhesion Strength ..............................................................................53

4.3 Assessment of CBPC Coating in Wet Exposure by Electro-Chemical Test.............55

4.3.1 After Exposure Pull-off and Thickness Measurement ……………………......56

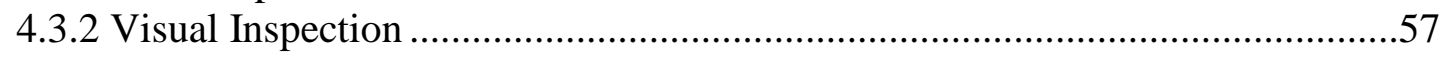

4.3.3 Electro-Chemical Test Results ..................................................................58

4.4 Assessment of CBPC Coating in Alternate Dry and Wet Exposure by Electro-

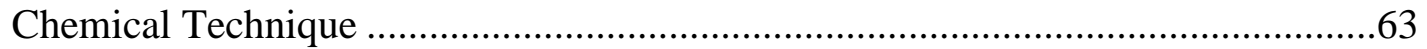

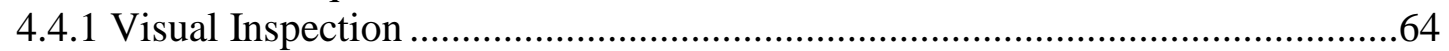

4.4.2 Coating Thickness and Pull-off Strength Measurement.....................................66

4.4.3 Electro-Chemical Test Results ....................................................................68

4.5 Metallurgical Assessment of the Exposed Samples .................................................71

4.5.1 Mercury Intrusion Porosimetry (MIP) ..........................................................71

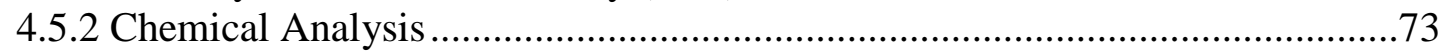

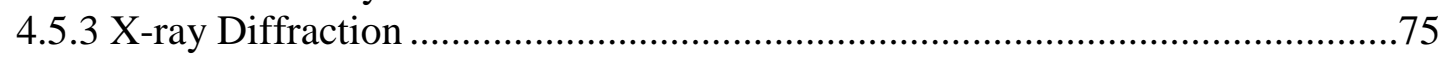

4.5.4 Optical Microscopy ………………………………..................................... 80

4.5.4 Scanning Electron Microscopy (SEM) and Energy Dispersive X-ray

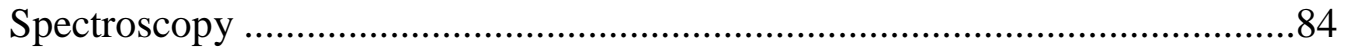

CHAPTER 5 DEGRADATION ASSESSMENT OF CBPC COATING BY ELECTROCHEMICAL IMPEDANCE SPECTROSCOPY .......................87

5.1 Coating Capacitance Measurement to Characterize Coating Degradation ...............87

5.1.1 Conversion Technique ( $\mathrm{Y}_{\mathrm{o}}$ to $\mathrm{C}$ ) by Van Westing............................................89

5.1.2 Conversion Technique ( $\mathrm{Y}_{\mathrm{o}}$ to $\mathrm{C}$ ) by Hsu and Mansfeld ....................................90

5.1.3 Comparison between Van Westing and (Hsu and Mansfeld) Approach for

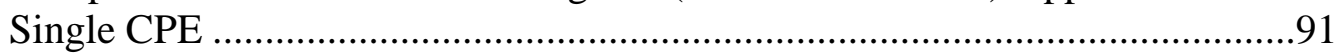

5.1.4 Conversion Approach ( $\mathrm{Y}_{\mathrm{o}}$ to $\mathrm{C}$ ) for Double CPE …………………………......94

5.1.5 Methodology to Measure the Capacitance of CBPC Coating ............................98

5.1.6 Application of Conversion Technique ( $\mathrm{Y}_{\mathrm{o}}$ to $\mathrm{C}$ ) for CBPC System...................99

5.1.7 CBPC Coating Capacitance and Water Absorption Capacity ……………........101

5.2 Calculation of Coating Defect Area from Coating Pore Resistance .......................103

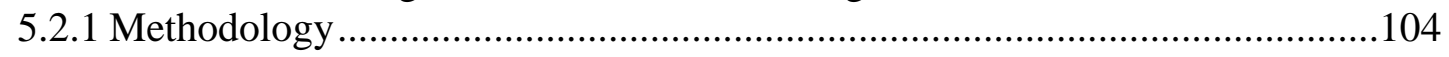

5.2.2 Assessment of the Coating Degradation by Pore Resistance ...........................104

CHAPTER 6 PROPOSED DEGRADATION MECHANISIM OF CBPC COATING..109

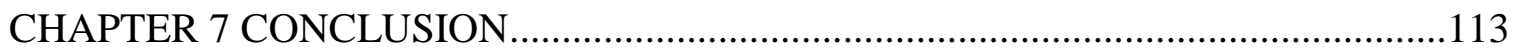

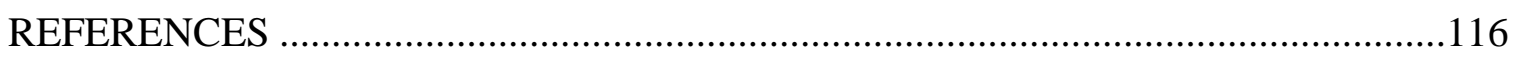

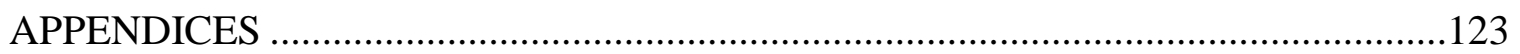




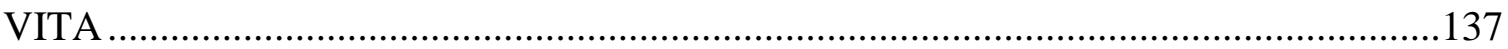




\section{LIST OF TABLES}

TABLE

PAGE

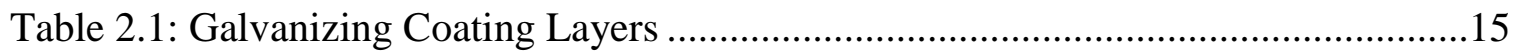

Table 4.1: Analytical Results of Electrolyte ............................................................. 74

Table 5.1: Calculation of $\mathrm{C}$ from Yo for Single CPE ................................................94

Table 5.2: Calculation of $\mathrm{C}$ from Yo for Double CPE .................................................98

Table 5.3: Calculation of $\mathrm{C}$ from Yo for CBPC ….....................................................101 


\section{LIST OF FIGURES}

FIGURE

PAGE

Figure 2.1. Thermal Spray Coating .....................................................................13

Figure 2.2. Hypereutectic Microstructure of ZnAl15 ............................................13

Figure 2.3: Microstructure of Hot Dip Galvanizing ................................................14

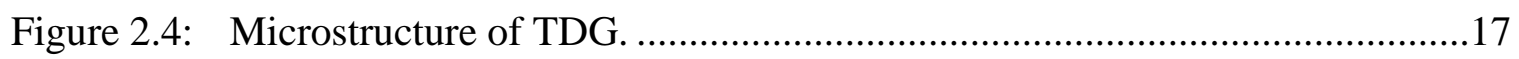

Figure 2.5: Electrical Equivalent Circuit of an Intact Coating in Contact with an Electrolyte.

Figure 2.6: Electrical Equivalent Circuit of a Coating in Contact with an Electrolyte by Considering the Base Property of the Steel.

Figure 2.7: Idealized Impedance Diagram of Coated Metal System with Coating Breaks and Equivalent Circuit Analog. ..................................................34

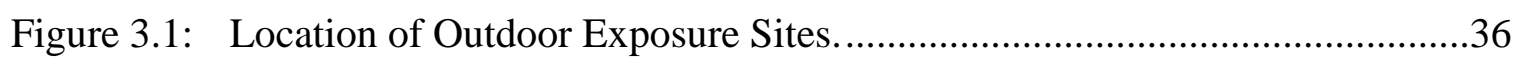

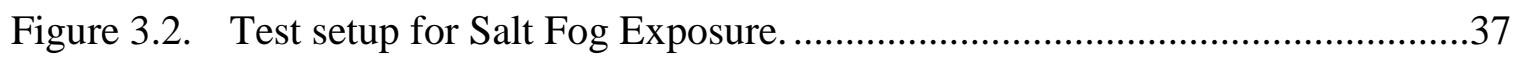

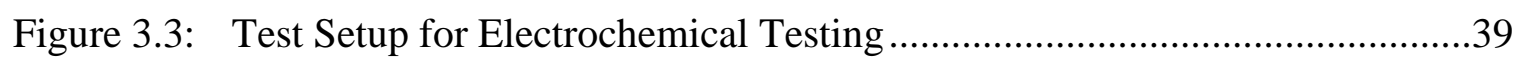

Figure 3.4: Test Setup for Electrochemical Testing.................................................39

Figure: 3.5 Sample Testing Surface Locations....................................................41

Figure: 4.1 CBPC Coating on Steel Cross-Section Micrographs...................................45

Figure 4.2: CBPC Sample Coating Thickness. .......................................................45

Figure 4.3: CBPC Coating Pull-off Strength......................................................46

Figure 4.4: Environmental Conditions at Outdoor Test Sites. ......................................48

Figure 4.5: Condition of the Samples after Exposure. .............................................49

Figure 4.6: After Exposure Coating Thickness of CBPC Coating.................................51

Figure 4.7: Pull-off Strength of CBPC Coating. ...........................................................53 
Figure 4.8: Coating Surface After Pull-off Testing..................................................54

Figure 4.9: Coating Degradation for Exposure. .....................................................58

Figure 4.10: OCP for CBPC Coating in Wet Exposure. ..............................................60

Figure 4.11: Corrosion Current for CBPC Coating in Wet Exposure.............................60

Figure 4.12: Nyquist Diagram for Non-scribed and Scribed CBPC Samples in Neutral $\mathrm{pH}$ with and without Chloride Solution (Representative Diagram)............................................................62

Figure 4.13: Solution Resistance for Non-scribed and Scribed Samples. .......................63

Figure 4.14: Coating Pore Resistance for Non-scribed and Scribed Samples. ................63

Figure 4.15: Coating Degradation after Wet and Dry Exposure..................................65

Figure 4.16: Micrograph of CBPC a) As-received b) Without Salt c) With Salt............. 65

Figure 4.17: CBPC Coating Thickness after Wet and Dry Exposure. ...........................67

Figure 4.18: CBPC Coating Pull-off Strength after Wet and Dry Exposure....................67

Figure 4.19: Visual Inspection of Coating Substrate after Pull-off Strength. ..................67

Figure 4.20: OCP for CBPC Coating during Wet and Dry Exposure...........................69

Figure 4.21: Corrosion Current for CBPC Coating during Wet and Dry Exposure..........69

Figure 4.22: Nyquist Diagram for Wet and Dry Exposure ........................................70

Figure 4.23: Solution Resistance for Wet and Dry Exposure. ....................................70

Figure 4.24: Coating Pore Resistance for Wet and Dry Exposure................................71

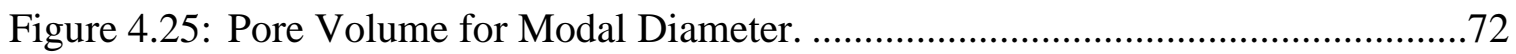

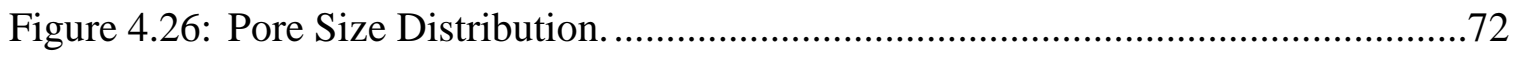

Figure 4.27: Electrolyte $\mathrm{pH}$ for Wet and Dry Exposure............................................75

Figure 4.28:Electrolyte Conductivity for Wet and Dry Exposure.................................75

Figure 4.29: X-ray Diffractogram for Inland Samples..........................................79 
Figure 4.30: X-ray Diffractogram for Beach Samples...................................................79

Figure 4.31: X-ray Diffractogram for Salt-fog Samples.................................................79

Figure 4.32: X-ray Diffractogram for Alternate Wet and Dry Exposed Samples..............80

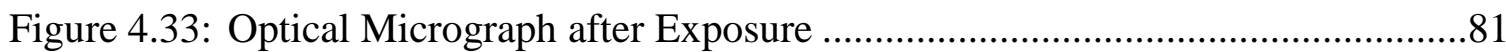

Figure 4.34: Optical Image after 5800 Hours Salt-fog Exposure.......................................81

Figure 4.35: Optical Micrograph of CBPC Coating at Salt-fog Exposure.........................83

Figure 4.36: Optical Micrograph of 24-Month Outdoor Exposed Samples.......................83

Figure 4.37: Optical Micrograph of CBPC Coating at Scribed Location. .........................83

Figure 4.38: SEM Picture on the Surface of the Coated Steel. ..........................................84

Figure 4.39: EDS Analysis for 24-month Beach Exposed Sample ………………..........85

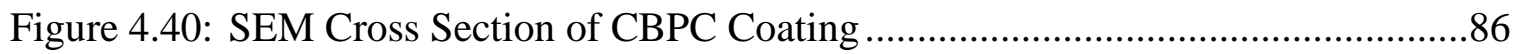

Figure 4.41: EDS Analysis on Cross Section of the Exposed Samples .............................86

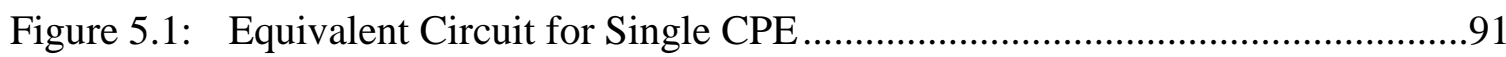

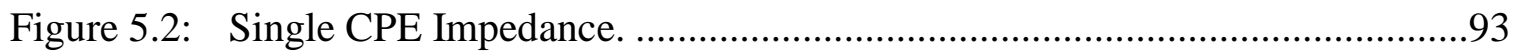

Figure 5.3: Frequency Dependance of Single CPE Impedance. ....................................93

Figure 5.4: Equivalent Circuit for Double CPE ………….........................................94

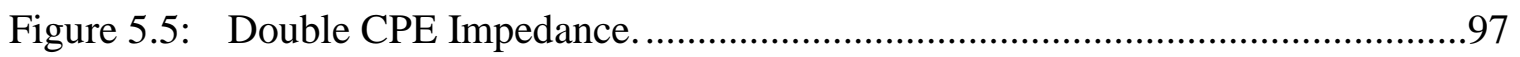

Figure 5.6: Frequency Dependence of Double CPE. ………………...........................97

Figure 5.7 Frequency Dependence of Impedance for CBPC Coating. ........................100

Figure 5.8: Frequency Dependence of Real Part of Impedance Z' for CBPC Coating. .101

Figure 5.9: CBPC Coating Capacitance ..................................................................102

Figure 5:10 Dielectric Constant of Electrolyte...........................................................103

Figure 5.11: Water Absorption of CBPC Coating.......................................................103 
Figure 5.12: Variation of Coating Pore Resistance and Coating Thickness with Time (Sample 1)

Figure 5.13: Variation of Coating Pore Resistance and Coating Pore Area with Time

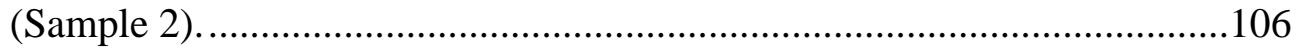

Figure 5.14: Correction Factor for Coating Pore Resistance ...........................................106

Figure 5.15: Calculation of Coating Pore Area .........................................................106 


\section{LIST OF SYMBOLS}

\begin{tabular}{|c|c|}
\hline $\mathrm{R}_{\mathrm{s}}$ & Solution resistance \\
\hline $\mathrm{R}_{\text {po }}$ & Coating pore resistance \\
\hline $\mathrm{C}_{\mathrm{c}}$ & Coating capacitance \\
\hline $\mathrm{C}_{\mathrm{dl}}$ & Double layer capacitance \\
\hline $\mathrm{R}_{\mathrm{p}}$ & Polarization resistance \\
\hline$\varepsilon_{0}$ & Vacuum permittivity \\
\hline$\varepsilon_{\mathrm{r}}$ & Relative permittivity \\
\hline A & Area \\
\hline $\mathrm{d}$ & Coating thickness \\
\hline$\rho$ & Resistivity \\
\hline $\mathrm{n}$ & Number of pores \\
\hline $\mathrm{Z}$ & Total impedance \\
\hline$\omega$ & Angular frequency \\
\hline$Y_{\mathrm{o}}$ & Pre-exponential term \\
\hline $\mathrm{I}_{\text {corr }}$ & Corrosion current \\
\hline $\mathrm{E}$ & Potential \\
\hline
\end{tabular}




\section{ABBREVIATIONS AND ACRONYMS}

\begin{tabular}{|c|c|}
\hline ATR & Activated Titanium Rod \\
\hline ASTM & American Society for Testing and Materials \\
\hline AWS & American Welding Society \\
\hline CBPC & Chemically Bonded Phosphate Ceramic \\
\hline CPE & Constant Phase Element \\
\hline CSA & Calcium Sulfonate Alkyd \\
\hline EDS & Energy Dispersive Spectroscopy \\
\hline EIS & Electrochemical Impedance Spectroscopy \\
\hline FHWA & Federal Highway Association \\
\hline HDG & Hot Dip Galvanizing \\
\hline LPR & Linear Polarization Resistance \\
\hline MIP & Mercury Intrusion Porosimetry \\
\hline NACE & National Association of Corrosion Engineers \\
\hline NASA & National Aeronautics and Space Administration \\
\hline $\mathrm{OCP}$ & Open Circuit Potential \\
\hline PVB & Polyvinyl Butyral \\
\hline SSPC & Society for Protective Coating \\
\hline SEM & Scanning Electron Microscopy \\
\hline SCE & Saturated Calomel Electrode \\
\hline TDG & Thermal Diffusion Galvanizing \\
\hline XRD & X-ray Diffraction \\
\hline
\end{tabular}




\section{CHAPTER 1}

\section{INTRODUCTION}

\subsection{Background}

In United States, $\sim 15 \%$ of the highway bridges were considered structurally deficient due to corrosion (Virmani \& Payer, 2002). Out of the estimated $\$ 8.3$ billion annual corrosion cost, half a billion dollars is spent on painting maintenance. The majority of steel bridges in the interstate highway system was constructed prior to 1970 and was generally coated by alkyd paint containing toxic lead and chromate (Federal Highway Association [FHWA], 2006). Those coating systems became prohibited by the Environmental Protection Agency due to environment and health hazards. More robust and economic coating systems are important in consideration of the large size and intrinsic importance of the US transportation infrastructure to the vitality of the national economy. Further, it is a national responsibility to address the concerns of rising costs and global sustainability. Novel coatings have continuously been introduced but stringent evaluation for application in aggressive environments relevant to highway bridges has not necessarily been made. The evaluation of novel coating system will directly benefit the national economy by contributing to the engineering of sustainable national infrastructure (Murray, 1997).

At present, the multilayered zinc-rich paint system (three-coat) is widely used but its rigorous application preparation and its required regular maintenance is not ideal for long-term bridge durability. Considering lifetime costs of the coating system, the major portion of the costs derives from the initial application. FHWA conducted a series of studies from 2006 to 2012 to identify robust and economic coated zinc-rich paint systems 
that may augment three-coat systems (FHWA, 2006; FHWA, 2011 \& FHWA, 2012).

Those studies concluded that none of the tested one or two-coat systems could meet a 100 years maintenance free requirement. Chemically bonded phosphate ceramics (CBPCs) coatings were selected for research in consideration of promising material properties and ease of application.

\subsection{Chemically Bonded Phosphate Ceramic (CBPC)}

CBPCs are a class of broadly defined geopolymers that have amorphous binding phases analogous to cement (Wagh, 2005). It is made by acid-base reactions between phosphoric acid and inorganic oxides. Aquasols from the dissolved metal oxides react with phosphate ions and condense to form a gel that proceeds to crystallize into monolithic ceramic (Wagh \& Jeong, 2003). One example of CBPC developed with magnesium oxide at Argonne National Laboratory is represented by Eq.1.1

$$
\mathrm{MgO}+\mathrm{KH}_{2} \mathrm{PO}_{4}+5 \mathrm{H}_{2} \mathrm{O}=\mathrm{MgKPO}_{4} \cdot 6 \mathrm{H}_{2} \mathrm{O}
$$

The two components of the coating, acid phosphate and metal oxides, are mixed together and sprayed on the metal surface with a dual component spray gun. The CBPC coating interacts with the metal substrate to form an insoluble passivation layer of stable oxides ( $\sim 20-\mu \mathrm{m}$ thick) that contains $\sim 60 \%$ iron with phosphate, potassium, magnesium, hydrogen, and oxygen (Materials Performance, 2011).

The CBPC coating was promoted as being compatible with aluminum, portland cement, gypsum, and steel. The CBPC can be used in environments with temperatures from $35^{\circ}$ to $200^{\circ} \mathrm{F}$ and $0 \%$ to $99 \%$ humidity. Testing indicated that CBPC coating could flex up to $19 \%$ before fracture (Materials Performance, 2011). 


\subsection{Problem Statement and Research Objective}

The commercial availability, industry promotion, and early testing of CBPC by the US Navy have garnered interest by transportation departments. Appropriate evaluations and specifications are needed for novel coatings, such as CBPC, that have not been used for highway bridge applications. Pertinent testing and evaluation are needed, due to the limited available information from independent testing of the material in severe conditions, especially for consideration of adoption in aggressive environments associated with marine bridges.

The first step to evaluate the CBPC coating is to identify the proper test method, which can give a proper understanding of the degradation and protective mechanism in relevant exposure environments. The results will also give the proper indication of the potential application of the CBPC coating. Further, the degradation and durability mechanism will eventually lead to predict the service life of the CBPC coating with their corresponding exposure conditions.

The objective of this study is to identify the degradation mechanism, durability, and ability to mitigate corrosion of CBPC coated steel components in exposure relevant to highway bridge structural steel.

\section{Research Questions}

- How can CBPC coatings degrade in environment and exposure conditions relevant to marine environment?

- What is the effect of coating damage on coating degradation, durability, and corrosion mitigation? 
- What are the corrosion protection mechanisms of the CBPC coatings in atmospheric environment?

- How can electrochemical techniques be used to assess the CBPC coating corrosion condition?

- How can the corrosion damage of CBPC be predicted over time in atmospheric environment?

\section{Hypothesis}

The durability of the CBPC coating is strongly connected to its barrier property. The durability of the material can be comprehensively assessed by a complete understanding of the microstructural property and electrochemical behavior of the barrier materials during degradation.

\section{$1.4 \quad$ Research Approach}

The proposed research approach includes to:

1. Expose coatings with and without intentional defects to aggressive outdoor exposure at beach site and inland locations.

2. Expose coating with and without intentional defects in accelerated corrosion saltfog environments.

3. Identify corrosion behavior of coated steel in laboratory testing with aqueous solutions representative of pooled runoff water.

4. Use electrochemical testing technique to identify coating and corrosion behavior during chemical exposure in aqueous solution. 
5. Identify coating degradation and corrosion development by physical evaluation of exposed test samples as well as other material evaluation techniques such as metallurgical assessment, optical and electron microscopy and XRD.

This study examined the CBPC coating degradation and corrosion development for the various aggressive exposures and identified important durability parameter that are responsible for later degradation. This study also aimed to evaluate the effectiveness of the electro-chemical techniques to assess the degradation of CBPC coating.

\subsection{Organization of the Dissertation}

This dissertation is organized as follows:

Chapter 2 provides general overview of the coating systems for steel bridge application and basic concept of the electrochemistry related to coating evaluation.

Chapter 3 represents the research methodology to achieve the objective of the research. The detail test procedures and evaluation technique of the tested samples is also documented in this chapter.

Chapter 4 presents the results of the tested samples, which were exposed in different test exposure. A comprehensive discussion is also made based on the test results to describe the degradation process related to that environment.

Chapter 5 presents the assessment of CBPC coating degradation by EIS measurement. The assessment indicates the important coating parameters to capture the coating response in aggressive marine bridge environment.

Chapter 6 summarizes the findings from the outdoor, accelerated salt-fog and electro-chemical tests and the sequential steps of coating degradation during exposure is proposed. 
Chapter 7 summarizes the general conclusion about the CBPC coating durability in exposure related to aggressive marine bridge environment.

Some content in this dissertation has been published in report form to the sponsoring agency (Sabbir and Lau, 2014) and published in conference proceedings (Sabbir et al, 2017). Those published contents have been in part reproduced here. 


\section{CHAPTER 2}

\section{LITERATURE REVIEW}

\subsection{Current Coating Practices}

Some coating systems that are commercially available or recently introduced in the market are described next.

\subsubsection{Three Coat Systems}

Among accepted paint coatings, the three-coat system has been considered to have good long-term performance and durability with some case studies with bridges in non-marine environments cited to have been effective for over 40 years (Kline, 2009). The three-coat system typically consists of either an organic or inorganic zinc-rich primer (although other primers have been formulated) followed by an epoxy midcoat and a topcoat.

The corrosion activity of zinc can provide cathodic protection of the steel substrate (Monlar \& Liszi, 2001). Research has also described positive performance of the zinc primer material by reducing its permeability. For example, some types of zinc dust used in primers have a plate-like structure, which may decrease permeability of the zinc primer layer and consequently less steel corrosion. The highest anticorrosion efficiency of the lamellar zinc particles observed at a concentration around $20 \mathrm{vol} \%$ (Kalendova, 2003). Insoluble zinc corrosion products (such as zinc carbonate) developed by the sacrificial zinc material may fill the pores of the zinc primer layer and reduce moisture penetration (Calla \& Modi, 2000). The corrosion protection of the three-coat system with inorganic zinc primers was reported to be better for new construction than 
with organic zinc primers. However, the sensitivity of inorganic zinc primers to surface conditions limits its application to controlled settings in shop.

The midcoat (typically epoxy binders) is used to provide additional separation from the steel substrate/primer from the environment providing a layer over defects in the primer and to reduce moisture and chemical ingress to the steel surface. Three types of epoxy intermediate coats are available including epoxy ester, epoxy lacquer, and a two components epoxy (Chang \& Chung, 1999). Epoxy ester is an oil modified epoxy resin with superior alkali resistant. Epoxy lacquer is a high molecular weight epoxy with short curing time. Two component epoxies are epoxy polyamides with superior flexibility, durability and pot ability. Generally, these high build epoxy intermediate coating offers excellent resistance to water and alkali. The disadvantages of epoxy are poor resistance against chalking, poor rating for gloss retention and are not recommended for cold temperature because of its expansion and shrinkage rate (Chang \& Chung, 1999).

Finishes and topcoats are used to retain coating aesthetics and provide wear and UV resistance. Urethane and polyurethane binders are typically employed as oil-modified urethane, moisture-cured urethane, and two-component urethane (Chang, L. et al., 1999). Oil modified pigmented urethanes are not used for exposed structural steel for the lack of durability. Moisture-cured urethane use air moisture for curing and produces a hard and tough coating. Pigmentation is difficult, so it is used for clear finishes. Two-component urethane use polyols, polyethers, polyesters or acrylics. For three coat systems, hydroxylated acrylic or hydroxylated polyester binded urethanes are most commonly used as they have better UV resistance and fast drying property. 
Of the lifetime costs of the coating system, the larger portion of the costs derives from the initial application (Kline, 2009) and coating systems with fewer layers are being evaluated to reduce those costs (Yao et al., 2011).

\subsubsection{Other Paint Coatings}

Two coat systems have been described eliminating the requirement of the intermediate coating (Chong \& Yao, 2006). The zinc rich primer is topcoated with a polymer coating such as polyurea, polyurethane, polysiloxane, and polyaspartics.

Polyurea is a rapid cure polymer for corrosion and abrasion mitigation. Polyurethane is a high-performance topcoat formed by reacting polyisocyanate with polyol or base resin. Polysiloxane is an inorganic polymer that offers resistance to water, chemicals, and oxidation; and has good color and gloss retention. Polyaspartics are a fast drying coating that builds on conventional polyurethanes with high thickness. Inorganic zinc and vinyl system is a two-coat system. Interaction of the polyvinyl butyral (PVB) resins with zinc chromate pigments and phosphoric acid provide good adhesion. However, the inorganic zinc and vinyl system has been reported to perform poorly in terms of gloss and UV prevention (Chang et al., 1999). Indiana DOT experienced effective lifetime about 15 years (Chang \& Chung, 1999).

The moisture cure urethane coating system is a single pack paint recently used in Wisconsin, Alaska, Maine, Vermont, New Hampshire, New York, Kentucky, and Minnesota with expected life time of 20 to 30 years. The moisture cure urethane is less sensitive to surface preparation and atmospheric moisture content. The reaction of the urethane with atmospheric water involves a two-stage process with the water and the isocyanate group first producing the unstable carbonic acid, which immediately 
dissociates to form an amine and carbon dioxide. The carbon dioxide leaves the film by evaporation, and the amine reacts with a second group giving a urea (Chang \& Chung, 1999).

Calcium sulfonate alkyd (CSA) is a one-coat package system that can be applied with minimum surface preparation with hand tool cleaning and solvent cleaning, and is ideal to overcoat-deteriorated painting. Use has been reported in Missouri (Myers et al., 2010). The limitation is the long curing time and according FHWA, the soft material picks up dirt easily (Myers et al., 2010). One coat systems including polyaspartic, epoxy mastic, high ratio calcium sulfonate alkyd, glass flake reinforced polyester, high-build waterborne acrylic, waterborne epoxy, polysiloxane, and urethane mastic were evaluated by the Federal Highway Administration in 2011 (Yao et al., 2011). General descriptions of the tested one-coat systems after Yao et al., 2011 follow. The polyaspartic coating is produced by reaction of ester compounds providing fast drying time and weatherability. Epoxy mastic is an aluminum-pigmented high solid epoxy coating. The high ratio calcium sulfonate alkyd is an alkaline coating that forms ionic bonding with the underlying metal and may promote steel passivity. Glass flake reinforced polyester coatings have good mechanical properties and chemical resistance. High build waterborne acrylic and waterborne epoxy coatings have low flammability, odor and VOC. Polysiloxane coatings are an organic-inorganic siloxane binder. Urethane mastics are a high build acrylic-urethane system.

\subsubsection{Top Coat}

The top coat reduces moisture penetration, degradation due to UV, and covers local defect in the intermediate coats. Additionally, it provides aesthetics that may be 
required in design (Chang \& chung, 1999). As generally recommended coating thickness is 5 to 6 mils, the top coat in part helps to satisfy the thickness requirements (Chang \& chung, 1999). The wetting mechanism of a coating is a function of surface energy of the barrier layer and the topcoat dispersion. The performance of a top coat depends upon the compatibility with the base coating and some investigation strongly recommended this fact. Common top coats are described next.

Two types of urethane are available: aliphatic and aromatic (which may have a binder of oil-modified urethane, moisture-cured urethane and two-component urethane). Oil-modified pigmented urethanes are not used for exposed structural steel for the lack of durability. Moisturecured urethane use air moisture for curing and produces a hard and tough coating. Pigmentation is difficult, so they are mainly used for clear finishes. Two component urethanes use polyols, polyethers, polyesters or acrylics. Hydroxylated acrylic or hydroxylated polyester binded urethanes are most commonly used as they have the better UV resistance and fast drying property. Polyurethane is another high-performance topcoat which formed by reacting polyisocyanate with polyol or base resin (FHWA, 2006). Calcium Sulfonate Alkyd (CSA) is a one-coat package system. It can be applied with minimum surface preparation with hand tool cleaning and solvent cleaning. CSA can be used to deteriorate overcoat painting but requires long curing time and may pick up dirt easily (Myers et al., 2010).

\subsubsection{Metallizing}

Metallizing refers to the application of zinc, aluminum, or zinc aluminum alloy to steel surfaces by thermal spray for corrosion control (Chang et al., 1999; Koger et al., 1998 \& Bernecki et al., 1997). The steel surface is prepared by grit blistering or chemical etching for proper mechanical bonding. Aluminum requires more surface roughness than zinc (Chang \& Georgy, 1999). Surface preparation specifications include SSPC-SP 5 
White metal blast cleaning, NACE No 1 White metal blast cleaned surface finish (comparable to SSPC-SP 5), SSPC-SP 10 Near white metal blast cleaning, NACE No 2 White metal blast cleaned surface finish (comparable to SSPC-SP 10) (Chang \& Georgy, 1999). Flame spraying and arc spraying among spraying techniques were developed. The coating porosity made by flame spraying may be around 20 percent due to the relatively low application velocity (Chang \& Georgy, 1999). Arc spraying can be more expensive but can create layers with better adhesion, better cohesion, and lower porosity due to the higher application velocity. The molten zinc, aluminum, or zinc aluminum alloy in both processes are accelerated and the resultant droplets form as splats on the steel substrate. An example of a thermal spray coating of zinc/aluminum alloy on steel and the metallizing material is shown in Figures 2.1 and 2.2. The desired thickness is made by applying additional passes over the steel. The American Welding Society (AWS) issued a guide, ANSI/AWS C2.18-93 and a joint standard SSPC-CS23.00/AWS C2.23M/NACE No. 12 for thermal spray coatings on steel. Research by the US Navy showed better corrosion mitigation performance with thermally sprayed aluminum than zinc in marine environments (Chang \& Georgy, 1999). Alloys 85 percent zinc/15 percent aluminum have also been used for thermal spray coatings. Cleanliness is of importance where moisture and contaminants may reduce bond of the coating to the steel (Chang \& Georgy, 1999). The expected life of metallization is 40 to 60 years if sealers are used (Chang \& Georgy, 1999). 


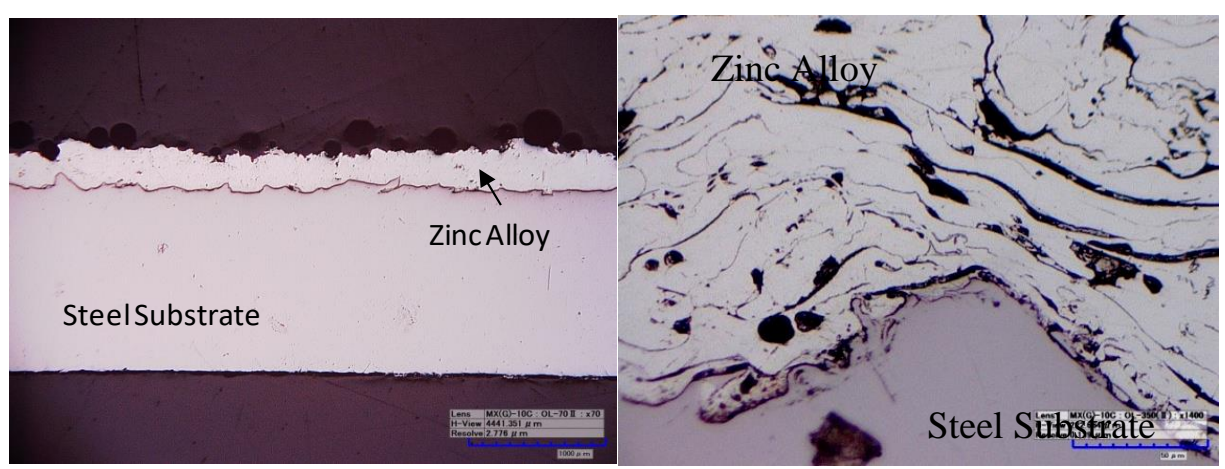

Figure 2.1. Thermal Spray Coating.

(Figure by Lau and courtesy of FDOT.)

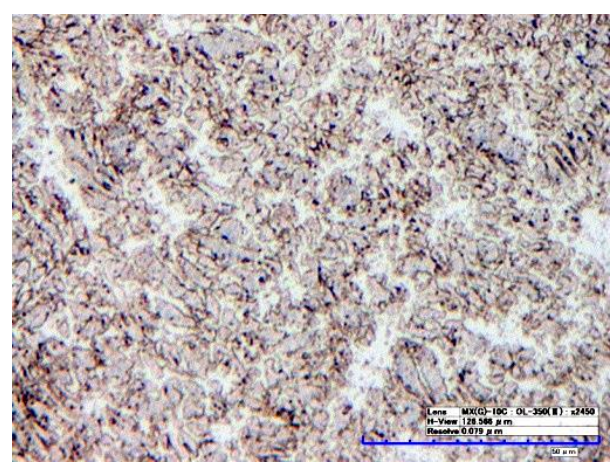

Figure 2.2. Hypereutectic Microstructure of ZnAl15.

(Figure by Lau and courtesy of FDOT.)

Sealers such as acrylic urethane, polyester urethanes, vinyls, phenolics, epoxy or thermal sprayed polymer can be used to enhance service life by sealing the pores in the coating. Seal coats are applied on the dry surface before visible oxidation and some protocol to remove moisture by heating (ie. $120^{\circ} \mathrm{C}$ ) have been suggested (Chang \& Georgy, 1999). Seal coats are typically applied soon after metallizing (ie. after within 8 hours for zinc and zinc alloys and within 24 hours for aluminum application) (Chang \& Georgy, 1999). 


\subsubsection{Galvanizing}

Batch hot-dip galvanizing (HDG) has been the most commonly used method of protecting steel products from corrosion for over 200 years (Zhmurkin, 2009). In this process an adherent, protective coating of zinc or zinc alloy is developed on the surfaces of iron and steel products by immersing them in a bath of molten zinc (Dallin, 2012). The galvanized steel develops a thick zinc-iron alloy coating with layers of different alloy composition (Figure 2.3); the properties of these layers are given in Table 1(Dallin, 2012).

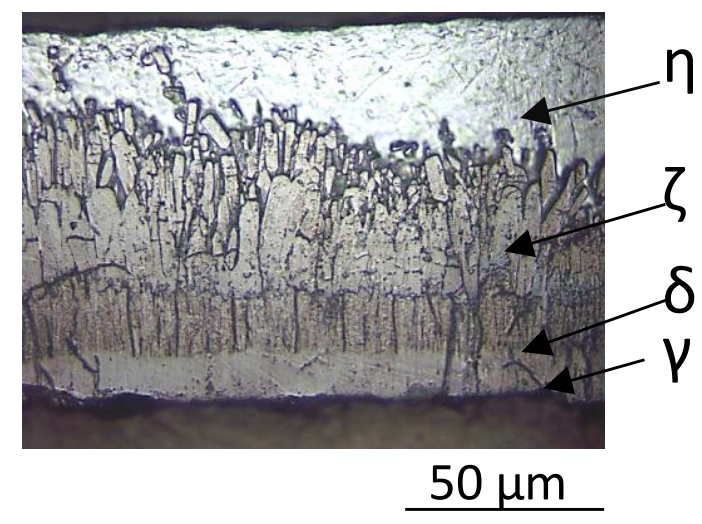

Figure 2.3: Microstructure of Hot Dip Galvanizing.

The continuous process consists of feeding cold rolled steel through a cleaner, an annealing furnace, and then into molten zinc bath at speeds up to $200 \mathrm{rpm}$. As the steel exits the molten zinc bath, excess coating from the steel sheet are removed to the specified requirement. The coating is left to set as traditional galvanizing methods. 
Table 2.1: Galvanizing Coating Layers (After Dallin,2012)

\begin{tabular}{|c|c|c|c|c|}
\hline Layer & Alloy & Iron $\%$ & $\begin{array}{c}\text { Crystal } \\
\text { Structure }\end{array}$ & $\begin{array}{c}\text { Alloy } \\
\text { Characteristics }\end{array}$ \\
\hline Eta, $\eta$ & Zinc & 0.03 & Hexagonal & Soft, ductile \\
\hline Zeta, $\zeta$ & FeZn $_{13}$ & $5.7-6.3$ & Monoclinic & Hard, brittle \\
\hline Delta, $\delta$ & $\mathrm{FeZn}_{7}$ & $7-11$ & Hexagonal & Ductile \\
\hline Gamma, $\Gamma$ & FeZn 10 & $20-27$ & Cubic & Hard, brittle \\
\hline Steel Base & Iron & $99+$ & Cubic & \\
\hline
\end{tabular}

\subsubsection{Galvanneal , Galvalume and Galfan}

If the hot deep galvanizing steel is future heated at $500-550^{\circ} \mathrm{C}$ for 10 secs after exiting the molten zinc bath and passing through the wiping dies, iron inter diffuses from the steel substrate and zinc diffuses from the galvanized coating to form Galvanneal coating (Zhang,1996). The outermost $\zeta$ layer contains $6 \% \mathrm{Fe}$ and intermediate $\delta$ layer 8$12 \% \mathrm{Fe}$. The $\Gamma$ layer possesses significant different mechanical property, which controls the formation of the coating.

Galvalume consists of 55\% Al, 1.5\% $\mathrm{Si}$ and $43.5 \% \mathrm{Zn}$ (Zhang, 1996). It has higher corrosion resistance with less galvanic action than HDG. The coating consists of outer layer and inter metallic layer. The intermetallic layer is future subdivided into two layers- the inner sub layer, quaternary, AL-Fe-Si-Zn and outer sub layer, ternary, Al-SiFe compound. The function of the silicon to control the reaction in hot dipping to maintain the thickness of inter metallic layer. 
Galfan coating consists of $95 \% \mathrm{Zn}, 5 \% \mathrm{Al}$ and small amount of other elements with lamellar structure of alternating zinc rich and aluminum phase (Zhang, 1996). The addition of misch metal facilitates the formability by eliminating the brittle intermetallic layer.

\subsubsection{Thermal Diffusion Galvanizing (TDG)}

Thermal diffusion galvanizing (TDG) was introduced in 1904 (Isakaev et al., 2010). Due to long processing time and difficulty in controlling thickness, use of TDG was diminished by 1950 . Renewed interest was made by 1993 for coating steel fasteners and hardware. Specification of zinc alloy thermo-diffusion coatings for hardware was made in ASTM standard A1059 (ASTM, 2008).

The coating process involves vapor diffusion of zinc into steel. The process creates a zinc/iron alloy by penetrating the surface on steel. The steel components and zinc powder are rotated within a closed cylinder inside of an oven and heated to a temperature of $710^{0}-1092^{0} \mathrm{~F}\left(320^{0}\right.$ to $\left.500^{\circ} \mathrm{C}\right)$ (ASTM, 2008). Zinc sublimation occurs at $500^{\circ} \mathrm{F}$ and by penetrating the steel, produces $\mathrm{Zn} / \mathrm{Fe}$ alloy. This process results in the formation of iron-zinc gamma (solid $\mathrm{Zn}$ ions inside $\mathrm{Fe}$ substrate), delta $\left(\mathrm{Fe}_{11} \mathrm{Zn}_{40}\right)$, and zeta $\left(\mathrm{FeZn}_{7}\right)$ layers, excluding the external eta layer of pure free zinc (ASTM, 2008). The coating metallurgy of zinc in thermal diffusion galvanizing (TDG) is analogous to hot dip galvanizing but the longer heat cycle associated with TDG allows much deeper penetration of zinc into the steel substrate. The thickness of the eta (pure zinc) in TDG is significantly thinner than in Hot Dip Galvanizing. The eta layer has much less corrosion resistance than the zinc/iron phases. The zinc/iron phases (zeta, delta, and gamma layers) can be thicker in TDG than hot dip galvanizing (Figure 2.4). 


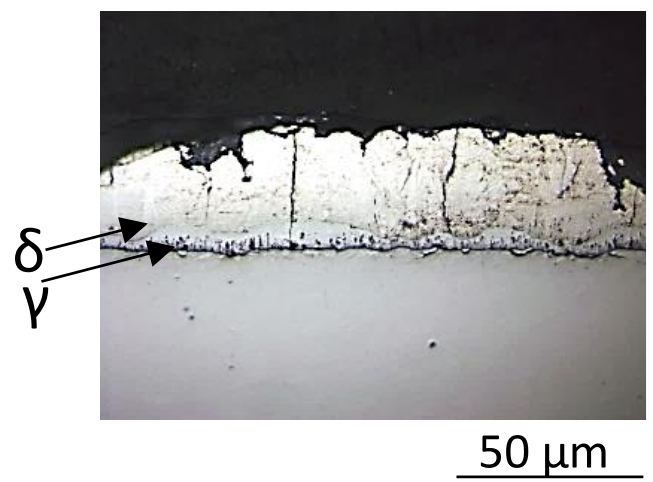

Figure 2.4: Microstructure of TDG.

Some properties of TDG from industry literature are described. TDG produces a material that is hard, weld able, spark free, anti-galling, non-magnetic and has low coefficient of friction. The hardness can exceed 35 Rockwell C depending on coating parameters (ASTM, 2008). The coated parts can be operated at continuous temperature up to $1200^{\circ} \mathrm{F}\left(650^{\circ} \mathrm{C}\right)$. The zinc layers has good adhesion to the steel substrate as the zinc penetrates the base metal about $1 / 3$ of the coating thickness (ASTM, 2008), the coating consists mainly of the iron-zinc delta-phase as shown in Figure 2.4, containing 4 to $10 \%$ of iron (ASTM, 2008). Adhesion of paint and top coats to the zinc has been promoted to be good due to the morphology of the TDG layer (ASTM, 2008). TDG has been suggested to not promote hydrogen embrittlement of the steel (ASTM, 2008). This feature can be beneficial to protect high tensile parts such as springs and fasteners as it offers a sufficient ductility (ASTM, 2008).

\subsubsection{Chemically Bonded Phosphate Coating}

Chemically bonded phosphate ceramics (CBPC) are a class of broadly defined geopolymers that have amorphous binding phases analogous to cement (Wagh, 2005). It is made by acid-base reactions between phosphoric acid (or acid phosphates) and inorganic oxides. Aquasols from the dissolved metal oxides react with phosphate ions and condense to form a gel that proceeds to crystallize into monolithic ceramic (Wagh \& 
Jeong, 2003). Ceramic has high mechanical property than cement and performs better in acid and high temperature environment.

Metal oxide forms cations, which react with the phosphate anions in an acid phosphate solution to produce phosphate gel. Ceramics are formed at near neutral $\mathrm{pH}$. Basically, the sparsely soluble solids are the best materials for ceramic formation. Most of the sparsely soluble solids are divalent and trivalent. The dissolution of divalent metal oxide is greater than the solubility of trivalent metal oxide. The solubility should be in between these two metals (Jeong \& Wagh, 2002) for the formation of the crystal. Among them, the divalent metals are suitable for crystal formation.

The reaction steps to form magnesium, aluminum, or iron phosphate ceramic are briefly described next. For magnesium phosphate, the magnesium is calcined at $1300^{\circ} \mathrm{C}$ to reduce presence of micro pores from the grain. Then the calcined magnesium is reacted with acid phosphate solution (ammonium or potassium dihydrogen phosphate solution) to create ceramic magnesium ammonium phosphate or magnesium potassium phosphate following the equation 2.1. The solubility of the calcined magnesium is too high for the preparation of large sample due to high exothermic heat reaction. To reduce the solubility, less than $1 \%$ boric acid is added to form lunebergite. For the formation of aluminum phosphate ceramic, the temperature of the acid base solution should be maintained at $150^{\circ} \mathrm{C}$ to increase the solubility of the alumina. For the formation of iron phosphate ceramic, the solubility of iron is increased by reducing iron trivalent to divalent cations. CBPC has been developed with magnesium oxide at Argonne National Laboratory to stabilize and encapsulate radioactive materials (Jeong \& Wagh, 2002). 
CBPC are now used in different fields like corrosion resistant coating, road repair, bone and dental cement in addition to waste stabilization.

$$
\mathrm{MgO}+\mathrm{KH}_{2} \mathrm{PO}_{4}+5 \mathrm{H}_{2} \mathrm{O}=\mathrm{MgKPO}_{4} \cdot 6 \mathrm{H}_{2} \mathrm{O}
$$

The CBPC coating consists of two component acid phosphate and water-based slurry that contains base minerals and metal oxides (eg. MgO). These two components are mixed together and sprayed on the metal surface with a dual component spray gun. The acid phosphate and oxides in the slurry interact with the metal substrate to form an insoluble passivation layer of stable oxides ( $\sim 20-\mu \mathrm{m}$ thick) that contains $\sim 60 \%$ iron with phosphate, potassium, magnesium, silicon, hydrogen, and oxygen (Materials Performance, 2011). The exothermic reactions create a temperature rise of 7 to $40^{\circ} \mathrm{F}$ in the material.

According to literature (Materials Performance, 2011) the passivation layer does not support oxidation of the steel substrate and the top dense ceramic outer layer protects the passivation layer and provides abrasion resistance. NACE 3 (commercial blast) or 5 (water-jetting) surface conditions allows for sufficient bonding of the coating with steel structures if all of the old paint materials are removed (Materials Performance, 2011). The CBPC coating was promoted as being compatible with aluminum, Portland cement, gypsum, and steel; but cannot be chemically bonded with polymers. The CBPC can be used in environments with temperatures from $35^{\circ}$ to $200^{\circ} \mathrm{F}$ and $0 \%$ to $99 \%$ humidity (Materials Performance, 2011). The coating cannot resist the strong acids such as hydrochloric acid $(\mathrm{HCl})$ and sulfuric acid $\left(\mathrm{H}_{2} \mathrm{SO}_{4}\right)$ (Materials Performance, 2011). Testing indicated that CBPC coating could flex up to $19 \%$ before fracture (Materials Performance, 2011). 


\subsection{Barrier Properties of Coating}

\subsubsection{Geopolymer}

Geopolymers are generally classified in two major categories: inorganic and organic geopolymers (Kim et al., 2006; Duxson et al., 2005; He et al., 2011). The inorganic geopolymer is prepared by mixing an aluminosilicate source such as metakaolin or fly ash into a low temperature $\left(25^{0}-80^{\circ} \mathrm{C}\right)$ alkaline silicate solution for a relatively short period of time ( 2-48 h) (Bell et al., 2009). As described by Davidovits, the geopolymer with only inorganic components create a material in the form of ceramic crystals. Geopolymer coatings may contain a small amount of organic material added to the inorganic base. The organic content creates a crosslink between the organic and inorganic components, which in part improves the strength and durability (Kim et al., 2006). Geopolymers are generally x-ray amorphous materials and converts to a ceramic structure upon heating (Bell et al., 2009). They are heat resistant because of their inorganic origin and they exhibit good adhesion with metal (Bell et al., 2009). The possible application field of geopolymers includes production of cements and coatings.

Vitreous-ceramic coating is an inorganic geopolymer material used for reinforced concrete. It incorporates calcium silicates from Portland cement in an alkali-resistant glass to increase the bond between the concrete to the reinforcing steel and to protect the steel from corrosion. The observed bond strength was as strong as the plain bars. The coating incorporates self-healing capabilities by reaction of the glass components with cement particles. The application procedure is as cumbersome as the parceling enamel procedure. 
Another potential inorganic geopolymer that can be used in reinforced concrete with ease of application is chemically bonded phosphate ceramic. Phosphate ceramic can make bond with ordinary Portland cement (Wagh, 2004). This important property could allow the possibility for repairing cracks in concrete structures such as buildings, geotechnical structures, and utility supply lines.

\subsubsection{Zinc-Fe Alloy Layers}

The thicknesses of the individual alloyed layer of galvanized coatings depend on the diffusion rate of zinc through the other layers (Zhang, 1996). The diffusion rate of the iron outward the steel surface is much slower compared to zinc diffusion. The composition of the different alloyed layers is described below-

The Eta, $\eta$ phase has a hexagonal close packed crystal structure that is zinc rich with $0.003 \mathrm{wt} \% \mathrm{Fe}$. This layer does not provide corrosion protection. The Zeta, $\zeta$ layer forms first during the galvanizing process at a faster rate initially but the rate reduces significantly afterwards. The monoclinic crystal structure of this layer contains 5.7-6.3 wt $\%$ of Fe. This is an intermetallic layer formed between the eta and delta phase. The molecular structure formed by an iron atom and a zinc atom surrounded by 12 zinc atoms at the vertices of a slightly distorted icosahedron which link together to form chains in a hexagonal array (Marder, 2000). The delta, $\delta$ layer forms after the $\zeta$ layer. The initial formation rate is slower than the $\zeta$ layer but becomes faster with time. The hexagonal close-packed crystal structure of this layer contains $7.0-11.5 \mathrm{wt} \%$ of Fe. The Gamma, $\Gamma$ Phase has a face-centered cubic crystal structure that contains $21.0-28.0$ wt $\%$ of Fe. The rate of formation of this layer is much slower than the rate of the previous two layers. 
This phase is produced due to the long heating at low temperature and has the highest reported micro hardness value (Marder, 2000).

The cathodic protection is offered by the sacrificial nature of the zinc. Due to the high zinc activity, the freshly placed concrete reacts with HDG and forms calcium hyrdoxyzincate along with hydrogen gas. The calcium hyrdoxyzincate acts as passivation layer but hydrogen gas impairs the surface aesthetics of the concrete. The evaluation of the hydrogen gas depends on the alloyed layer. The electrode potential of these $\mathrm{Zn}-\mathrm{Fe}$ layers is more noble than the zinc coating (Yadav et al., 2007). The intermetallic electrochemical behavior needs to be evaluated to identify the long-term performance of the galvanized coating. Also, corrosion activities of these layers need to be evaluated when they are covered with zinc corrosion product.

For use as reinforcement in concrete, rebar fabrication is ideally done prior to galvanizing to get the total benefit of corrosion protection. Extensive research on HDG demonstrates the fact that galvanizing does not adversely affect the tensile property of the base steel but the outer zinc eta, $\eta$ layer is subjected to cracking depending on the thickness of the HDG and bend diameter. For fabrication, the minimum recommended bend diameter is $3 \mathrm{~d}$ to minimize the damage of the microstructure where $\mathrm{d}$ is the diameter of the bar. Some research indicates longer time requirements for the development of the bond strength but all of the research findings confirm that the bond between zinc and cement paste is higher than iron and cement paste.

The performance of the coating depends on the coating continuity and bond strength. The steel substrate needs to be cleaned carefully at the time of application. Adhesive failure of the coating can result in failure of the coating system. Zinc-iron alloy 
layers not only provide barrier protection from the aggressive environment but also provide cathodic protection to the base steel.

\subsection{Performance Evaluations for Structural Steel}

\subsubsection{Performance of Paint Coatings}

The Federal Highway Administration (FHWA), NASA, numerous transportation department and different coating manufacturers published several studies on paint coatings. The following sections contain a synopsis of those studies.

FHWA conducted a study in 2006 on two coat systems to eliminate the intermediate epoxy layer for rapid paint application and economy (Brigham, 2009). The researchers investigated eight two-coat systems with comparison of three traditional three-coat systems. Testing consisted of cyclic environmental exposure to temperature, UV, moisture, and salt in accelerated laboratory testing and outdoor exposure. The study concluded that the two-coat systems performed comparably to the three-coat systems. The conventional three coat systems with aliphatic polyurethane performed better in terms of gloss retention. Two-coat systems with manufacturer design configurations performed well but systems with polyaspartic topcoats (not specified by manufacturers of organic-rich epoxy and inorganic zinc-rich alkyl silicate) had reduced performance including development of topcoat wrinkling and cracking.

FHWA initiated a research program in August 2009 to identify coating systems that can provide long-term durability with minimal maintenance. Eight selected coating systems with promising performance in part based on prior experimental data from accelerated laboratory testing and outdoor exposure testing were evaluated (Kodumuri \& Lee, 2012). Evaluation consisted of accelerated laboratory testing (consisting of cyclic 
environmental exposure to temperature, UV, and moisture, and salt) and outdoor marine and simulated salt exposure environments. The study concluded that the three coat systems with zinc rich epoxy and polyurethane top coats performed well but none of the coating system can meet the 100 years maintenance free coating application. The thermally sprayed zinc and zinc two coat systems had poor performance in the study.

FHWA conducted a study in 2011 of eight one coat paint systems including polyaspartic, epoxy mastic, high ratio calcium sulfonate alkyd, glass flake reinforced polyester, high-build waterborne acrylic, waterborne epoxy, polysiloxane, and urethane mastic (Yao et al., 2011). The evaluation included accelerated laboratory testing for 6840 hours and three outdoor exposure conditions including marine exposure for 24 months, mild natural weathering for 18 months and a mild natural weathering plus salt solution spray tests for 18 months. The evaluation procedure was based on VOC, pigment content, FTIR analysis, sag resistance, drying time, gloss, color, pencil scratch hardness, adhesion, detection of coating defects, blistering, and rust creepage. The study provided performance ranking of the eight one-coat systems as well as a three-coat (zinc-rich epoxy, epoxy, and polyurethane topcoat) and two-coat system (zinc-rich moisture-cure urethane and polyaspartic topcoat). It was concluded that the one-coat system did not perform as well as the three-coat system in accelerated laboratory and outdoor test conditions. The two-coat system (which showed promising results in the study by Chong and Yao in 2006 also showed development of coating defects, rust creepage and significant reduction in gloss. 


\subsubsection{Performance of Metal Coatings}

Many transportation departments have adopted metallization due to its performance but the high cost has been an important factor. Some transportation departments also include sealers and topcoats to thermal spray coatings for better protection. Thermal spray coatings also require greater control including strict surface preparation requirements, which may limit their efficacy for field application (Chang \& Georgy, 1999). Of note, localized corrosion was observed in early use of metalized coating of a bridge in Connecticut due to improper surface preparation (Chang et al., 1999 \& Koger et al., 1998).

The formation of the alloyed layer depends on the steel chemistry and the processing condition. Not all the layers may be formed depending on these conditions (Yeomans, 2004). Furthermore, hydrogen embrittlement due to the accommodation of hydrogen at the time of surface cleaning prior to HDG is another negative aspect. For reinforced concrete applications, the outer zinc layer is stretched after stress relief from the alloyed layers due to fabrication (Yeomans, 2004). This bending stress causes the flaking of the coating. Hence, excessive thick coating (> 250 microns) is not recommended for bending. Furthermore, heat should be avoided for bending of the galvanized coating for the possibility of liquid metal embrittlement. When a freshly placed concrete comes in contact with galvanized bars, it produces calcium hyrdoxyzincate and hydrogen gas. This hydrogen gas may accumulate and rise to the surface of the concrete due to the buoyancy force. The accumulated gas may impair the surface aesthetics of the concrete (Yeomans, 2004). Some research suggested that the evaluation of hydrogen gas is related to the $\mathrm{Zn}-\mathrm{Fe}$ alloyed layer, and not the pure zinc 
layer (Yeomans, 2004). By considering this fact, the thick eta layer of pure zinc on galvanized coating should have less hydrogen gas development compering to Galvanneal, Galvalume and Galfan coating without the eta layer. In environmental perspective, hexavalent chromium $\mathrm{Cr} 6+$ is found in the acid used in hot-dip galvanizing quench baths, which is a high toxic substance (Zhmurkin, 2009).

Thermal diffusion galvanizing (TDG) was tested on lashing by the U.S. Navy and showed excellent corrosion protection (ArmorGalv, 2013). The Florida Department of Transportation did a cursory evaluation of TDG in 2013 (FDOT, 2013). The evaluation compared the corrosion development on steel reinforcement coated by TDG and hotdipped galvanizing after exposure to either partial immersion condition in $3.5 \%$ salt water or in $5 \%$ salt fog at $95^{0} \mathrm{~F}$. TDG performed better than the hot-dipped galvanizing. After 3000 hours in salt-fog condition, no corrosion was observed on the samples coated with TDG and significant corrosion formed on the hot-dipped galvanized samples.

\subsubsection{Performance of Ceramic Coatings}

Testing of CBPC coated steel plate by NASA consisted of continuous cycles of four hours seawater spray (an average of 14 gal of seawater are sprayed on the samples) followed by four hours simulated sunlight (426-nm light waves) in a test chamber. Testing showed no sign of corrosion after 170 days (Materials Performance, 2011).

Chemically Bonded Phosphate Ceramic coatings were of interest for study in consideration of the coating material characteristics, ease of application, environmental concern, installation cost, wide range of application and earlier promising investigation. Initial indication as described earlier provides some early indication for suitable application in reinforced concrete. 


\subsection{Electro Chemical Evaluation Basic Principles}

\subsubsection{Corrosion Process}

Corrosion of steel involves electrochemical reactions including the oxidation of iron (Eq. 2.2) and typically the reduction of atmospheric oxygen (Eq. 2.3). The total reaction can be written in the form of (Eq. 2.4)

$$
\begin{gathered}
\mathrm{Fe} \rightarrow \mathrm{Fe}^{2+}+2 \mathrm{e}^{-} \\
\mathrm{O}_{2}+2 \mathrm{H}_{2} \mathrm{O}+4 \mathrm{e}^{-} \rightarrow 4 \mathrm{OH}^{-} \\
2 \mathrm{Fe}+\mathrm{O}_{2}+2 \mathrm{H}_{2} \mathrm{O} \rightarrow 2 \mathrm{Fe}(\mathrm{OH})_{2}
\end{gathered}
$$

As oxygen is readily dissolved in water, the excess oxygen reacts with the iron hydroxide (Eq. 2.5) to form the rust

$$
4 \mathrm{Fe}(\mathrm{OH})_{2}+\mathrm{O}_{2}=2 \mathrm{H}_{2} \mathrm{O}+2 \mathrm{Fe}_{2} \mathrm{O}_{3} \cdot \mathrm{H}_{2} \mathrm{O} \text { (rust) }
$$

\subsubsection{Important Types of Corrosion}

Some important mechanism of localized corrosion is described in the following paragraphs.

Galvanic corrosion is induced when two dissimilar materials are coupled together in a corrosive environment (Jones, 1996). One of them acts as an anode and another one act as a cathode. The alloy with more positive or noble potential will be protected by the other. So for galvanic corrosion three conditions needs to be satisfied - 1) two electro chemically dissimilar materials, 2) electric connection and 3) electrolyte.

Pitting corrosion is a localized form of corrosion which initiated by localized chemical or mechanical damage to the protective oxide film, low dissolved oxygen concentrations and high concentrations of chloride. Pitting corrosion is an autocatalytic 
process. Rapid dissolution of metal ion occurs if the reduction of oxygen ion is supported by the surrounding surface. When the concentration of positive metal ion increases the negatively charged chloride ion is attracted by the pit and forms the metal chloride. This metal chloride forms hydrogen ion through hydrolysis process. Both the hydrogen and chloride ion accelerates the dissolution of metal ions with time. Pitting is considered to be more dangerous than uniform corrosion damage because of its difficulty to detect, predict and design. A small, narrow pit with minimal overall metal loss can lead to the failure of an entire engineering system.

Crevice corrosion is a type of localized corrosion with the presence of stagnant solution in the crevice. Crevice environment may be formed in the small sheltered volume of two similar or dissimilar materials, deposition of mud, sand or other insoluble solids or a non-metallic gasket or packing. Differential aeration and chloride concentration are the two important mechanisms for crevice corrosion. The mechanism of crevice corrosion (Rashidi et al., 2007) is described next.

Corrosion occurs both inside and outside the crevice. The associated anodic and cathodic reactions are shown in Eq. 2.6 and Eq. 2.7 respectively.

$$
\begin{gathered}
\mathrm{M} \rightarrow \mathrm{Mn}^{+}+\mathrm{ne}^{-} \\
\mathrm{O}_{2}+2 \mathrm{H}_{2} \mathrm{O}+4 \mathrm{e}^{-}=4 \mathrm{OH}^{-}
\end{gathered}
$$

The positively charged metallic ions are electrostatically counter balanced by $\mathrm{OH}^{-}$. The cathodic reaction inside the crevice consumed most of the available oxygen. At the same time, $\mathrm{Cl}^{-}$and $\mathrm{OH}^{-}$diffuse into the crevice to maintain a minimum potential energy and metal chloride is formed. Finally, the hydrolysis of metal chloride lowers the pH. More 
metal ions attack more chloride ions, which lead to lower $\mathrm{pH}$ inside crevice and accelerate the metal dissolution. As a result, more metal ions will be produced that will lower pH again.

Crevice corrosion of the coated steel forms due to defect, hole and the deposits of dirt. The opening of the defect should be sufficiently large for moisture to enter the solution and narrow enough to hold the stagnant solution.

\subsubsection{Test Procedure}

\subsubsection{3-electrode system}

The 3-electrode configuration is an electrochemical test arrangement consisting of a working, counter and reference electrode. The electric current passes through the working and counter electrode to complete the electrochemical cell and the purpose of the reference electrode is to monitor the potential of the working electrode.

Electrochemically stable materials are used as counter electrode to prevent formation of any product and for the measurement of the potential difference between working and counter electrode. High impedance potentiometer is used for the measurement of the electrical potential.

\subsubsection{Open Circuit Potential}

When a metal is immersed in a solution, the tendency of metal ions to cross the metal/solution interface depends on the electrochemical energy of the metal. Conventionally only the positively charged cations can pass through the interface. The negatively charged electrons cannot pass into the solution, and the anions cannot pass into the metal. Consequently, charge accumulation occurs at the interface forming an electrical double layer. At electric double layer, the metal surface becomes negatively 
charged because of the accumulation of the electrons and the solution layer near the metal surface becomes positively charged because of the accumulation of cations. The potential difference between the metal and the solution phases under these conditions is called the open circuit potential. In short, the potential (OCP) of a metal in solution is the energy released at the time of corrosion. This potential difference cannot be measured directly because an electrical connection cannot be made to the solution phase without setting up another electrode potential. The electrode potentials are always measured against a reference electrode whose potential is known on an arbitrary scale such as hydrogen electrode. In other words, open circuit potential may be described as electric potential at zero current flow (McCafferty, 2010).

\subsubsection{Linear Polarization Resistance (LPR)}

Corroding system can be characterized by artificially changing its potential from its OCP by a small amount and measuring the corresponding current. From that Rp, polarization resistance, can be calculated as the ratio of change in potential to amount of required current. Then the corrosion currents, $\mathrm{I}_{\text {corr }}$, is calculated by Faradic Conversion (Fontana \& Greene, 1986). using Eq. 2.8,

$$
I_{\text {corr }}=\frac{B}{R p}
$$

where the Stern-Geary Coefficient, B, was assumed to be $26 \mathrm{mV}$ for active corrosion conditions. To determine the corrosion rate for coated steel area from the linear polarization technique is complicated due to the actual affected steel area and other current confinement issues. 


\subsubsection{Electrochemical Impedance Spectroscopy}

Electrochemical impedance spectroscopy testing is a non-destructive method to assess the electrochemical properties of the corrosion system and a method to assess physical coating conditions by a range of sinusoidal signal frequency perturbation to their corresponding electrical analog (Barsoukov \& Macdonald, 2005).

Like other electrochemical system, the EIS measurement can incorporate the three-electrode system. The working electrode is the metal sample in interest and the potentiostat maintain a desire level of potential with respect to reference electrode. The uniform distribution of electric current for excitation is maintained by counter electrode, which eventually completes the full electric circuit. The acquired impedance spectra for a range of frequency is interpreted as that corresponding to an electrical analog to possible physio-electrochemical properties and processes in the corrosion system (Barsoukov \& Macdonald, 2005).

When an intact coating comes in contact with the electrolyte, the solution can enter the pores of that coating. The pore resistance, $R_{p o}$ decreases with the passage of electrolyte intrusion. Initially the pore resistance is considered as infinite. The entire system is represented in equivalent circuit as shown in the Figure 2.5 where $R_{s}$ is the solution resistance and $\mathrm{C}_{\mathrm{c}}$ is coating capacitance.

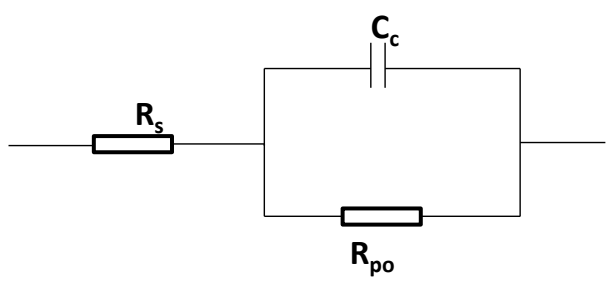

Figure 2.5: Electrical Equivalent Circuit of an Intact Coating in Contact with an Electrolyte. 
A new phase is included with this equivalent circuit when corrosion reactions can take place at the metal electrolyte interface as shown in the Figure 2.6. This circuit incorporates a capacitor characterizing the double layer capacitance of the metal/solution interface, $\mathrm{C}_{\mathrm{dl}}$, and a resistor element describing the polarization resistance, $\mathrm{R}_{\mathrm{P}}$, both proportional to the active metallic area in contact with the electrolyte and

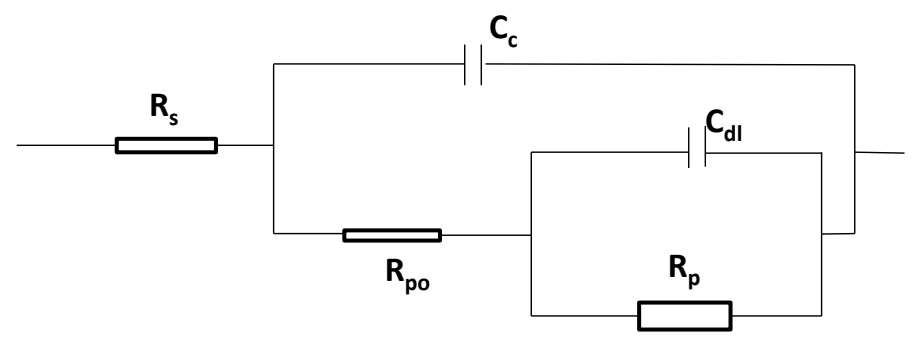

Figure 2.6: Electrical Equivalent Circuit of a Coating in Contact with an Electrolyte by Considering the Base Property of the Steel.

Cc, the coating capacitance defined by Eq. 2.9,

$$
\mathrm{C}_{\mathrm{c}}=\frac{\varepsilon_{\mathrm{o}} \varepsilon_{\mathrm{r}} \mathrm{A}}{\mathrm{d}}
$$

where $\boldsymbol{\varepsilon}_{\mathrm{o}}$ is the vacuum permittivity or the permittivity of the free space, $\boldsymbol{\varepsilon}_{\mathrm{r}}$ is the relative permittivity or coating dielectric constant, $\mathrm{A}$ is coating surface area and d its thickness. Rp, the pore resistance defined by Eq. 2.10,

$$
\mathrm{R}_{\mathrm{po}}=\frac{\rho \mathrm{d}}{\mathrm{n} \pi \mathrm{r}^{2}}
$$

where the coating defects can be idealized as a distribution of cylindrical pores (Grundmeier et al., 2000) of radius r, $\rho$ is the electrolyte resistivity within the pore, $\mathrm{d}$ is the thickness, $\mathrm{r}$ is the pore radius, and $\mathrm{n}$ is the number of pores. 
The decrease of $\mathrm{R}_{\mathrm{po}}$, can be attributed to the penetration of electrolyte into the pores and the increase of $\mathrm{R}_{\mathrm{po}}$ may be due to delamination of the pore area or formation of new pores.

Non-ideal capacitive behavior and other factors due to heterogeneities including non-uniform current distribution in the coating and metal-electrolyte interface were in part represented by constant phase elements. The total impedance on first approach was expressed as shown in Equation 2.11.

$$
Z=R s+\frac{1}{Y_{o c}(j \omega)^{n_{c}}+\frac{1}{R p o+\frac{1}{Y_{o m}(j \omega)^{n_{m}}+\frac{1}{R p}}}}
$$

The solution resistance, Rs, is the resistance between the working and reference electrodes, the pore resistance, Rpo, is the resistance associated with pores and defects in the coating, the polarization resistance, $\mathrm{Rp}$, is a function of the corrosion rate. The impedance of the electrical double layer and the coating capacitance are expressed in the form of constant phase elements $Z_{C P E}=1 /\left(Y_{o}(j \omega)^{n}\right.$ where $Y_{o}$ is the pre-exponential term, $\omega$ is the angular frequency, and $\mathrm{n}$ is a real number $0<\mathrm{n}<1$ (Orazem \& Tribollet, 2008).

The subscripts $\mathrm{c}$ and $\mathrm{m}$ refer to the impedance of the coating and double layer, respectively.

The conventional interpretation of the impedance response of a coated metal interface was assumed as first approach represented by Nyquist diagram of two semicircles as shown in the Figure 2.7. The two semicircles represent two times constant. 
The first semicircle with radius $\mathrm{Rpo} / 2$ represents the coating characteristics and the second semicircle with radius $\mathrm{Rp} / 2$ represents the steel/ coating interface property.

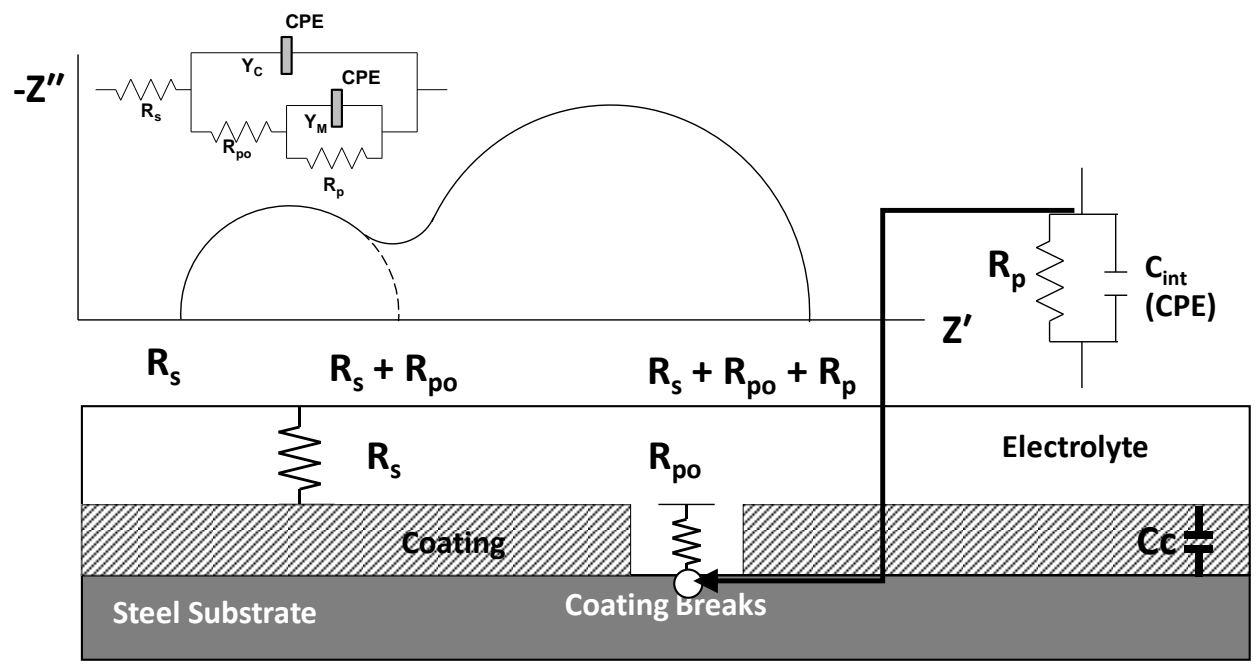

Figure 2.7: Idealized Impedance Diagram of Coated Metal System with Coating Breaks and Equivalent Circuit Analog. 


\section{CHAPTER 3}

\section{METHODOLOGY}

The corrosion performance of the CBPC coating was assessed in outdoor exposures, salt-fog exposure and wet environmental condition in laboratory set-up. The CBPC coated steel coupons ( 3 by 5 inch) were provided by the manufacturer for testing. Surface blasting was conducted by the coating applicators according to their best practices prior to application of the coating. Half of the panels had intentional damage by scribing to expose the underlying steel. The scribe was $25.4 \mathrm{~mm}$ in length and $0.5 \mathrm{~mm}$ in thickness. The detailed test procedures are explained in the following sections

\subsection{Outdoor Testing}

Two outdoor exposure test sites and exposure racks generally conforming to ASTM G7-11 were prepared in South Florida for testing. The locations of the test sites are shown in Figure 3.1. Aluminum test racks approximately 10 feet in length and 5 feet in height were made available at both sites. The Beach Test Site at Tea Table Key in Islamorada, FL maintained by FDOT is situated immediately adjacent to the ocean with strong presence of warm humid salt air. The ground cover was typically limestone rock. The Inland Test Site was located on the Florida International University engineering campus in Miami, FL located approximately 10 miles from the coast. The ground cover at the Inland Test Site was short grass. Coated steel sample coupons were placed on the test rack and oriented at $45^{\circ}$ to the horizon facing south per ASTM, 2011. Weather conditions such as temperature, relative humidity, and rainfall was monitored during the time of testing. Part of the samples was collected after 4-month, 8-month and the rest was after 24-month for destructive examination of the coating and corrosion development. 
Testing included examination of coating degradation by visual observation, optical microscopy, and physical testing. Degradation such as corrosion product development and coating damage were assessed. Photo documentation after 4, 8 and 24-month was made for visual comparison of material degradation. Material testing such as chemical analysis for contaminants in corrosion product by XRD and EDS analysis of the coating was made as appropriate.

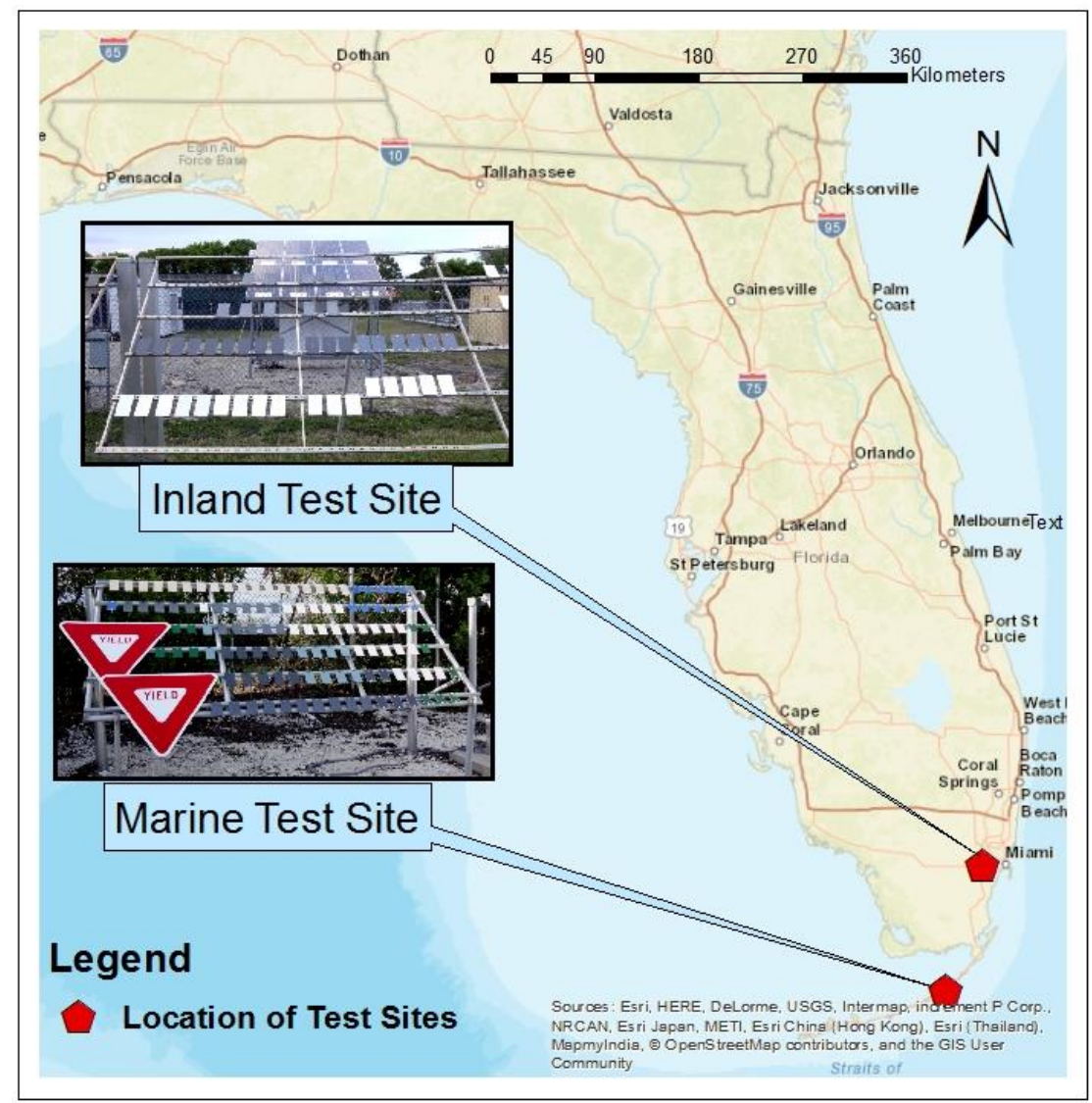

Figure 3.1: Location of Outdoor Exposure Sites. 


\subsection{Salt Fog Exposure}

A salt-fog chamber conforming to ASTM B117-03 was setup as shown in the Figure 3.2. Tests included exposure in a salt fog chamber with use of $5 \% \mathrm{NaCl}$ saturated salt solution for at least 2200,5800 hours and 14600 hours to evaluate the effects of the various aggressive exposure conditions on the integrity of the coating and corrosion of the steel coupons. The salt-fog chamber temperature was maintained $\sim 32^{\circ} \mathrm{C}$. The samples were placed at a $\sim 40^{\circ}$ inclination with support along the bottom edge of the coupon and along an edge at the upper third of the sample. Corrosion development was photodocumented with time. The replicate panels were removed at previously mentioned duration from environmental exposure to identify degradation of the coating by physical testing and other material testing as discussed in section 3.4.
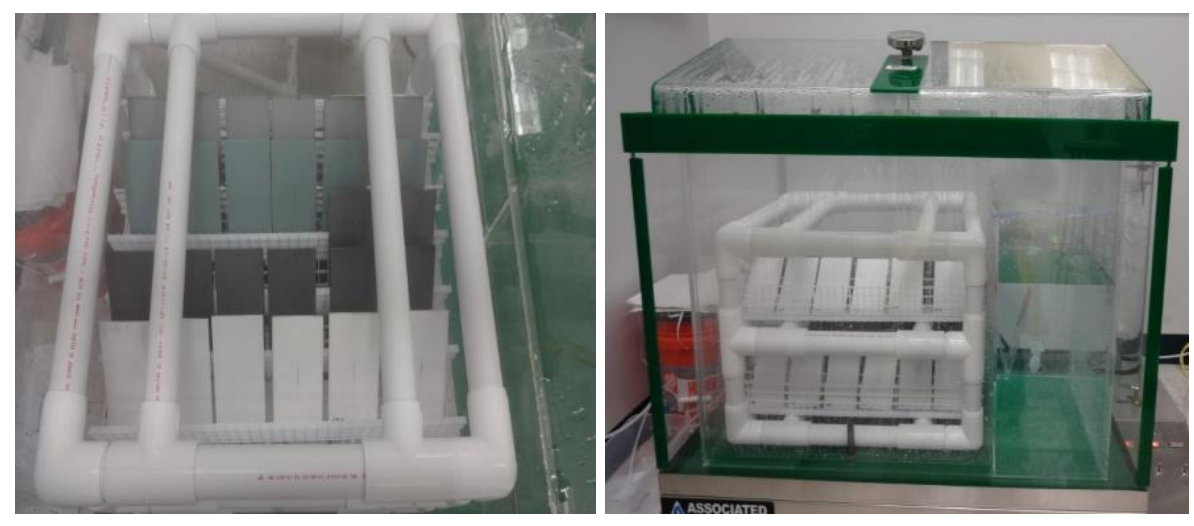

Figure 3.2. Test setup for Salt Fog Exposure. 


\subsection{Electro Chemical Testing}

Samples of as received condition and with defect (scribed) were exposed in neutral $\mathrm{pH}$ solutions for $\sim 30$ days. Scribing was done to expose the underlying steel of $25.4 \mathrm{~mm}$ in length and $0.5 \mathrm{~mm}$ in wide. Acrylic test cells as shown in Figure 3.3 was made to accommodate reference and auxiliary electrodes require for corrosion and electrochemical impedance spectroscopy (EIS) testing. Activated titanium was used as temporary reference and counter electrodes (Castro et al., 1992). The activated titanium reference electrode was calibrated with a saturated calomel reference electrode (SCE). The neutral $\mathrm{pH}$ solution simulating runoff and pooled drainage water was made from distilled water with and without $3.5 \%$ sodium chloride. Electrochemical testing included use of a Gamry Reference 600 potentiostat and impedance analyzer as well as an ECM8 Multiplexer as shown in Figure 3.4. Corrosion testing was comprised of open-circuit potential (OCP) measurements, linear polarization resistance (LPR), and electrochemical impedance spectroscopy (EIS). LPR testing was done from the initial OCP to $-25 \mathrm{mV}$ vs. $\mathrm{OCP}$ at a scan rate of $0.05 \mathrm{mV} / \mathrm{s}$. EIS testing was done at the OCP condition with $10 \mathrm{mV}$ AC perturbation voltage (Murray, 1997; El-Mahdy et al., 2000; \& Mahdavian \& Attar, 2006) from frequencies $100 \mathrm{kHz}>\mathrm{f}>1 \mathrm{mHz}$ for evaluation of the corrosion mechanism considering the steel interface and from frequencies $1 \mathrm{MHz}>\mathrm{f}>1 \mathrm{~Hz}$ for the evaluation of the coating surface property. Corrosion development was photo-documented by considering before and after exposure. Coating and steel damage was assessed by physical testing and other material testing as discussed in section 3.4. The same test was repeated for cyclic testing of alternate dry and wet condition up to 35 days to gage the performance of CBPC coating related to working environment. 


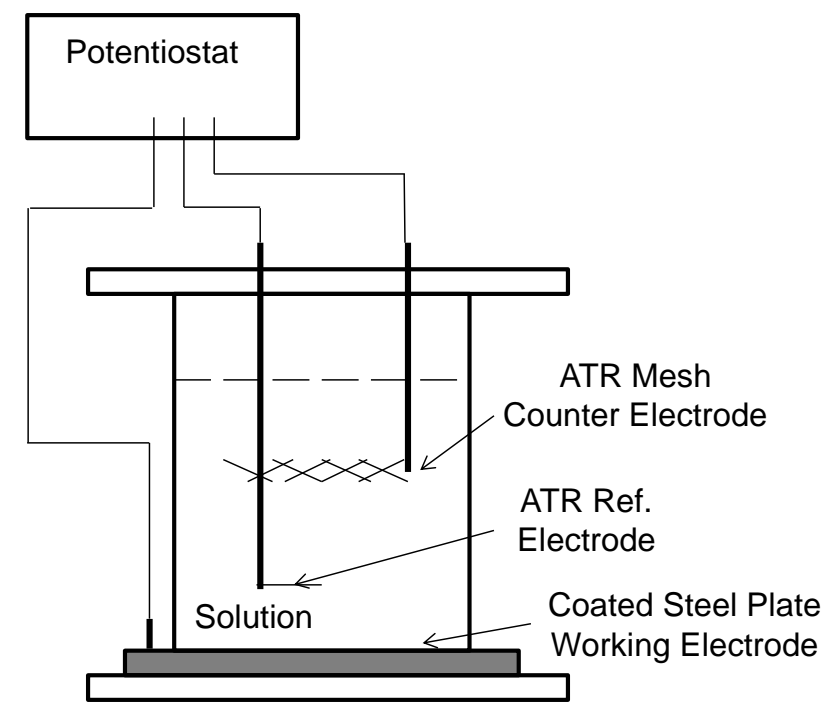

Figure 3.3: Test Setup for Electrochemical Testing.

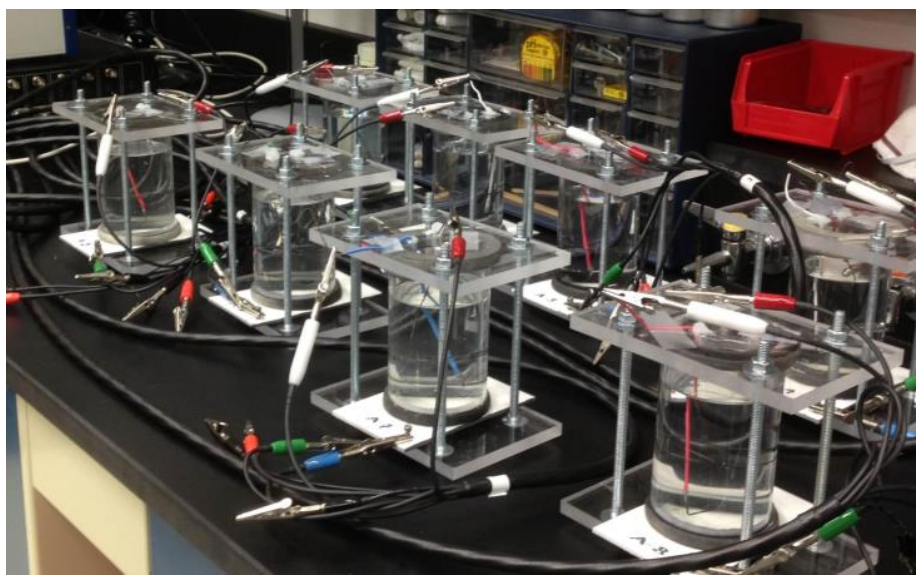

Figure 3.4: Test Setup for Electrochemical Testing.

\subsection{Material Evaluation}

Material evaluation included measurement of thickness change and pull-off strength. The coating thicknesses and pull-off strength can be used to evaluate coating changes due to exposure conditions (Mittal, 1983). Optical microscopy evaluation test including XRD, SEM and EDS were conducted to examine material surface condition and composition. 
The coating thickness or change of coating thickness from pre-exposure conditions was calculated from the average of multiple readings on the surface of the coated samples. For non-scribed samples, the coating thickness was measured at 9 locations on the coupon front face. For scribed samples, the coating thickness was measured at 8 locations on the coupon front face as shown in the Figure 3.4. The coating thickness was measured using a DeFelsko Positector 6000 magnetic coating thickness gage.

Pull-off strength measurement was made by using DeFelsko AT manual pull-off adhesion tester. Metal dollies were glued to the surface of the coated coupon using a twopart epoxy and allowed to set for 24 hours. The perimeter around the fastened dolly was then scored down to the steel substrate prior to testing with a pull-off adhesion tester (O’Dea et al., 2016 \& Seneviratne et al., 2000). The reported coating pull-off strengths are from at least three locations on the sample surface for both scribed and non-scribed samples as shown in the Figure 3.5.

Mercury intrusion porosimetry was conducted on as-received and selected exposed duplicate samples in each exposure. Around $3 \mathrm{~cm}^{2}$ representative area was tested with a pressure range of 0.202 psia to 60000 psia. MIP gave the information about pore number, size, area, and volume. The direct comparison with as-received sample to exposed sample was expected to give an indication of influence of pore characteristics on the degradation mechanism of the coating.

Metallographic preparation of samples for optical microscopy examination of coating cross-sections were followed conventional methodologies. The grinding steps used 74,20 , and $10 \mu \mathrm{m}$ size abrasives followed by polishing with $3 \mu \mathrm{m}$ diamond paste and 
$0.03 \mu \mathrm{m}$ silica/alumina suspension. After exposure conditions were compared with the as received condition from these micrographs. It will give an indication of the level of deterioration of the coating surface and other coating interfaces at different exposure condition.

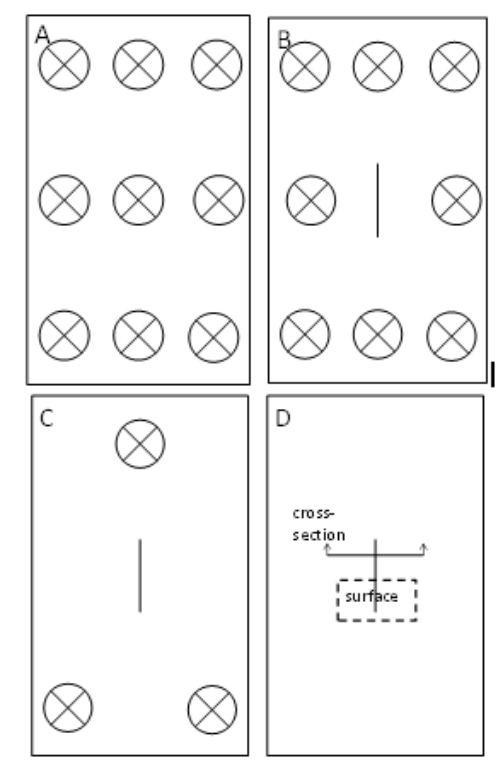

Figure: 3.5 Sample Testing Surface Locations.

A) Approximate coating thickness locations for as-rec'd coupon.

B) Approximate coating thickness locations for scribed coupon. C) Approximate coating pull-off locations. D) Approximate locations for metallographic sampling.

X-Ray diffraction was conducted by using Diffraktometer D5000 along with data acquisition Diffrac Plus software. X-ray diffraction (XRD) was conducted on the coated steel coupons (50 X $50 \mathrm{~mm}$ ) of as-received and exposed samples to identify any reaction products. The test procedure included diffraction scan with $2 \theta$ from $5^{0}$ to $70^{0}$ with $2^{0} /$ minute scan rate. Exposed and as-received samples were selected for testing. Peak normalization, subtraction of the background and integration was performed with Origin Lab 7.5 software. The data base PDF 4 was used for crystalline material identification. 
The XRD spectrum will help to identify any crystalline products on the surface that may form during exposure.

Scanning electron microscopy and energy dispersive spectroscopy was used for coating characterization. A JEOL 6330F SEM with Energy dispersive X-ray spectroscopy (EDS) analytical software (Noran System Six) was used for the investigations. An accelerating voltage of $5-15 \mathrm{kV}$ was used for imaging to reduce charging of the ceramic coating. The nonconductive ceramic coating was coated with gold for $55 \mathrm{~s}$ to build $5 \mathrm{~nm}$ thickness of Au over the sample to make it conductive. A carbon tape was attached to the steel face to the mold for connectivity as the coating samples were epoxy mounted. The working distance was maintained at $15 \mathrm{~mm}$ for EDS analysis. The voltage was increased to $20 \mathrm{kV}$ to increase resolution without concern of charge effect. From the SEM images and EDS spectrum the coating micro structure like different alloyed layers, pores, breakage along with elemental identification can be assessed. This will give supporting evidence about the durability of the material.

Coating material, exposure and defect presence are the three important variables for this investigation. The focus is to identify influence of exposure and defect on the durability of the material and it's protecting mechanism. To achieve this objective, the as received thickness, coating adhesion and alloyed layer property were identified by the previously mentioned test procedures. These properties were evaluated at subsequent time interval under the consideration of the individual exposure. Eventually it will give the indication of the deterioration mode and their propagation with time. Additionally, deterioration mechanism of the micro structure of the coating was evaluated by identifying physio-electrochemical parameters. For example, degradation of the coating 
may be described by changes in coating resistance and capacitance by the electrochemical testing. In-situ electrochemical testing may also allow for determination of time scale associated with the modes of material degradation and corrosion development. 


\section{CHAPTER 4}

\section{RESULTS AND DISCUSSION}

This chapter represents the results (visual observation, thickness and pull-off strength) of the outdoor and salt-fog exposed samples along with as-received condition. The electro-chemical tests result of the wet exposure and alternate wet and dry exposure are also included in this chapter.

\subsection{As-received CBPC Coating Property}

The samples were coated by the manufacturer according to their best practice. Thus the desired coating thickness was to be based on the coating manufacturers best practice guidelines. However, a large variability in coating thickness was apparent in the received samples, indicating that the manufacturer's coating process was not properly controlled. The micrographs in Figure 4.1 show the typical appearance of the CPBC coating. The cross section indicates existences of pores in as-received condition which will be further clarified by mercury intrusion Porosimetry (MIP) and scanning electron microscopy (SEM). As seen in Figure 4.2, the coating thickness ranged from 250-1300 $\mu \mathrm{m}$. Product literature suggests that the coating thickness of the CPBC layer is dependent on the number of passes the sample receives during the spray application process. Samples also had local coating thickness variability with standard deviations ranging from 13 to $\sim 150 \mu \mathrm{m}$. For testing, samples were sorted by similar coating thickness to avoid possible testing artifacts that may be associated with coating application. Presence of a protective phosphate rich layer on the steel substrate described in product literature as $2-20 \mu \mathrm{m}$ thick was not readily visible by optical microscopy. At the highest magnification shown in Figure 4.1, there was visual indication of material of varying 
textures with a layer between the ceramic and steel substrate. That intermediate layer did not appear to be continuous throughout the steel-to-ceramic coating interface. As will be described later, imaging with SEM also did not consistently reveal a continuous intermediate layer on the steel substrate.
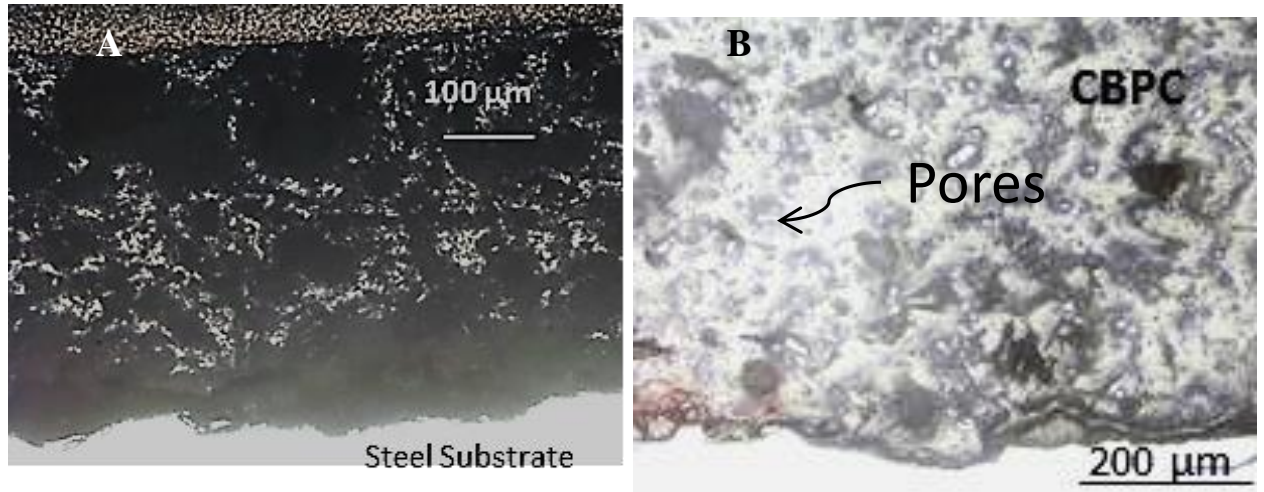

Figure: 4.1 CBPC Coating on Steel Cross-Section Micrographs.

A) Rough Surface. B) Presence of Pores.

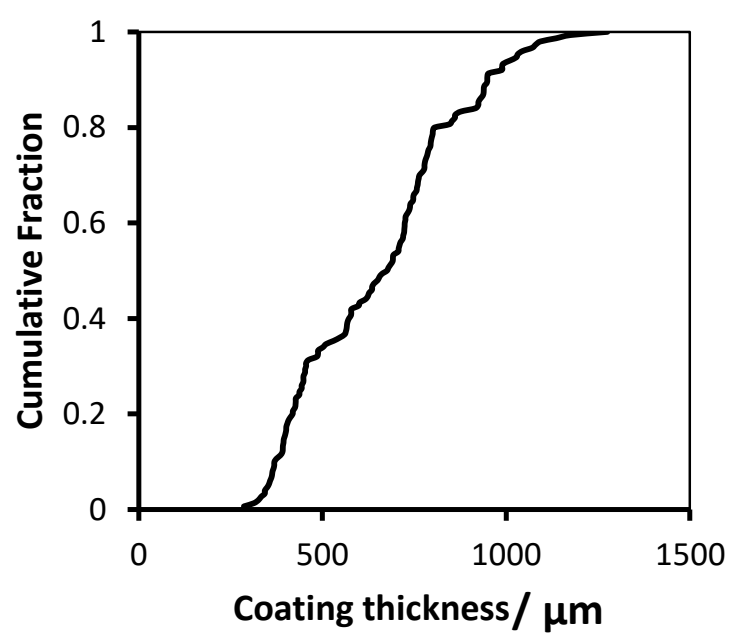

Figure 4.2: CBPC Sample Coating Thickness. 
Although variability in the thickness of the CBPC coating was observed, the asreceived pull-off strengths were not greatly affected by coating thickness. All pull-off testing of coatings in the as-received condition had removal of the CBPC coating and had strengths less than $1400 \mathrm{kPa}$ as shown in Figure 4.3. The coating was typically separated at the coating/steel substrate but some residue of the CBPC typically remained on the steel substrate. It is noted that the pull-off strength may not directly indicate efficacy in corrosion mitigation. However, this parameter is expected to give insight on material performance after exposure in aggressive environments such as coating degradation or disbondment that may possibly be important in corrosion development.

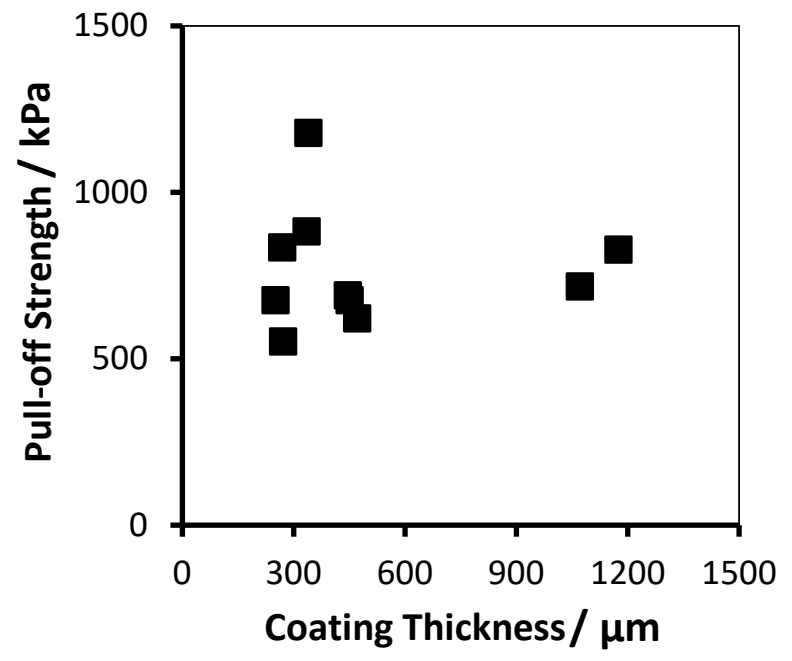

Figure 4.3: CBPC Coating Pull-off Strength.

\subsection{Coating Degradation after Out-door and Salt-fog Exposure}

The corrosion performance of the coating in outdoor exposures was assessed by placing CBPC steel coupons at a beach test site in the Florida Keys as well as at inland test site in South Florida $\sim 16 \mathrm{~km}$ (10 miles) from the coast. The coated samples were exposed at $45^{\circ}$ facing south according to ASTM G 7M. The 4, 8 and 24-month exposure 
times were proposed to identify coating degradation and corrosion development with time. Coated steel coupons were initially installed on November 1, 2013. Sets were removed on February 28, 2014; on June 30, 2014 and on November 03, 2015. Record of environmental parameters of the test sites is shown in Figure 4.4. Temperature and relative humidity at the two outdoor test sites were comparable but the precipitation data for inland site was higher than the beach site. Samples were exposed to salt-fog conditions with 5\% NaCl solution according to ASTM B 117 for 2200, 5800 or 14600 hours to evaluate the effects of the aggressive exposure conditions on the integrity of the coating and corrosion durability of the steel coupons. Visual comparisons of the sample coating conditions and degree of corrosion were made. Assessment of coating thickness and coating adhesive strength before and after exposure were also made. The coating pull-off strengths and thicknesses were meant to evaluate changes due to test exposure conditions and not necessarily to prescribe quantitative values to degradation. 

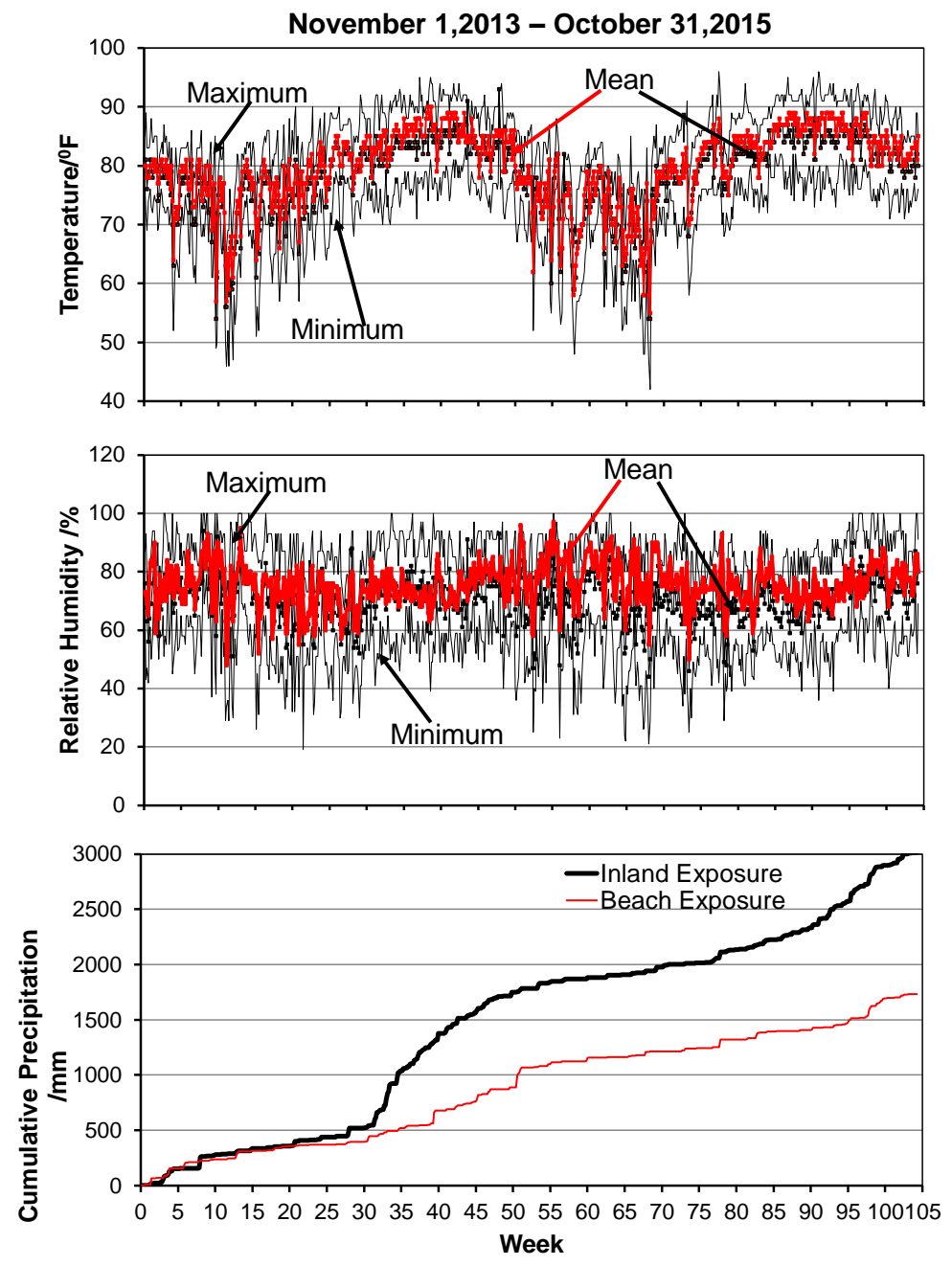

Figure 4.4: Environmental Conditions at Outdoor Test Sites. Black (Inland). Red (Beach). 


\subsubsection{Visual Observation}

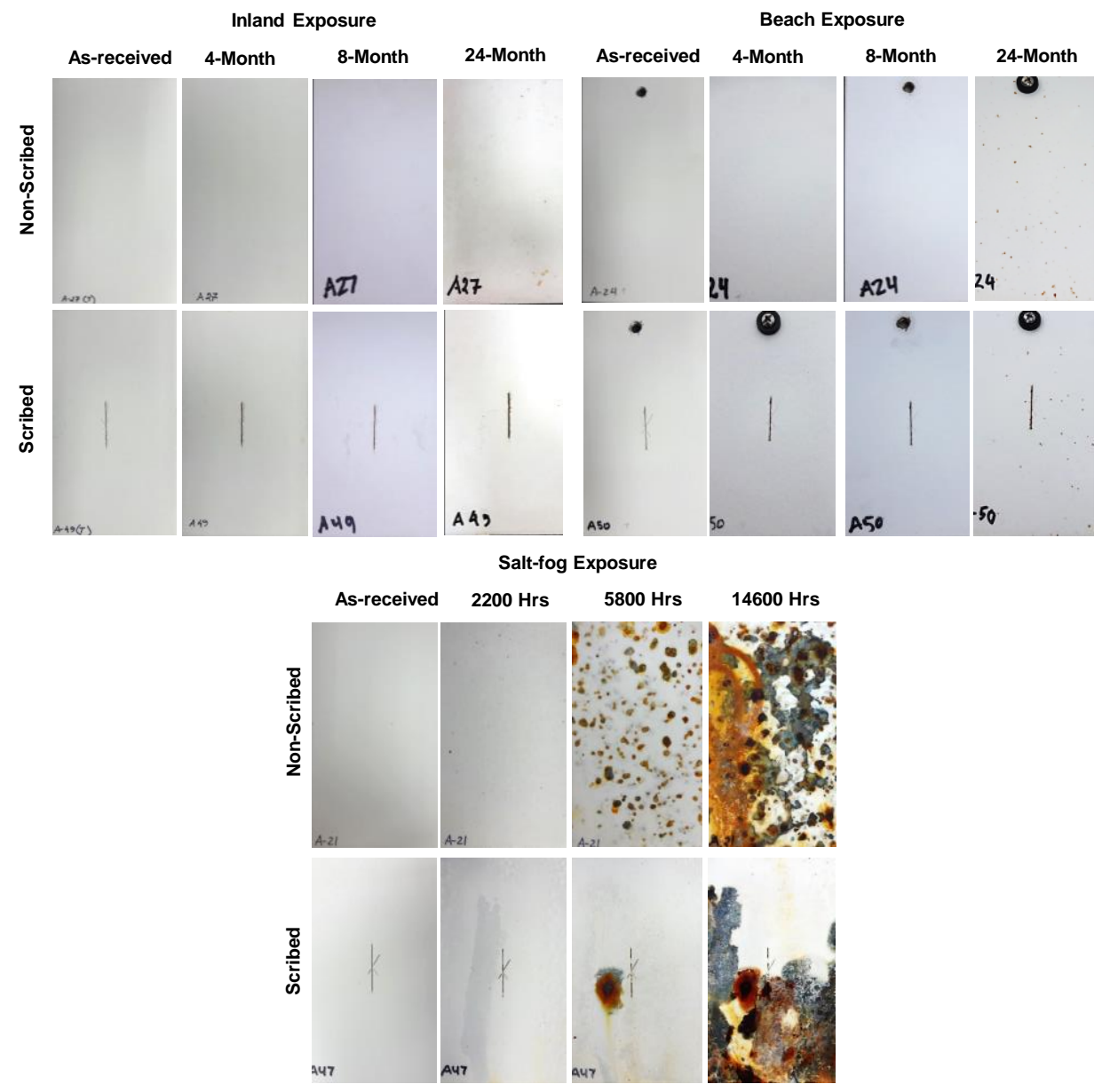

Figure 4.5: Condition of the Samples after Exposure.

Photo documentation of the samples was done at different times during the test exposure to identify any coating degradation that can be identified visually (Figure 4.5). The ceramic degraded in the form of chalky powder materials during the first 4 months of exposure in both outdoor conditions. As observed in photo documentation made after 24 months, spot staining was identified on the coating surface. No significant steel rust formation was observed at scribed defect locations. Similar degradation of barrier ceramic was observed in the form of chalky powder within 2200 hours of salt-fog 
exposure and the surface staining appeared within 5800 hours in salt-fog exposure. The formed spot staining expanded severely during extended exposure of 14600 hours. No steel rust formation was observed along the scribed defect during this long exposure time even though significant coating degradation occurred. It was apparent that moisture from the environment is related to degradation of the outer ceramic coating. In outdoor conditions, the degradation after 2 years appeared to be mostly benign by outward visual inspection and only resulted in surface chalking and some spot staining. In several samples, severe localized coating blistering was observed. The continuous moist condition in the aggressive salt-fog exposure accelerated the degradation process of the CBPC coating. 


\subsubsection{Coating Thickness}

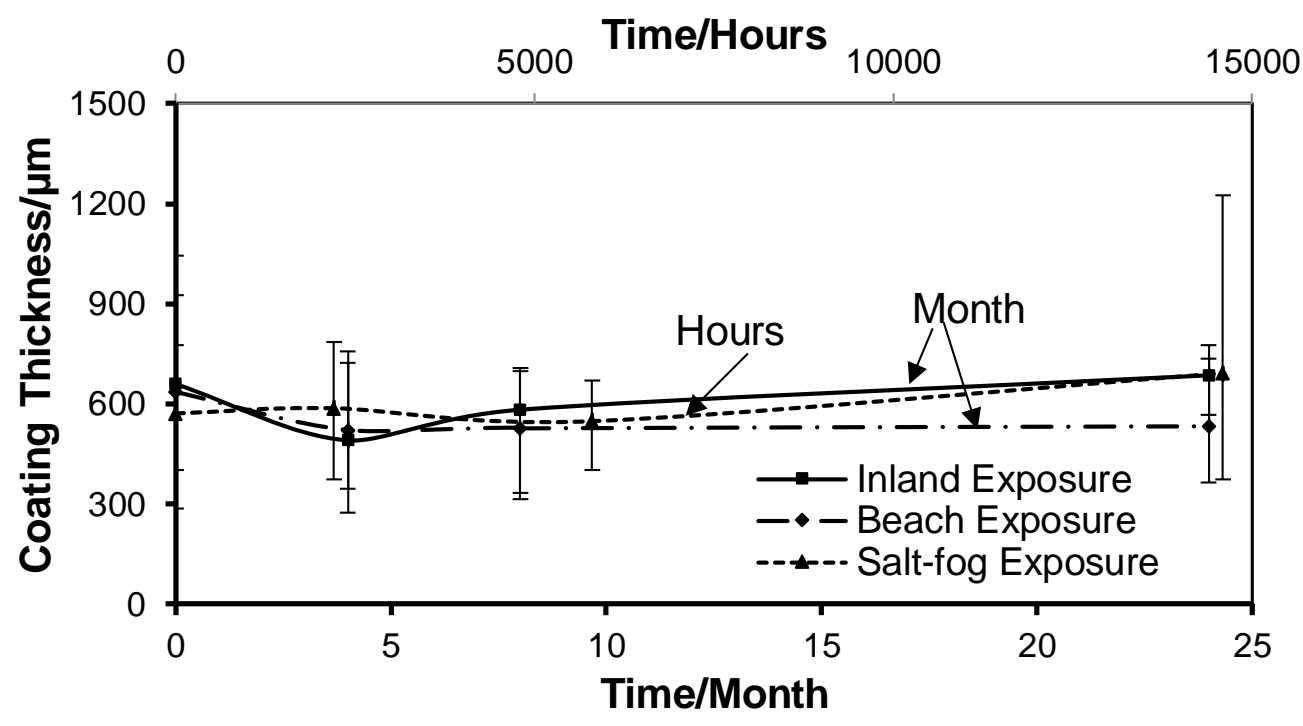

Figure 4.6: After Exposure Coating Thickness of CBPC Coating.

Coating degradation assessed by visual observation can be further detailed by coating thickness trend during exposure. Figure 4.6 represents the median, maximum and minimum coating thickness in inland, beach and salt-fog exposure. The statistical error may be attributed due to the large variation in coating thickness and differential degradation during exposure. For the first four months the coating thickness measurements were similar for the samples placed in inland and beach exposures. There the median thickness was reduced from $\sim 650 \mu \mathrm{m}$ to $\sim 500 \mu \mathrm{m}$. After 4 months, the median coating thickness for samples exposed in outdoor inland conditions increased to $\sim 700 \mu \mathrm{m}$ by the 24 th months of testing. The median coating thickness for beach site samples remained at $\sim 500 \mu \mathrm{m}$ up to 24 months. The somewhat discrepant behavior was thought to be due to the differences in the extent of coating degradation caused by available surface moisture produced by rainfall. As mentioned earlier, the inland site had higher cumulative rainfall which would produce enhanced wet and dry cycling. This was 
thought to facilitate loss of coating integrity and enhance porosity. Also prolonged exposure to moisture can contribute to coating degradation. Furthermore, available moisture may facilitate formation of intermediate hydrate product (Balasubramaniam, 2000) that would in part account for the increase in coating thickness. Other mechanical explanations may include scouring and re-deposition of ceramic hydrate constituents. The coating thickness of samples exposed in salt-fog exposure increased in a similar manner. The initial coating thickness was $\sim 550 \mu \mathrm{m}$ and it increased to $\sim 700 \mu \mathrm{m}$ after 14600 hours of exposure. The constant high level of available moisture observed for degradation of the outer coating facilitated formation of the intermediate hydrate product. As mentioned earlier, even though severe coating degradation and staining was observed, there was limited evidence of steel rust formation in the high salt and moisture environment. 


\subsubsection{Pull-off Adhesion Strength}
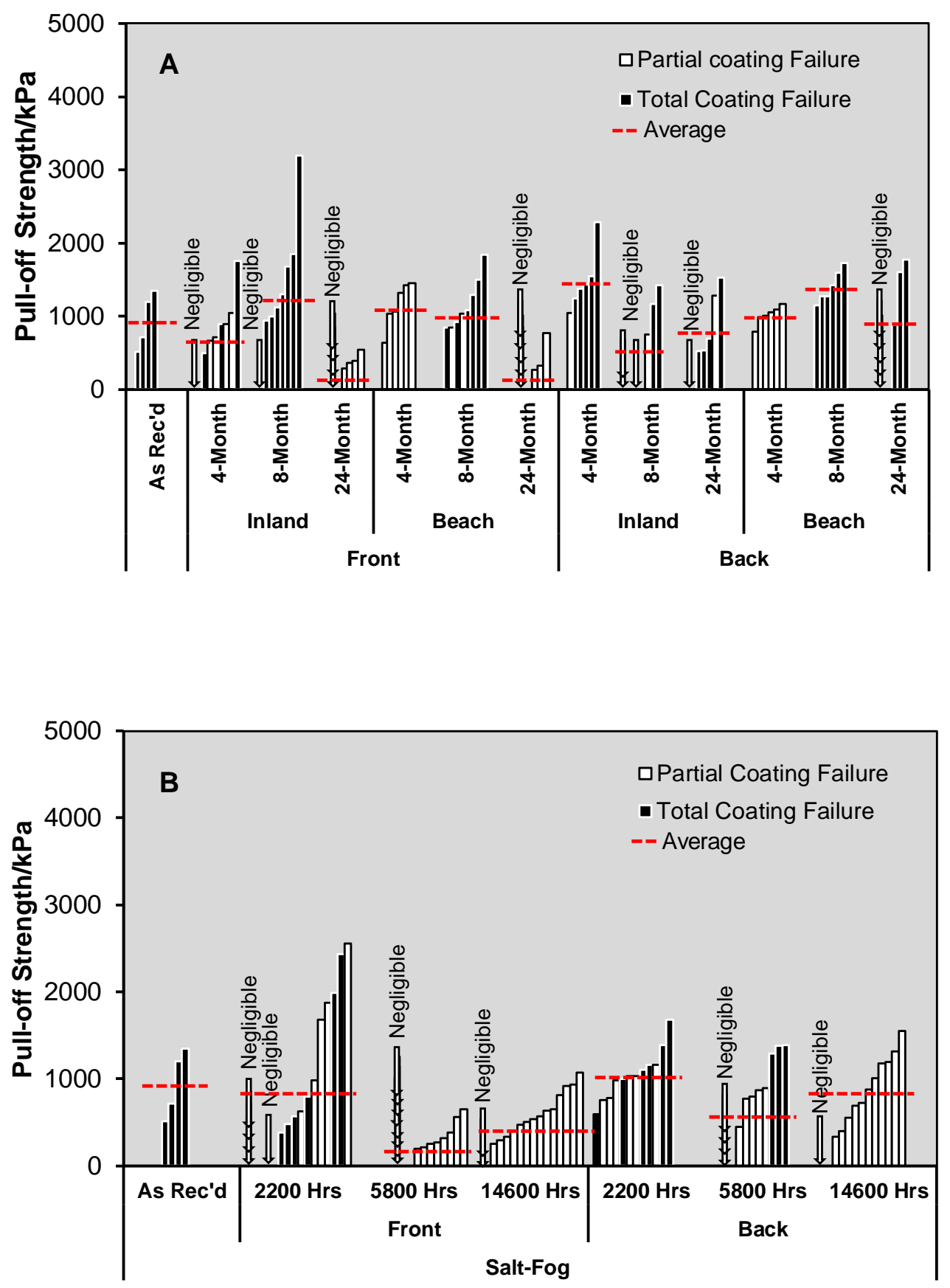

Figure 4.7: Pull-off Strength of CBPC Coating.

A) Outdoor Exposure B) Salt-Fog Exposure. 


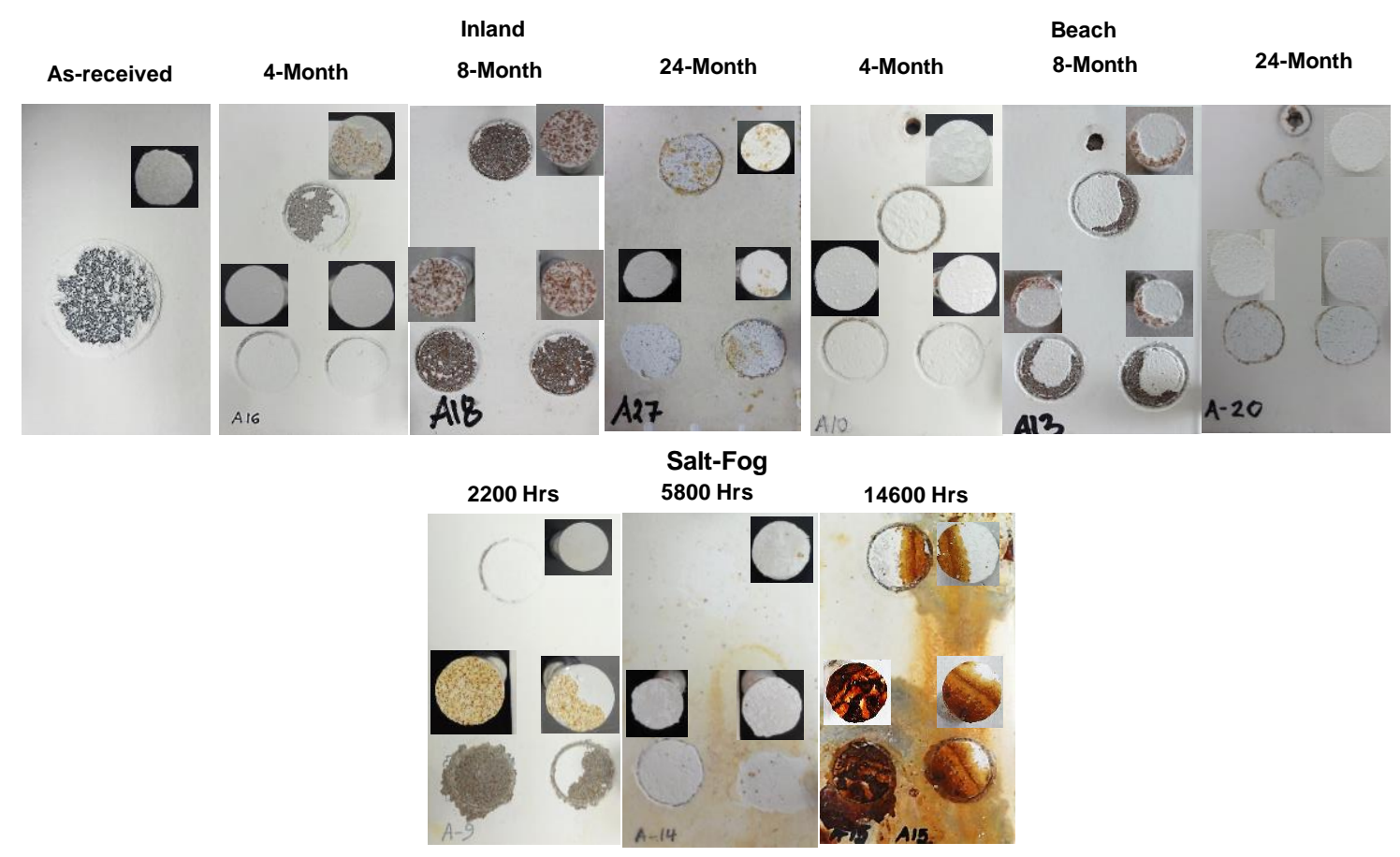

Figure 4.8: Coating Surface After Pull-off Testing.

The pull-off test results and the photographs of the exposed surface after testing are shown in Figure 4.7 and Figure 4.8 respectively. The coating pull-off strength for CBPC was low $(<2000 \mathrm{kPa})$ regardless of exposures. The as-received pull-off strength was less than $2000 \mathrm{kPa}$ and the coating separated by removal of the ceramic from an intermediate hydrate layer (labeled as total coating failure) that appeared as surface discoloration. Pull-off testing never resulted in complete separation of the intermediate hydrate layer from the steel substrate. Pull-off testing of samples exposed in outdoor conditions sometimes showed similar modality of coating separation. In these samples however, the intermediate hydrate layer appeared to be thicker, especially with time of exposure. There was an overall apparent trend for the samples to exhibit cohesive weakening of the bulk coating (labeled as partial coating failure) that was exacerbated with longer exposure. Here the ceramic coating exhibited cohesive failure with low and 
sometimes negligible pull-off strengths. Pull-off testing for salt-fog samples showed similar but enhanced development of the intermediate hydrate product and cohesive weakening of the bulk coating. The long-term exposures in salt fog resulted in severe staining but the coating always separated as partial coating failure. Even though the formation of an intermediate hydrate product (accounted by the discoloration) was thought to contribute to the overall low pull-off strength of the coating system, the degradation of cohesive strength of the bulk coating appeared to be more significant than adhesion loss relating to the development of the hydrate product. Indeed, the inland outdoor samples gave indication to thickening of the coating by hydrate formation yet the pull-off failure mechanism was characterized as partial coating failure after up to 24 months of testing. The cohesive failure of the coating and the reduced pull-off strength is in part explained by the loss of coating integrity and degradation associated with the available moisture from the environment and is generally consistent with the observed bulk coating degradation. The interplay between bulk coating degradation and intermediate hydrate product formation was not directly assessed here but it is likely that the constituent materials of both are related.

\subsection{Assessment of CBPC Coating in Wet Exposure by Electro-Chemical Test}

Assessment of possible coating degradation and corrosion development was made by physical and electrochemical techniques (i.e. visual assessment, pull-off tests, open circuit potential (OCP), linear polarization technique (LPR) and electrical impedance spectroscopy (EIS). CBPC steel coupons were immersed in neutral $\mathrm{pH}$ solutions for $\sim 30$ days. The neutral $\mathrm{pH}$ solution, simulated runoff and pooled drainage water, was made from distilled water with and without $3.5 \%$ sodium chloride (Lau \& Sagues, 2009). A 1- 
in scribe was introduced on some samples by using a $0.5 \mathrm{~mm}$ cutter. Both non-scribed and scribed samples were introduced to identify the distinctive behavior of coatings with defects.

LPR testing was made from the initial OCP to $-25 \mathrm{mV}$ vs. OCP at a scan rate of $0.05 \mathrm{mV} / \mathrm{s}$. The corrosion currents, $\mathrm{I}_{\mathrm{corr}}$, measured by a linear polarization method, were calculated using Equation 2.8. The polarization resistance, $\mathrm{Rp}$, is defined as the ratio of change in potential to amount of required current (Vetter, 1967). EIS testing was made at the OCP condition with $10 \mathrm{mV}$ AC perturbation voltage from frequencies of $100 \mathrm{kHz}$ to 1 $\mathrm{mHz}$. The conventional interpretation of the impedance response of a coated metal interface was assumed as a first approach to evaluate possible degradation, and an equivalent circuit analog, as shown in Figure 2.6, was used to fit the impedance data to

the physico-electrochemical parameters associated with that system. Non-ideal capacitive behavior and other factors due to heterogeneities, including non-uniform current distribution in the coating and metal-electrolyte interface, were in part represented by constant phase elements. The total impedance on first approach was expressed as shown in Equation 2.11. Finally, the results of the electrochemical parameters were justified with qualitative visual inspection.

\subsubsection{After Exposure Pull-off and Thickness Measurement}

All of the coupons exposed to solution with and without chlorides had some level of coating surface discoloration and surface roughening indicative of coating degradation. The as-received pull-off adhesion of the coating was low, $<1400 \mathrm{kPa}$, and no significant differentiation was observed after immersion testing. In some instances, the pull-off tests of samples after immersion resulted in adhesive strengths of $0 \mathrm{kPa}$ due to the complete 
separation of the coating from the steel substrate. Coating thickness measurements before and after exposure showed as much as a $13 \%$ decrease, but in some cases an increase in thickness was measured. This was in part attributed to the averaging of thickness values from several coupon locations when large coating thickness variance existed in the asreceived condition. Furthermore, as discussed later, undercoating hydration product developed in samples exposed to chloride solution, which would cause error in coating thickness measurements. No distinct trend in coating degradation could be deduced from the presence of the scribe.

\subsubsection{Visual Inspection}

As expected, no outward signs of rust were observed in any of the samples in chloride-free solution, and corrosion product was outwardly visible in all samples (both scribed and non-scribed) exposed in chloride solution. In the scribed samples, the corrosion product only emanated from the scribed location (Figure 4.9B) and showed localized bleed-out. In the non-scribed samples immersed in chloride solution, small corrosion pits were observed at locations around the periphery of the test-cell solution vessel (Figure 4.9A). Initial thought would attribute this corrosion product to crevice corrosion, but the behavior was not observed in the test cells with the scribed coupons.

Observation of the steel surface that was exposed from pull-off testing showed no significant corrosion in any of the samples immersed in chloride-free solution. The steel substrate was clean even at locations directly adjacent to the scribe. In the samples immersed in chloride solution, no corrosion was observed on the steel directly adjacent to the scribes that showed oxide product and confirmed that the corrosion was localized directly within the defect. Outwardly, corrosion-like pits were observed in the periphery 
of the exposed coating area in the non-scribed coupon, but it was apparent that significant under-coating hydration product developed within the entire area exposed to the chloride solution. Locations directly adjacent to the immersed area showed no corrosion. As mentioned earlier, conflicting results in coating thickness measurements were due to the combined effects of apparent coating degradation and undercoating hydration product formation.

Severe cracking of the outer coating is illustrated in Figure 4.9 for the non-scribed samples immersed in chloride solution; however, the degradation eventually occurred for all samples. The cracks formed after samples were removed from the solution and allowed to dry.
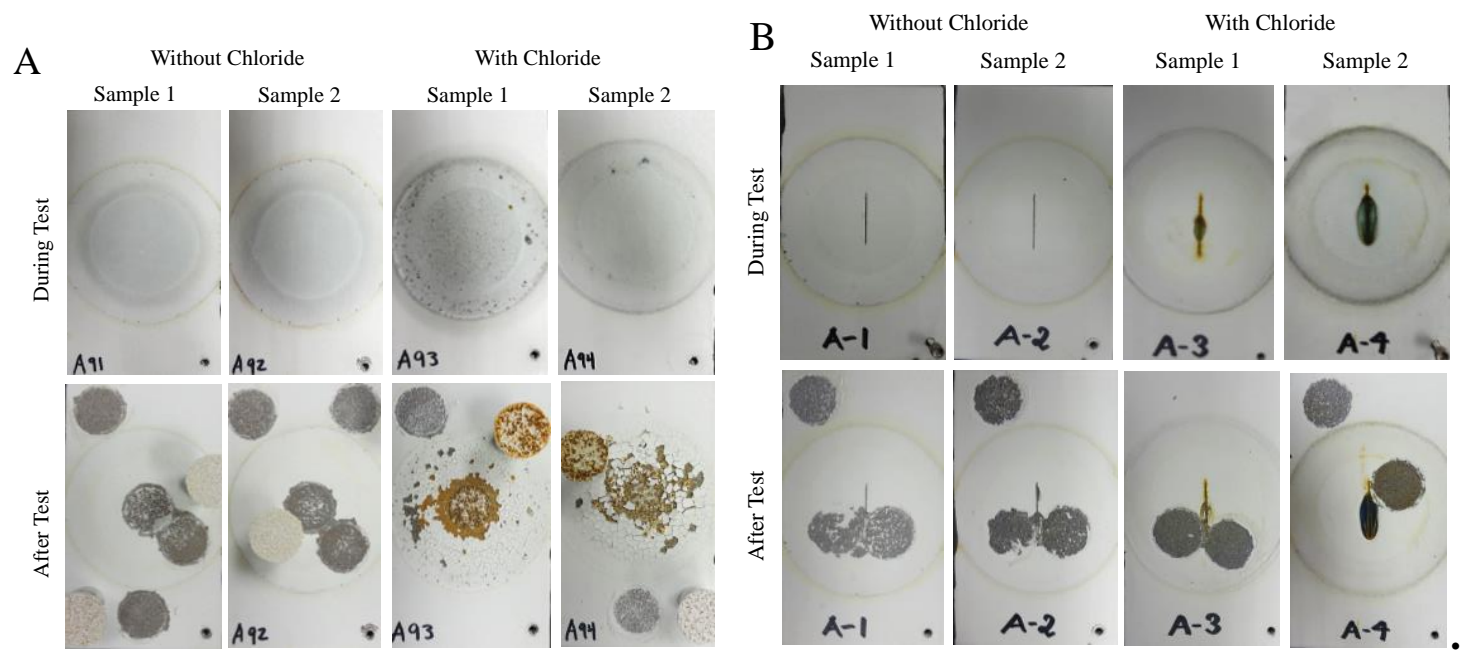

Figure 4.9: Coating Degradation for Exposure. A) Non-scribed Sample. B) Scribed Sample.

\subsubsection{Electro-Chemical Test Results}

The initial measured OCP (Figure 4.10) of all of the samples after a few hours was -500 $\mathrm{mV}_{\text {SCE. }}$ The potential of the samples immersed in non-chloride solution 
gradually increased to $\sim-300 \mathrm{mV}_{\mathrm{SCE}}$. The shift to more noble potentials with time indicated a trend towards passive-like conditions. The role of any intermediate alloy layer on the corrosion activity was not ascertained. The samples (scribed and nonscribed) in chloride solution maintained active corrosion conditions throughout the 30 day test period. The corrosion currents determined from LPR measurements (Figure 4.11) were consistent with the trends described by the OCP measurements. As expected, moderate to high corrosion currents were initially observed in all test conditions. The corrosion current declined from $\sim 15 \mu \mathrm{A}$ to $\sim 4 \mu \mathrm{A}$ with time in chloride-free solution. For samples immersed in chloride solution, the corrosion current ( 15 to $100 \mu \mathrm{A})$ remained constant throughout the test period. Of note, the absence of intentional surface coating defects did not result in mitigation of corrosion when immersed in chloride solution. The OCP measurements for the non-scribed samples, similar to the scribed samples, were indicative of active conditions throughout the test. Even so, the corrosion current for the scribed samples was initially assumed to be higher than the non-scribed samples since nominally $0.13 \mathrm{~cm}^{2}$ of steel was directly exposed at the scribe defect, and the $\mathrm{CBPC}$ coating was intact for the as-received condition. On the contrary, greater corrosion currents were measured for the non-scribed conditions. 


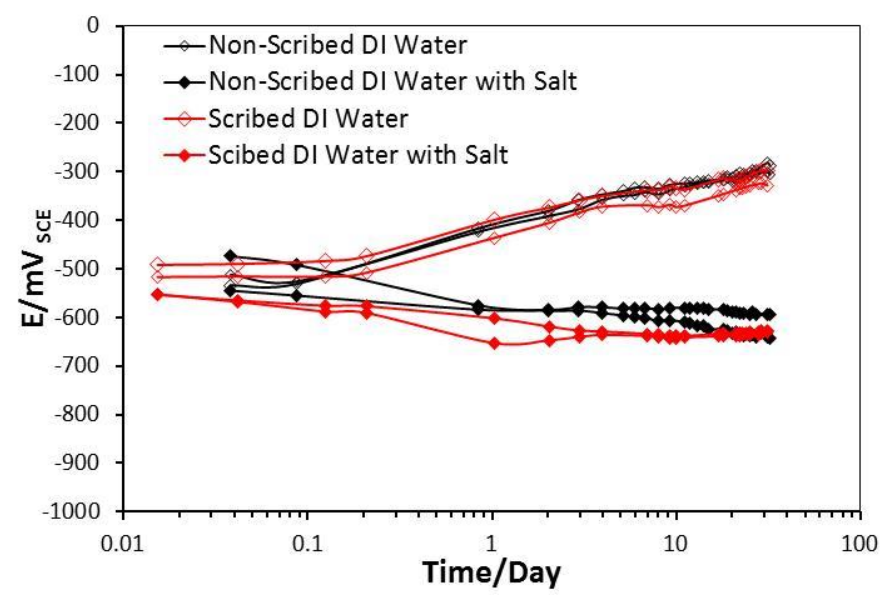

Figure 4.10: OCP for CBPC Coating in Wet Exposure.

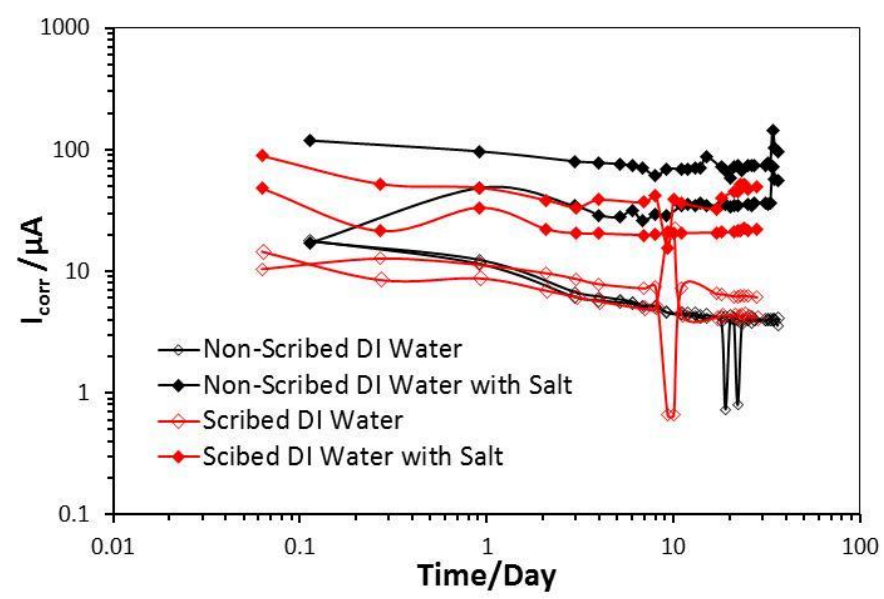

\section{Figure 4.11: Corrosion Current for CBPC Coating in Wet Exposure.}

The visual observations of coating degradation and oxide product formation were consistent with the OCP and LPR results. No significant corrosion developed where passive-like conditions were measured in the chloride-free solutions, and oxide product formation occurred in the chloride solutions where active corrosion conditions were measured. Therefore, a greater degree of oxide product formation throughout the coating exposure surface area was consistent with the measurement of larger corrosion currents compared to those obtained for localized corrosion within the scribe defect. These results 
were indicative of the poor barrier properties of the ceramic coating. The ceramic coating was likely porous and allowed for significant penetration of solution to the substrate, allowing for electrochemical processes to occur at early exposure times, as indicated by the active potentials and high corrosion rates. Further, coating degradation, as exemplified by the visual discoloration and material loss, allowed enhanced corrosion development.

The hydration product appeared localized to the scribe defect when present. In this case, it was thought the anodic region remained localized at the initially exposed steel area, and the remaining steel below the porous coating acted as a net cathodic region, and perhaps phenomena such as cathodic prevention may have hampered corrosion development elsewhere. In the non-scribed coated samples, local coating defects throughout the exposed surface would have initiated, causing the formation of hydration product throughout. It was noted that corrosion penetration into the steel substrate was minor and interaction with an apparent intermediate layer at the steel substrate, when present, may have mitigated substantial metal loss. Further investigation results will be presented later in this chapter.

Representative impedances for the coatings are presented by a Nyquist plot in Figure 4.12. The resolved solution resistances are shown in Figure 4.13. As expected, low solution resistance representative of the chloride solution was resolved as compared to the choloride-free solution. The solution resistance did show decrease specially for saltfree solutions. This was due to the leaching of minerals from the bulk material during exposure to the solution which will be discussed in the next chapter. The pore resistance resolved from the EIS analysis is shown in Figure 4.14. Generally constant pore 
resistance was observed for non-chloride solution throughout the immersion period, but an increasing trend was identified for chloride solution. The constant pore resistance with time for the coating in chloride-free solution corroborates previous discussion on early saturation of the coating pores with solution, but does not capture any possible physical degradation of the coating. Assessment of coating permeabiliy is in progress. The increase in pore resistance with time for the coated steel immersed in chloride solution was thought to be due to formation of hydration product within the pores or coating defects, as seen in Figure 4.9. The pre exponential term of the coaitng capacitance was also resolved from impedance analysis but the pre exponential term have to be transferred to coaitng capacitance to describe the coating degradation. This part is elaborated in chapter five.
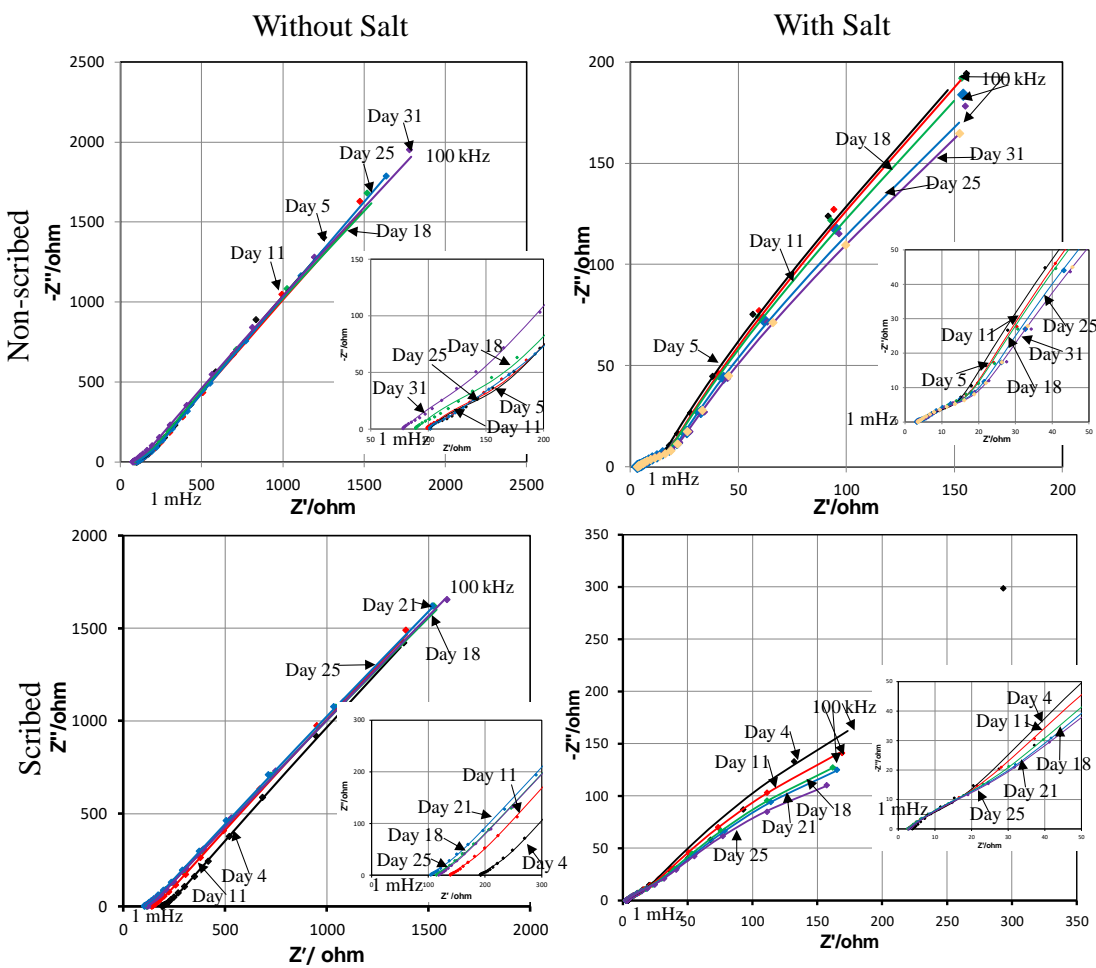

Figure 4.12: Nyquist Diagram for Non-scribed and Scribed CBPC Samples in Neutral pH with and without Chloride Solution (Representative Diagram). 


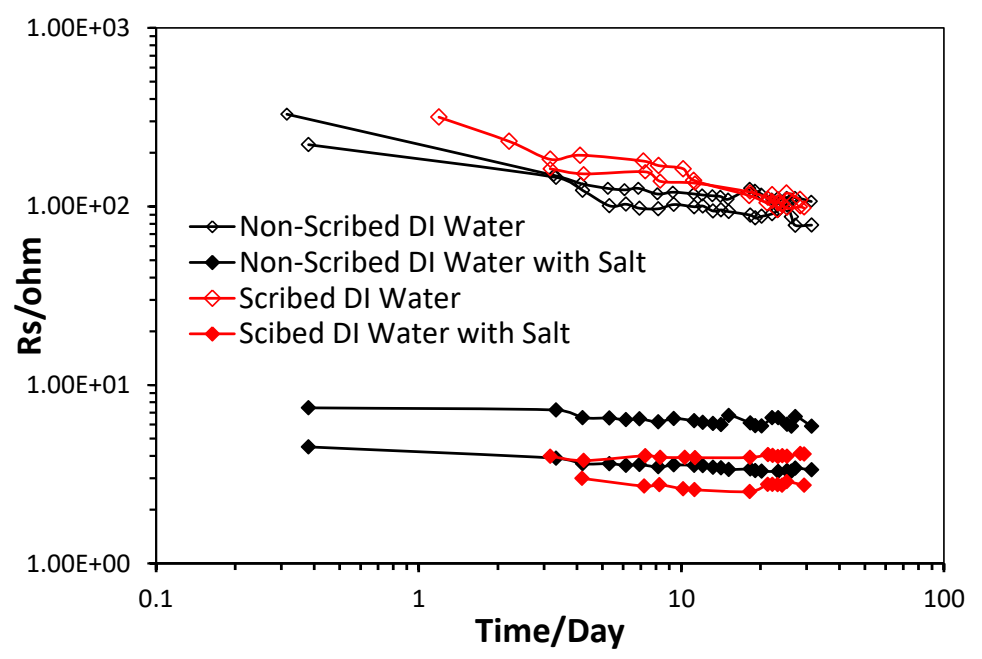

Figure 4.13: Solution Resistance for Non-scribed and Scribed Samples.

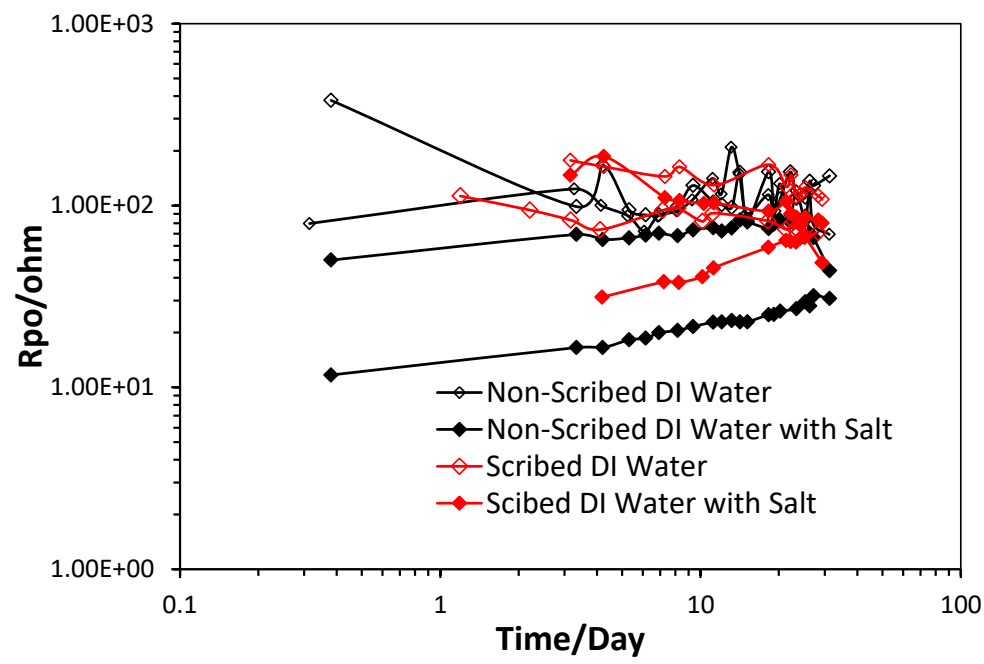

Figure 4.14: Coating Pore Resistance Non-scribed and Scribed Samples.

\subsection{Assessment of CBPC Coating in Alternate Dry and Wet Exposure by}

\section{Electro-Chemical Technique}

Alternate wet and dry exposure test was done for only non-scribed samples (with and without chloride solution) as there was no significant differentiation observed between non-scribed and scribed samples in outdoor, salt-fog exposure and earlier electro-chemical testing. CBPC coated steel coupons were exposed to 2-day alternate wet 
and dry exposure for up to 30 days (cumulative 15 days in wet condition and 15 days in dry condition). The samples were submerged in distilled water (with and without $3.5 \%$ sodium chloride solution) to simulate the presence of accumulated runoff and pooled drainage water during the wet cycle and stored in a controlled humidity chamber $\left(\sim 75^{\circ} \mathrm{F}\right.$ temperature and $<20 \%$ relative humidity) during the dry cycle. Test cells were made for the wet cycle to accommodate reference and auxiliary electrodes required for electrochemical testing.

EIS testing was made at the OCP condition with $10 \mathrm{mV}$ AC perturbation voltage at frequencies from $1 \mathrm{MHz}$ to $1 \mathrm{~Hz}$ to ideally capture the responses associated with a bulk coating. As a first approach, the impedance response of a coated metal interface relating to the physico-electrochemical parameters as shown in Figure 2.6 was assumed. Nonideal capacitive behavior and other factors due to heterogeneities including non-uniform current distribution in the coating and metal-electrolyte interface were in part represented by constant phase elements. Photo documentation and coating thickness measurements of the samples were made prior to testing and after exposure to identify physical degradation.

\subsubsection{Visual Inspection}

Coating degradation as surface roughening and chalking was visually observed on coupons exposed in both salt and salt-free solution (Figure 4.15). Coupons exposed to cyclic testing in salt solutions exhibited severe surface cracking and fracturing of a highly friable material caused by the wet and dry exposure cycles of a weakened matrix of CBPC hydrates. On the outer surface, fracturing was less apparent on coupons exposed to salt-free solutions even with similar wet and dry cycling. This reduced degree of 
fracturing may be due to formation of some hydration product of magnesium and phosphate that may act to either limit the extent of cracking or fill free spaces. However, as shown in Figure 4.16, surface scouring and crack formation in the body of the coating can be significant regardless of salt presence.

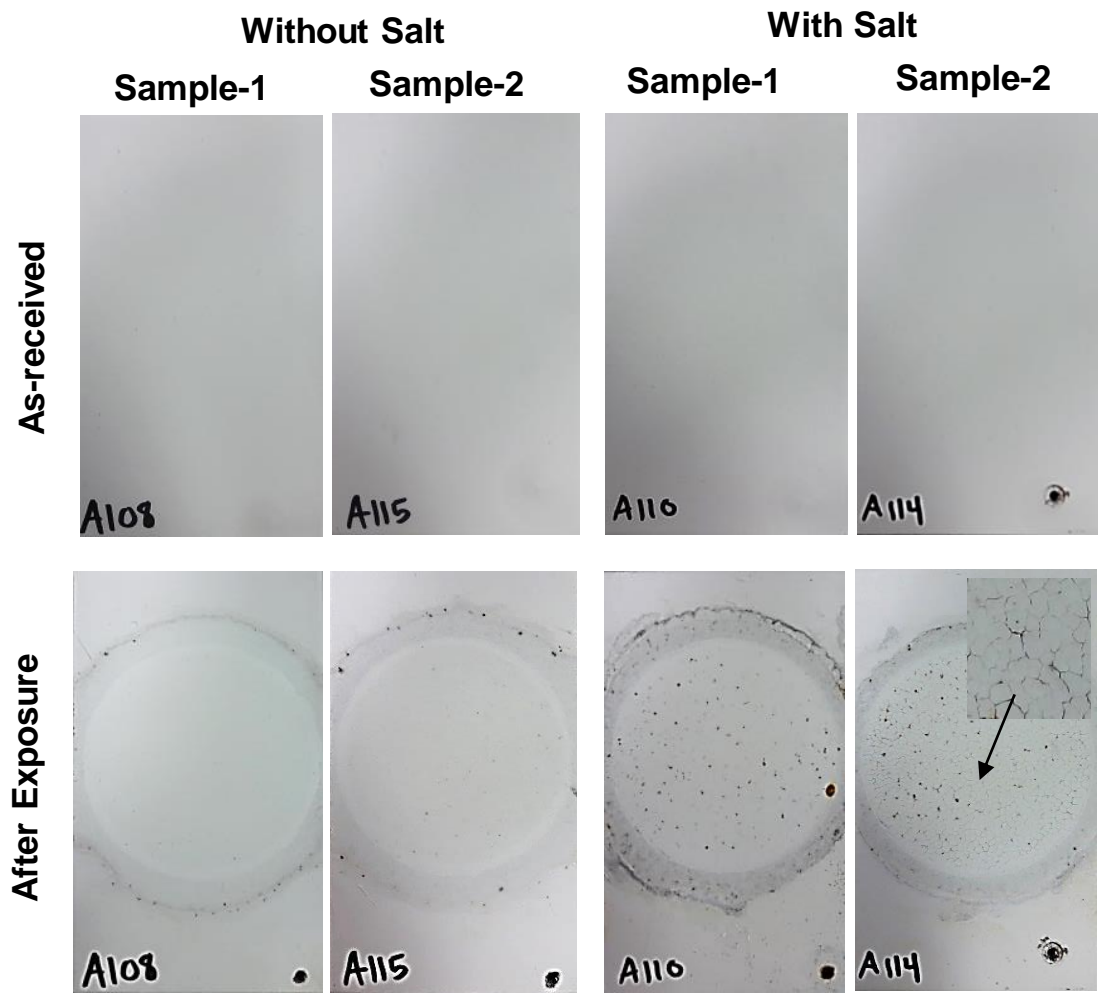

Figure 4.15: Coating Degradation after Wet and Dry Exposure.
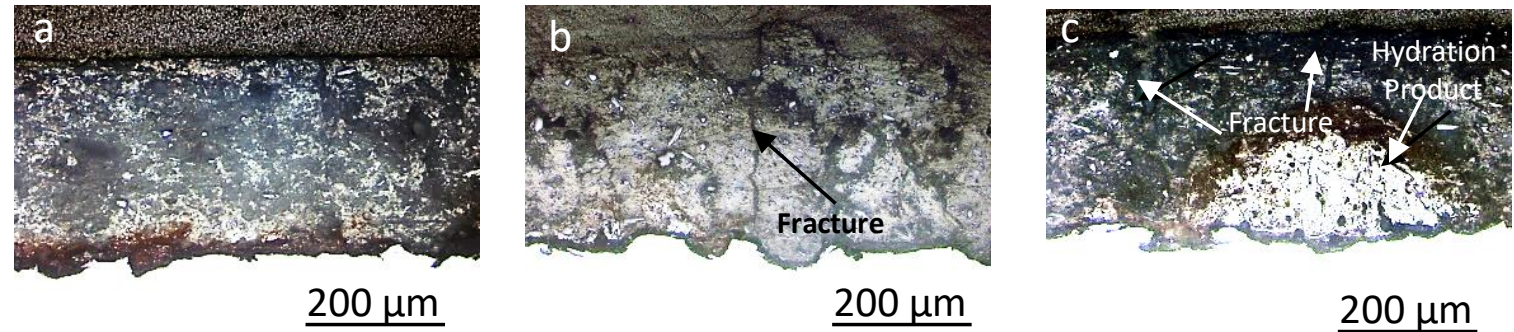

Figure 4.16: Micrograph of CBPC Samples. a) As-received b) Without Salt c) With Salt 


\subsubsection{Coating Thickness and Pull-off Strength Measurement}

The coating thickness increased for majority of the samples exposed to wet and dry exposure after 30 days of testing. It was observed that the increase in thickness was somewhat larger when exposed in test conditions without salt (Figure 4.17). The average increment in coating thickness for salt-free and salt test cases was $\sim 25 \mu \mathrm{m}$ and $\sim 7 \mu \mathrm{m}$, respectively. Pull-off strength was relatively low, less than 2,000 kPa, and generally exposed the metal substrate with minor presence of residual hydrate coating materials for all samples in the as-received condition and in all test conditions (Figure 4.18). Pull-off testing typically resulted in apparent cohesive failure of a layer of coating near the steel interface, possibly related to interfacial products associated with reaction with the base iron (Figure 4.19) and the degraded coating integrity caused by the wet and dry exposures. For the bulk material, the coating may be denser near the steel substrate when the ceramic material initially forms during the spray application. Material layered during subsequent passes was thought to contain higher portions of unreacted constituent materials such as magnesium hydroxide and magnesium phosphate hydrate. Exposure to solution in the testing here would likely lead to subsequent reactions involving these materials including formation of hydrates leading to the increase in coating thickness described above. The expected reduced cohesion in bulk coating layers due to the wet and dry exposures was not well defined by the pull-off testing and was deemed to be due to the overall low cohesive strength. 


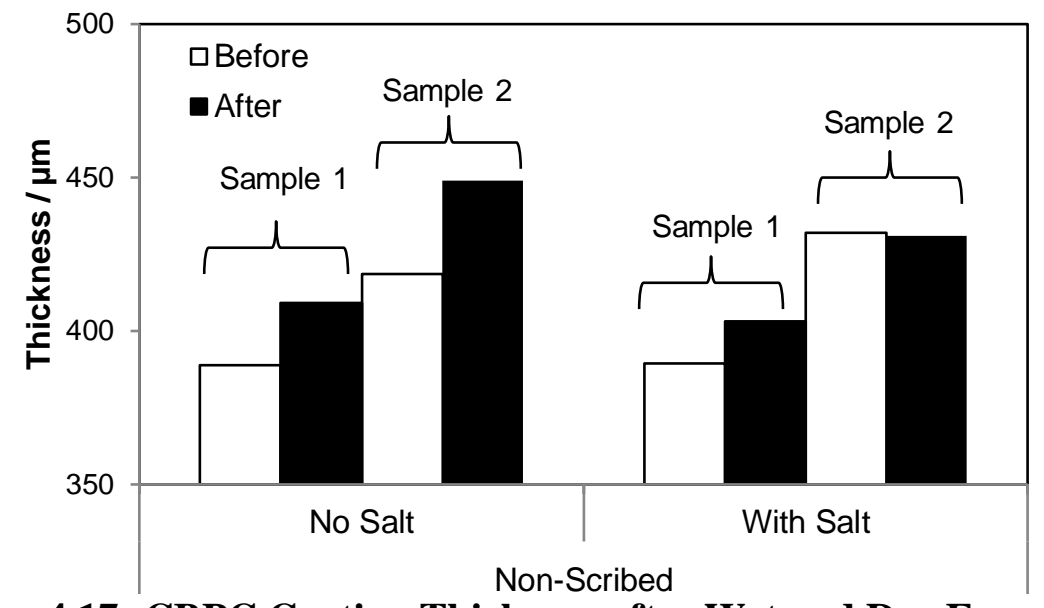

Figure 4.17: CBPC Coating Thickness after Wet and Dry Exposure.

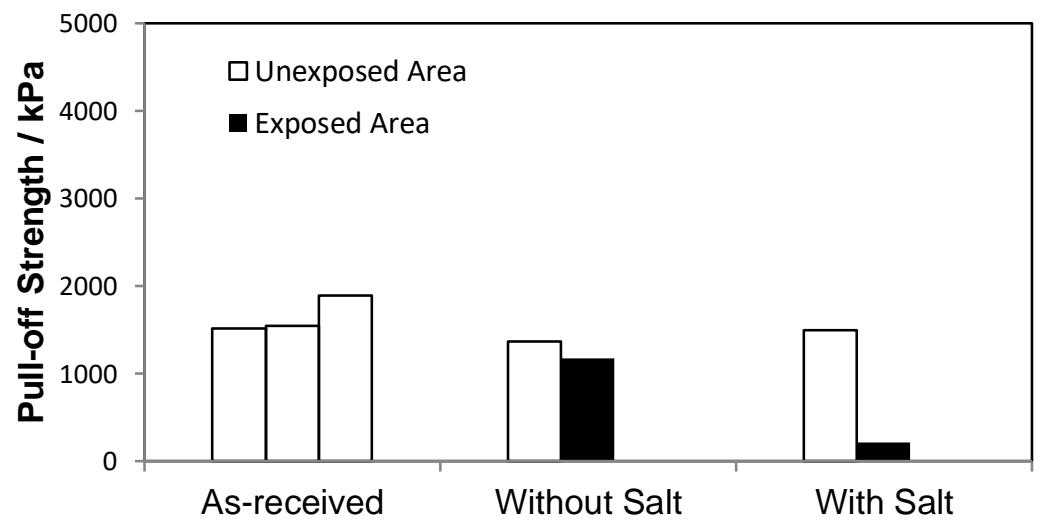

Figure 4.18: CBPC Coating Pull-off Strength after Wet and Dry Exposure.
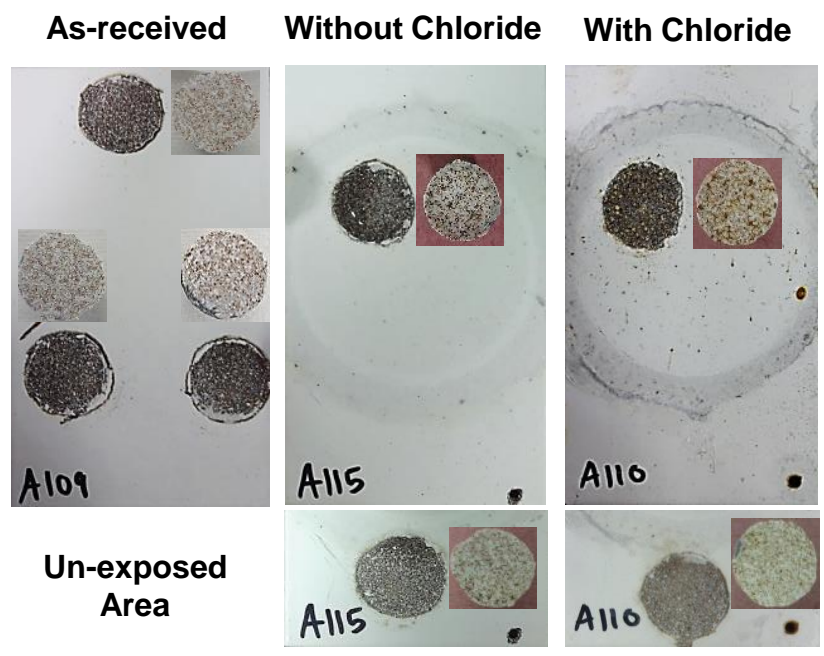

Figure 4.19: Visual Inspection of Coating Substrate after Pull-off Strength after Wet and Dry Exposure. 


\subsubsection{Electro-Chemical Test Results}

The initial open circuit potential $(\mathrm{OCP})$ for non-salt solution was $\sim-0.3 \mathrm{~V}_{\mathrm{SCE}}$ and the OCP gradually shifted to more novel potential of $\sim-0.2 \mathrm{~V}_{\mathrm{SCE}}$ during the exposure. The open circuit potential (OCP) was $\sim-0.4 \mathrm{~V}_{\mathrm{SCE}}$ at the beginning of the test of salt solution (Figure 4.20). The potential increased to -0.6 VSCE after 5 days of exposure and maintained that OCP for the rest of the exposure. The corrosion current determined from LPR measurement were consistent with the trends described by the OCP measurements (Figure 4.21). High corrosion current of $250 \mu \mathrm{A}-300 \mu \mathrm{A}$ was observed for salt solution during the test period. Contrastingly, low corrosion current of less than $20 \mu \mathrm{A}$ observed for non-salt solution and the corrosion current was decreasing during exposure. However, active condition observed at the beginning of the test regardless of the type of solution. The early active condition was due to the characteristics porous nature which facilitated moisture to the steel substrate which were apparently observed in optical micrograph in as-received condition. The observed passive like condition in non-chloride solution was due to the formation of proposed hydrate of magnesium and iron which will be discussed in the section of X-ray diffraction. The increase in thickness and reduction in pull-off strength in outdoor and salt-fog exposure also consistent with the electrochemical nature of the coating. Further, high corrosion current in chloride solution was associated with activity of the proposed iron phosphate hydrated and interaction of water with steel substrate due to the enhancement of the pores for high solubility of bulk magnesium coating in salt solution. 


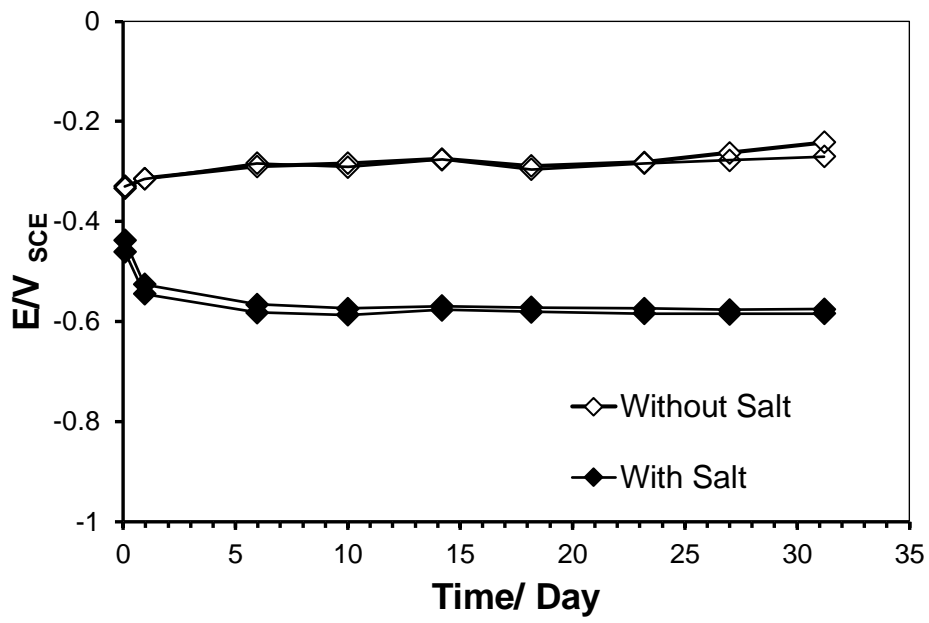

Figure 4.20: OCP for CBPC Coating during Wet and Dry Exposure.

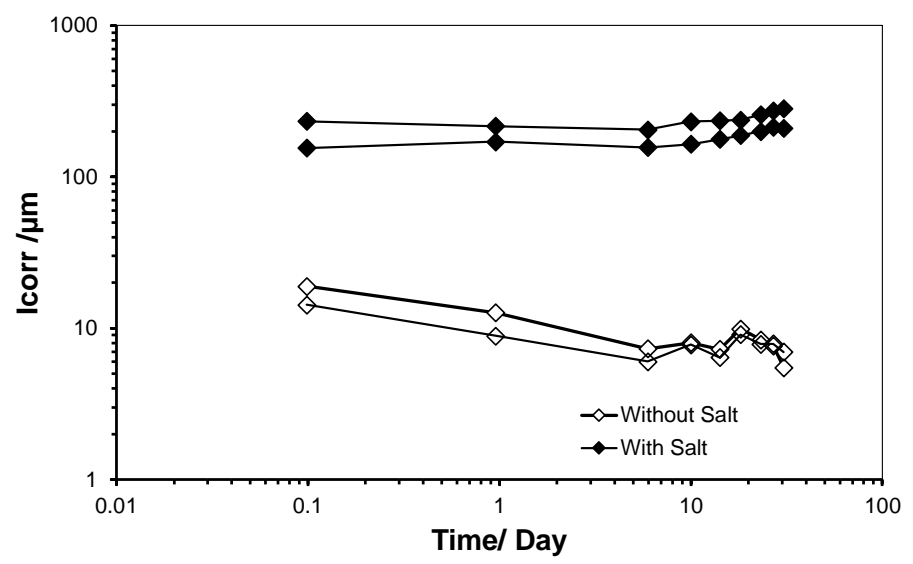

Figure 4.21: Corrosion Current for CBPC Coating during Wet and Dry Exposure.

Representative Nyquist diagrams for samples tested in salt and salt-free solutions are shown in Figure 4.22. Resolved solution resistance and coating pore resistance were consistent to the conductivity of the two test solutions (Figure $4.23 \& 4.24$ ). Low solution resistance $(<3 \mathrm{ohm})$ was observed for salt-solution during the test period relatively high solution resistance of $\sim 70 \mathrm{ohm}$ was observed for non-salt solution. The solution resistance did show decrease for all samples in both salt and salt-free solutions. This was due to the leaching of minerals from the bulk material during exposure to the solution. 
The collected leachate was analyzed for potassium and magnesium which will be discussed later in this chapter. Otherwise resolved impedance coating parameters did not show any other distinct trends with time or exposure environment and it was evident that the extent of coating permeability and degradation could not be resolved by conventional approaches for data analysis for conventional coatings.
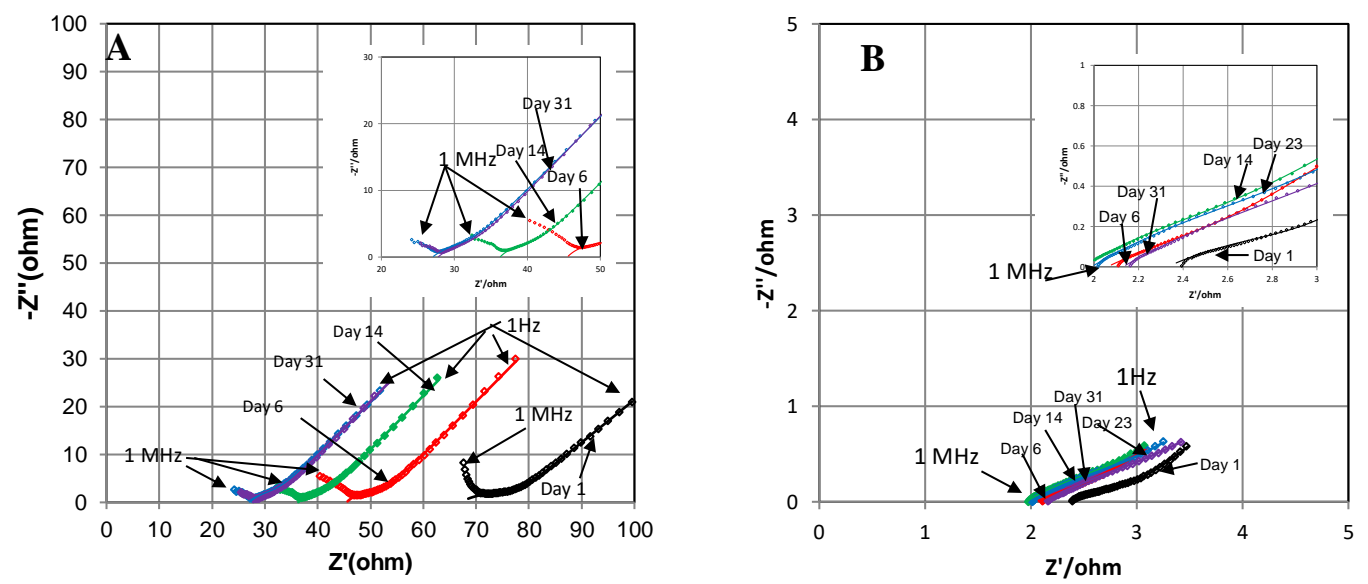

Figure 4.22: Nyquist Diagram for Wet and Dry Exposure.

A) W/O salt Sample $(1 \mathrm{MHz}<\mathrm{f}<1 \mathrm{~Hz})$ B) With Salt Sample $(1 \mathrm{MHz}<\mathrm{f}<1 \mathrm{~Hz})$ (Dot points for real data $\&$ Solid lines for fitted data)

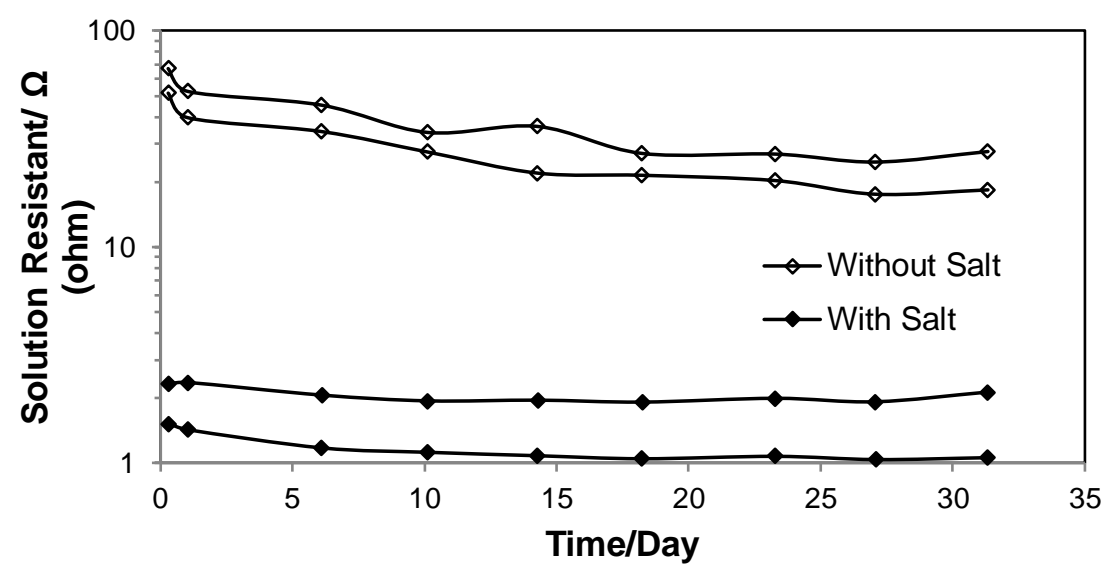

Figure 4.23: Solution Resistance for Wet and Dry Exposure. 


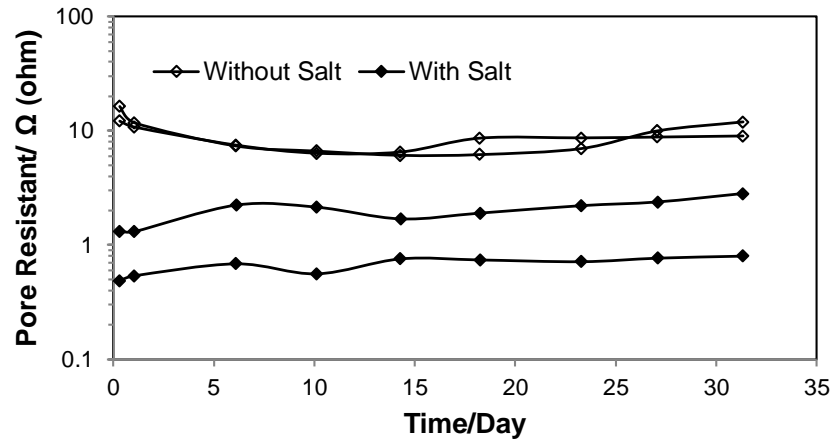

Figure 4.24: Coating Pore Resistance for Wet and Dry Exposure.

\subsection{Metallurgical Assessment of the Exposed Samples}

This chapter represents the results of morphological change of CBPC coating during exposure. Mercury Intrusion Porosimetry (MIP), Chemical Analysis, X-ray Diffraction (XRD), Scanning Electron Microscopy (SEM) and Energy Dispersive X-ray Spectroscopy (EDS) was introduced to capture that morphological change.

\subsubsection{Mercury Intrusion Porosimetry (MIP)}

Mercury intrusion porosimetry was done for as-received and each of the exposed duplicate samples for electro-chemical testing in alternate wet and dry exposure. The samples were exposed in neutral $\mathrm{pH}$ environment with chloride and non-chloride solution for around 30 days. Around $3 \mathrm{~cm}^{2}$ representative area was tested with a pressure range of 0.202 psia to 60000 psia. MIP was done for one of the as-received samples for direct comparison with exposed samples to have the information of pore influence on the degradation mechanism of the CBPC coating. The interpreted results from MIP testing as modal volume and pore size-volume distribution curve is shown in Figure 4.25 and Figure 4.26. The analysis result is reported based on statistical modal diameter and pore volume is calculated by using log formula for normalization. The calculated pore volume 
for as-received sample $0.0902 \mathrm{cc} / \mathrm{g}$ at mode diameter $0.1126 \mu \mathrm{m}$, for salt-free solution test sample $0.09388 \mathrm{cc} / \mathrm{g}$ at mode diameter $0.567 \mu \mathrm{m}$ and for salt solution test sample $0.0606 \mathrm{cc} / \mathrm{g}$ at mode diameter $0.1829 \mu \mathrm{m}$. For the as-received condition, it was apparent that there was a significant volume of pores that had diameter less than $10 \mu \mathrm{m}$. When exposed to solution, there was apparent increase in pore volumes greater than $10 \mu \mathrm{m}$ which would indicate enhancement in pore volume and size due to the environmental exposure. It is noted that the friable degraded bulk material from coupons exposed in salt solutions may have separated from the sample prior to MIP testing.

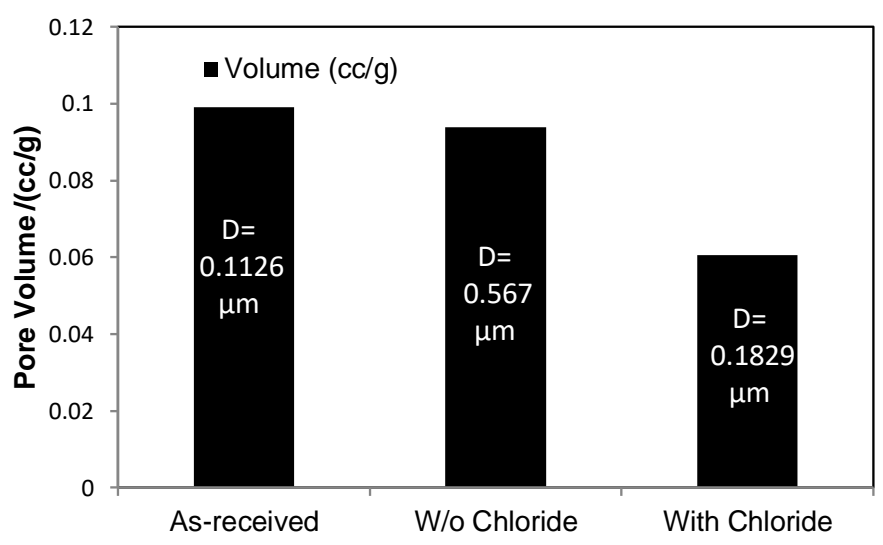

Figure 4.25: Pore Volume for Modal Diameter.

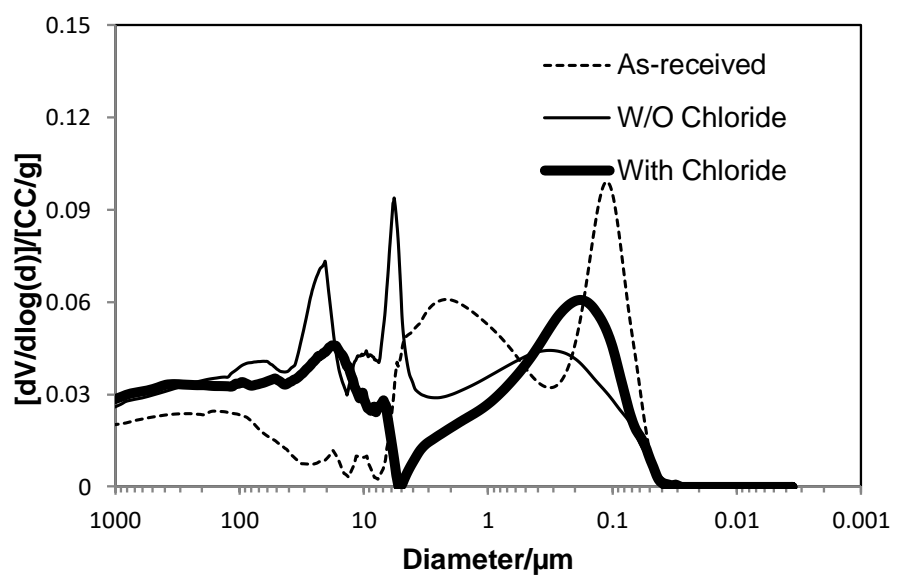

Figure 4.26: Pore Size Distribution. 


\subsubsection{Chemical Analysis}

The electrolytes that was used for electro-chemical analysis of alternate wet and dry exposer were chemically analyzed after 30 days of exposure. The electrolytes were stored in dry cycle and reused the same electrolyte for wet cycle. So, the chemical analysis was expected to give indication about the degradation mechanism of the coating by identifying the soluble coating constituents in the electrolyte. The electrolytes were analyzed for iron, phosphorus and magnesium. Iron and magnesium were analyzed by following analytical method SW-846 6010 and EPA 365.4 for Phosphorus. The results are shown in Table 4.1. Negligible amount of iron was identified in both solution comparing to other two elements. Variation in amount of magnesium as $7.7 \mathrm{mg} / \mathrm{L}$ in nonchloride and $93 \mathrm{mg} / \mathrm{L}$ in chloride solution was identified. The existence of magnesium was due to the apparent presence of the unreacted magnesium hydroxide during application process and formation of soluble magnesium product during exposure (Wagh, 2004). The amount of magnesium is higher in salt solution because the magnesium hydroxide reacted with chloride solution to form highly soluble magnesium chloride which eventually increased the degradation of magnesium products (Xin et al., 2008 \& Song and Atrens, 2003). For total phosphorus (soluble and non-soluble) the amount in non-chloride sample is $109 \mathrm{mg} / \mathrm{L}$ and for chloride sample is $32 \mathrm{gm} / \mathrm{L}$. The higher amount of phosphorus presence in non-chloride solution indicates the apparent higher degradation of the phosphate coating in non-chloride solution. Electrolyte $\mathrm{pH}$ and conductivity were also measured along with temperature during the test. The results are represented in Figure 4.27 \& Figure 4.28. The pH changed from 7.85 to 9.8 in nonchloride solution and 7.23 to 8.6 in chloride solution within 2 days of testing. The $\mathrm{pH}$ 
remained stable at rest of the test period and the temperature was recored $75^{\circ} \mathrm{F}$ at the time of measurements. The change of $\mathrm{pH}$ to $\sim 9$ also support the argument of ionic dissociation of magnesium product in aqueous solution (Wagh, 2004). As expected very high conductivity as $\sim 60 \mathrm{~ms} / \mathrm{cm}$ was observed for chloride solution during the test period but initially low conductivity was identified for non-chloride solution. The conductivity gradually increased with time form $1.62 \mu \mathrm{s} / \mathrm{cm}$ to $1959 \mu \mathrm{s} / \mathrm{cm}$. The increase in conductivity is an apparent indication of degradation of phosphate coating in neutral $\mathrm{pH}$ environment. From the above discussion, it can be opined that the degradation of the coating was due to the leaching of minerals from the bulk material during exposure to the solution.

Table 4.1: Analytical Results of Electrolyte

\begin{tabular}{|c|c|c|c|}
\hline Sample & $\begin{array}{c}\text { Iron, Fe } \\
(\mathrm{mg} / \mathrm{L})\end{array}$ & $\begin{array}{c}\text { Magnesium, Mg } \\
(\mathrm{mg} / \mathrm{L})\end{array}$ & $\begin{array}{c}\text { Phosphorus, } \mathrm{P} \\
(\mathrm{mg} / \mathrm{L})\end{array}$ \\
\hline Without Salt & 2.2 & 7.7 & 190 \\
\hline With Salt & 0.08 & 93 & 32 \\
\hline
\end{tabular}




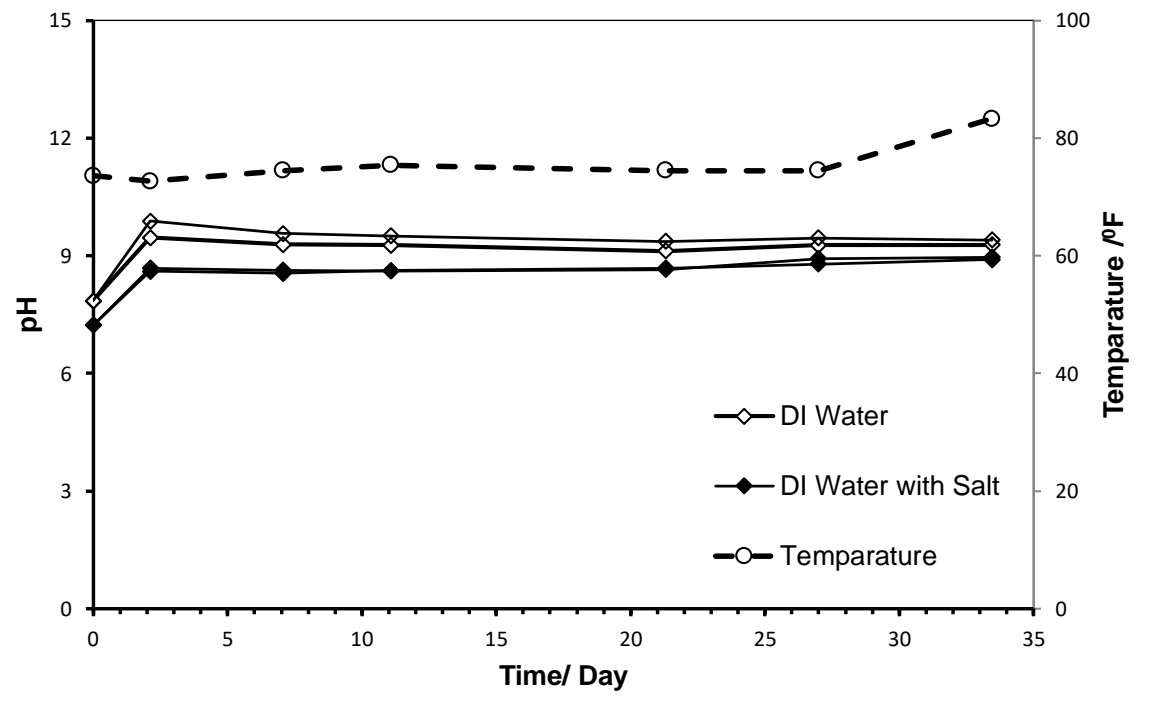

Figure 4.27: Electrolyte pH for Wet and Dry Exposure.

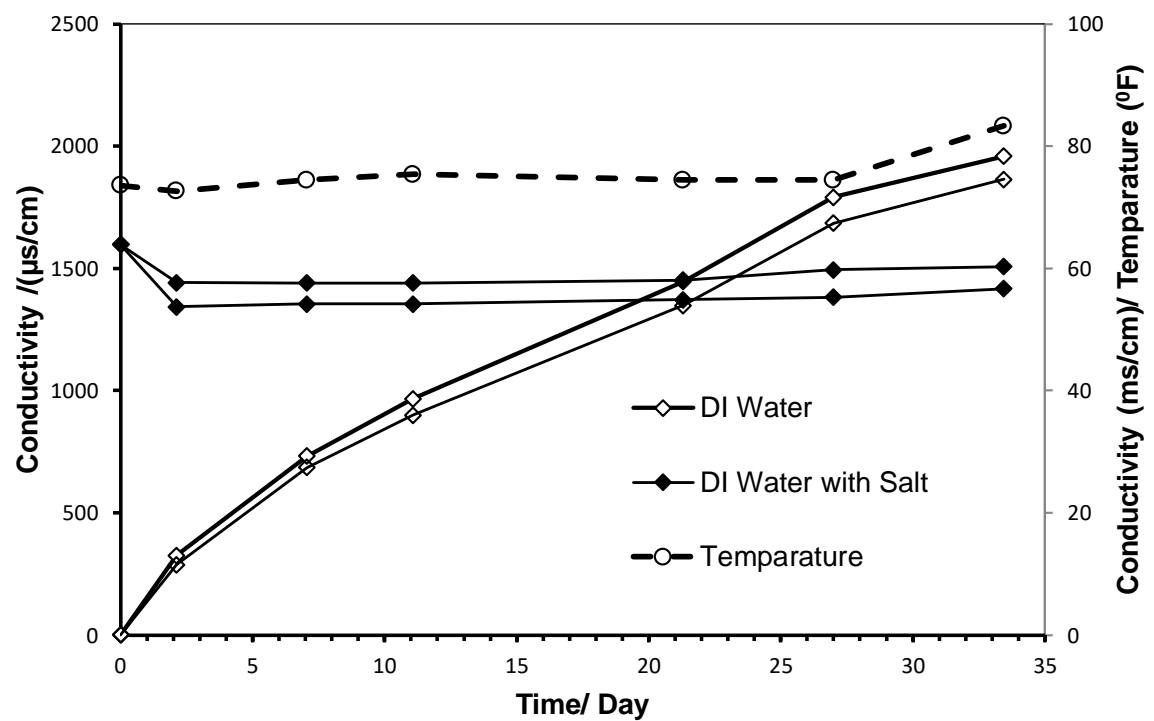

Figure 4.28: Electrolyte Conductivity for Wet and Dry Exposure.

\subsubsection{X-ray Diffraction}

X-ray diffraction was conducted on as-received, inland, beach, salt-fog and alternate wet and dry exposed samples. The X-ray diffraction was performed in different time interval to identify any metallurgical change during exposure. The diffractograms of the representative samples are presented in Figure 4.29- Figure 4.32. Some of the 
exposed samples degraded severely and sample preparation for X-ray diffraction was not possible. Therefore, testing was primarily made on the remnant coating substrate after pull-off testing. For simplicity, the remnant substrate coating is addressed here as under coating. Additional testing on the sample surface to verify CBPC bulk material constituency was also made.

Unreacted magnesium hydroxide $\left[\mathrm{Mg}(\mathrm{OH})_{2}\right]$, magnesium hydrogen phosphate $\left[\mathrm{Mg}\left(\mathrm{H}_{2} \mathrm{PO}_{4}\right)_{2}\right]$, iron and iron hydrogen phosphate hydrate $\left[\left(\mathrm{Fe}\left(\mathrm{H}_{2} \mathrm{PO}_{4}\right)_{3} 2 \mathrm{H}_{2} \mathrm{O}\right]\right.$ was identified along with potassium magnesium phosphate hydrate[ $\left[\mathrm{KMgPO}_{4} 6 \mathrm{H}_{2} \mathrm{O}\right]$ in the as received condition for both the coating surface and under coating. In addition to those compounds, iron hydrogen phosphate hydrate was identified under the coating of the as-received sample. The product is likely associated with the intermediate hydrate layer. The results give indication of generally uniform initial distribution of constituent components from the bulk coating and indication of the iron rich components associated with the intermediate layer. This is to be expected as the coating application is an exothermic reaction made by spraying of two components onto the steel surface. It was reported that unreacted constituents of the CBPC coating can later react upon exposure to moisture to form a magnesium phosphate hydrate (Wagh, 2004). Moisture presence and further hydration of the coating constituents may lead to further differential distribution of material components. Testing primarily of under coating locations may not well represent the spatial variation in the possible subsequent reactions that may account for the observed coating degradation. Nevertheless, testing with time may provide some indicators of overall coating behavior after extended exposure periods. 
As shown in Figures 4.29 and 4.30, the potassium magnesium phosphate hydrate constituent was observed at all times for the outdoor exposures indicating general stability of the CBPC component (Wagh, 2004). After up to 2 years of outdoor exposure, the initially unreacted components such as magnesium hydroxide hydrated to other forms that can possibly be amorphous (Balasubramaniam, 2000). The visual observation of surface chalking was thought to be related to this subsequent reaction. Other forms such as magnesium phosphate hydrate that may form on the coating surface where moisture was introduced were not detected in the undercoating testing. Also over time, it appeared that iron hydrogen phosphate hydrate remained stable and can be ascribed to the intermediate hydrate layer.

XRD of samples from up to 2200 hours in salt-fog exposure as expected showed the potassium magnesium phosphate hydrate associated with the bulk coating and the iron hydrogen phosphate hydrate associated with the intermediate hydrate layer. Samples from the under coating at 5800 hours as described earlier had severe coating degradation and staining. Even though the sample was considered to have partial coating failure (i.e. coating residue remained on the substrate), the XRD did not identify the CBPC coating. The iron hydrogen phosphate hydrate appeared less prominent and iron corrosion products were detected. Samples from the under coating at 14600 hours also had severe surface damage but was still considered to have partial coating failure. XRD conducted on that surface only identified iron phosphate hydrate which would indicate that a change in morphology of the intermediate hydrate layer and little presence of CBPC. It is generally understood that these long-term salt-fog exposures cannot represent actual 
environmental exposures or actual coating behavior in service. However, the results can be useful to understand possible degradation paths.

The X-ray diffractogram of alternate wet and dry exposed samples are shown in Figure 4.32. The coating evaluation supports the previous discussions of formation of iron phosphate hydrate on the coating substrate but it is important to note that magnesium phosphate hydrate $\left[\mathrm{Mg}_{3}\left(\mathrm{PO}_{4}\right)_{2} 22 \mathrm{H}_{2} \mathrm{O}\right]$ was only identified in bulk coating of non-salt solution. That implies the unreacted constituents of magnesium hydroxide and magnesium hydrogen phosphate reacted further with presence of moisture and transformed to chalky magnesium phosphate hydrate. That type of hydrate was not identified in salt solution because of the high solubility of magnesium in chloride solution.

The intermediate hydrate layer identified as iron hydrogen phosphate hydrate (Balasubramaniam, 2000) was thought to initially form during coating application involving the phosphoric acid. This layer was thought to provide beneficial corrosion mitigation characteristics (Balasubramaniam, 2000). However, the continued formation of the compound would require iron oxidation that could result in steel corrosion. In some situation, formation of a uniform intermediate hydrate layer may promote barrier protection but aggressive exposure conditions may disrupt this protection. Optical microscopy of samples discussed next provide further examination on the role of the iron phosphate intermediate layers. 


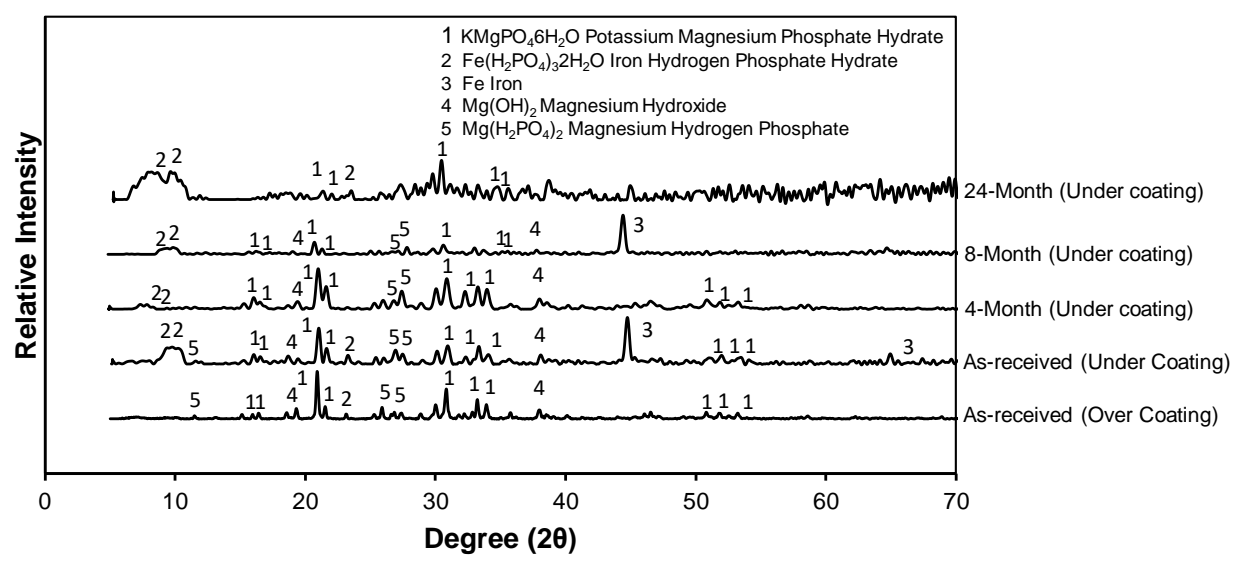

Figure 4.29: X-ray Diffractogram for Inland Samples.

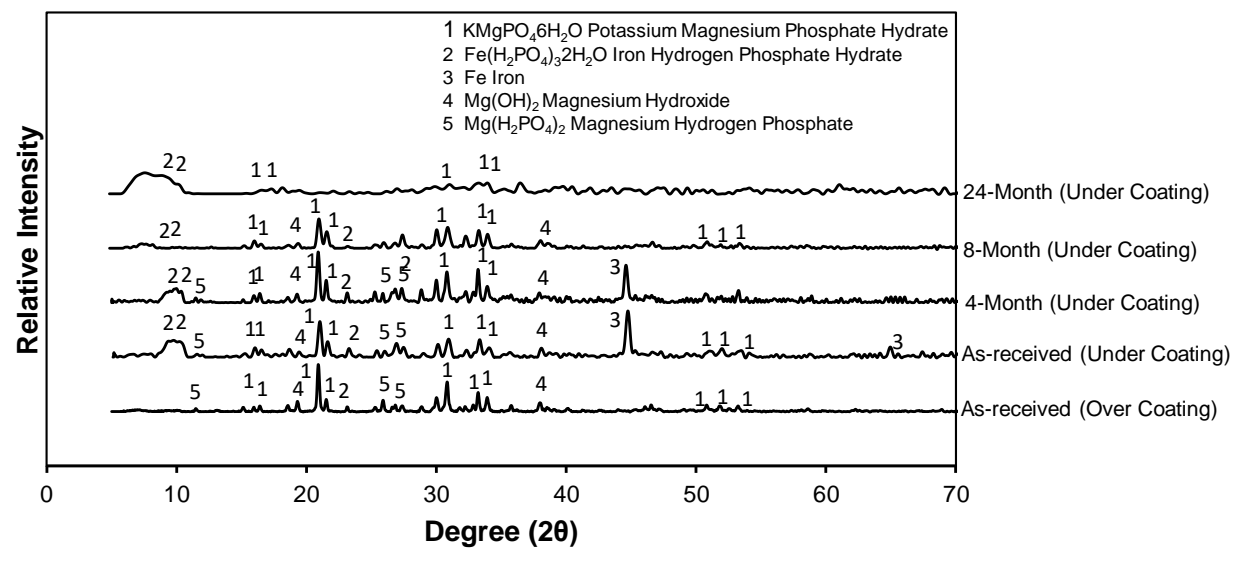

Figure 4.30: X-ray Diffractogram for Beach Samples.

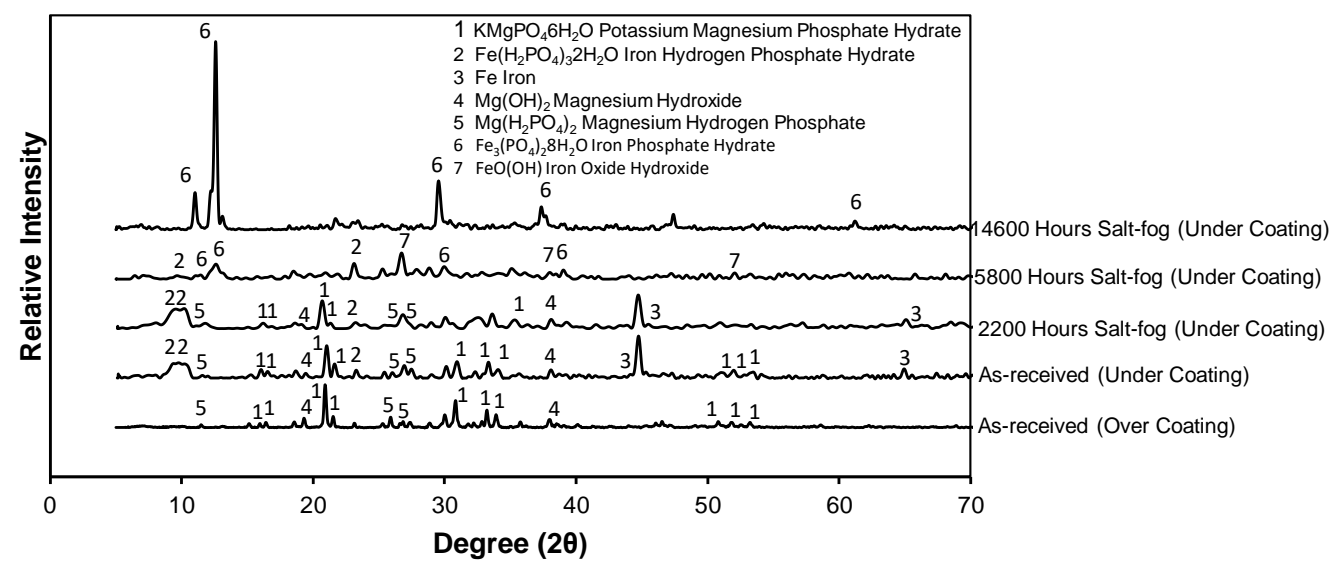

Figure 4.31: X-ray Diffractogram for Salt-fog Samples. 


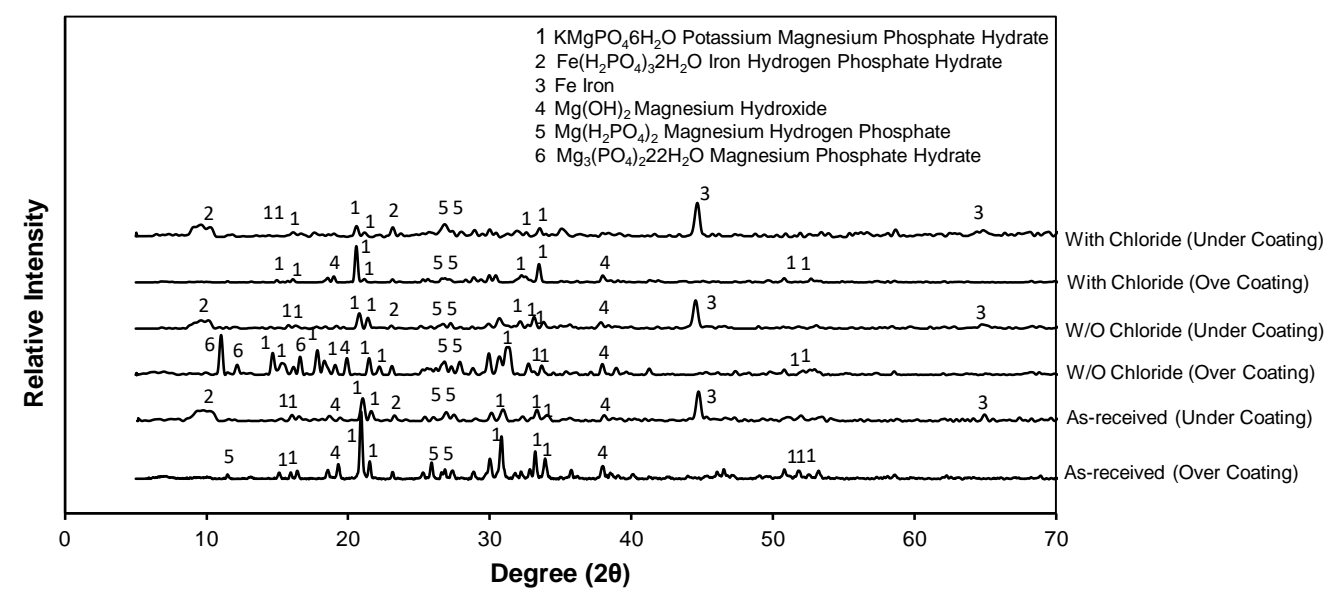

Figure 4.32: X-ray Diffractogram for Alternate Wet and Dry Exposed Samples.

\subsubsection{Optical Microscopy}

Optical microscopic evaluation of the exposed samples was done to evaluate the coating and steel substrate condition. Micrographs of samples exposed outdoor for 24 months and salt fog up to 14600 hours are shown in Figure 4.33 and Figure 4.34. In comparison of cross-section from a sample in the as-received condition, it is evident that large pores are initially present in the bulk coating. The coating degradation that accounts for the observed surface chalking and loss of bulk cohesive strength was not well distinguished in the relatively low magnification from optical microscopy. Due to the wide distribution of pores in the bulk coating, SEM images will be presented in the next section to describe further coating degradation. 

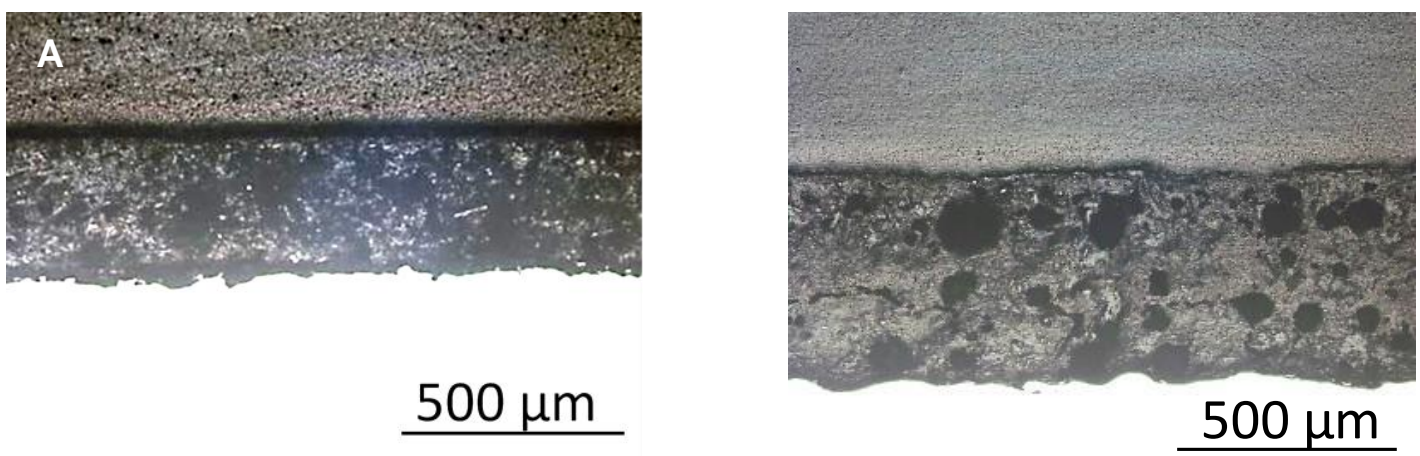

Figure 4.33: Optical Micrograph after Exposure. A) As-received and B) Inland Outdoor Exposure after 24-Months.
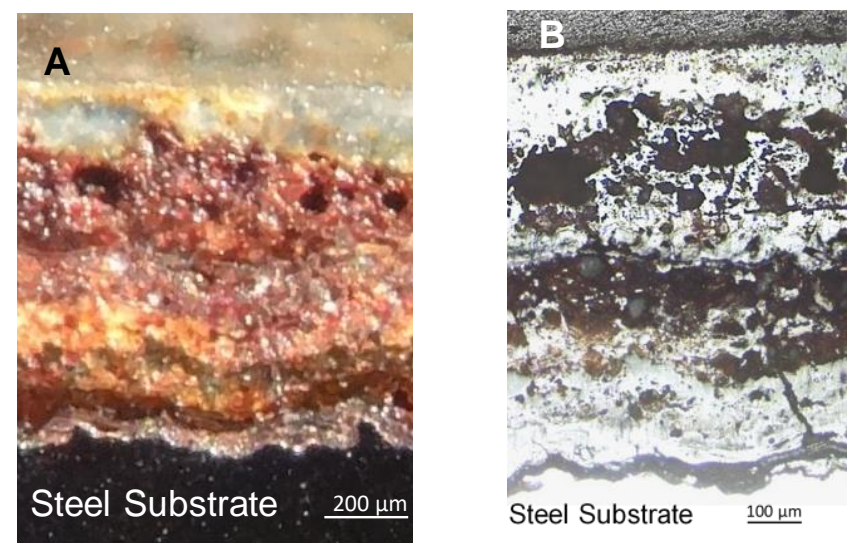

Figure 4.34: Optical Image after 5800 Hours Salt-fog Exposure.

However, general results from mercury intrusion porosimetry discussed in earlier laboratory testing to identify changes in coating physical structure after exposure to moisture are described here for discussion (Figure 4.26). After cyclic exposure to wet and dry conditions, the pore size distribution indicated more numerous larger-sized pore. There remained a network of large and small pores in the coatings after testing that was associated with the large vestigial pores formed during initial spray location and a network of fine pores in the CBPC hydrate. The increase in pores between 1 and $10 \mu \mathrm{m}$ were thought to be related to the coating degradation behavior described earlier. Images 
of the intermediate hydrate product discussed earlier are seen in Figures 4.35 and Figure 4.36. Figure 4.35 shows that there is a general increase in the thickness of the intermediate layer with longer times of exposure. The enhanced porosity could facilitate moisture to produce the intermediate hydrate product by reacting with the steel substrate. In Figure 4.35, cross section of a sample exposed in outdoor conditions for 24 months that formed a coating blister shows a layer that was identified by XRD to be iron hydrogen phosphate hydrate, like the intermediate hydrate layers observed elsewhere (Balasubramaniam, 2000). The extent of steel consumption occurring under the coating at the blister site was not consistent with the general lack of external steel rust accumulation as described earlier for the most of the samples. It was apparent that the layer here formed in relation to apparent significant corrosion of the steel substrate. The steel consumption at the blister site under the hydrate layer is disconcerting as there are apparent conditions where coating corrosion mitigation is compromised. The lack of visible iron rust accumulation in the scribe defects of samples exposed in aggressive saltfog environments also did not account for the level of hydrate product formation as observed in cross-section micrographs such as in Figure 4.37. It is apparent that the role of the intermediate hydrate layer requires further scrutiny to identify conditions where the coated system may be susceptible to steel corrosion. Though it was thought that intermediate iron phosphate hydrate could provide some level of corrosion mitigation, some instances indicated possibility of steel substrate corrosion. 

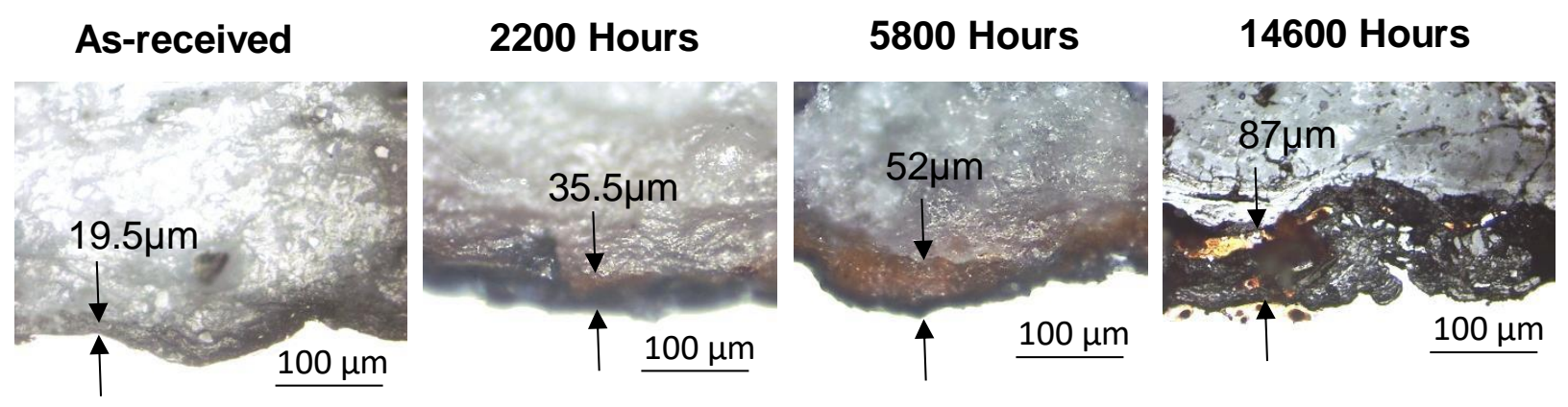

Figure 4.35: Optical Micrograph of CBPC Coating at Salt-fog Exposure.

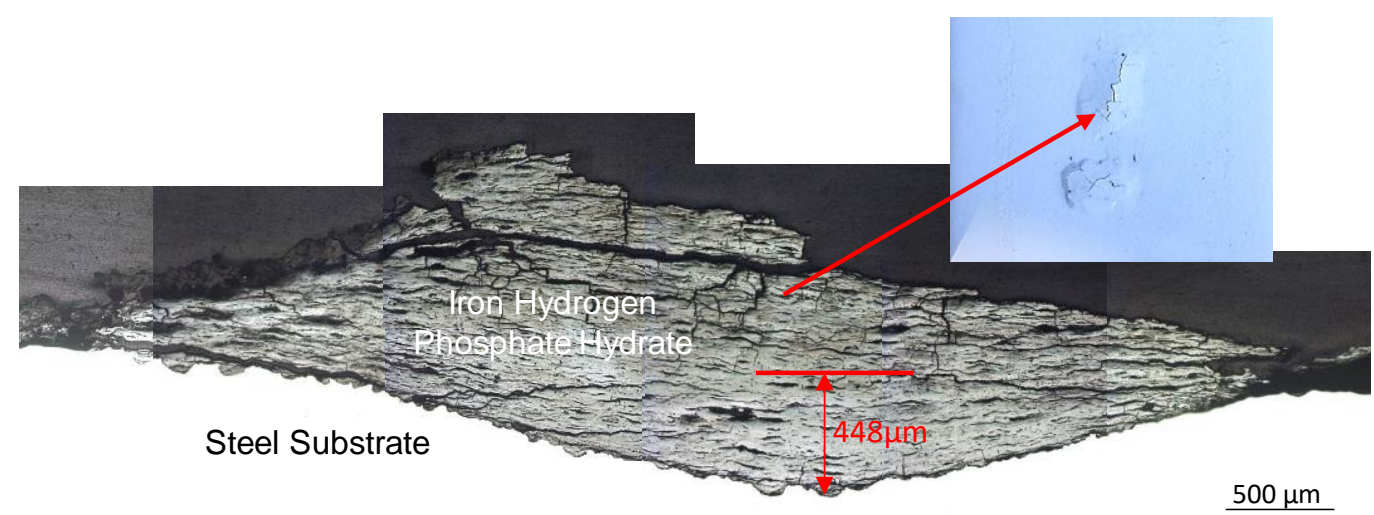

Figure 4.36: Optical Micrograph of 24-Month Outdoor Exposed Samples.

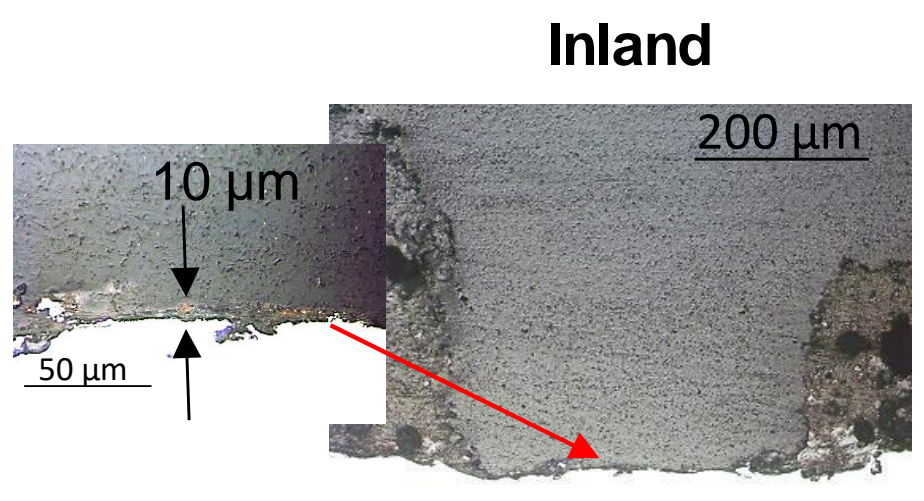

Salt-fog

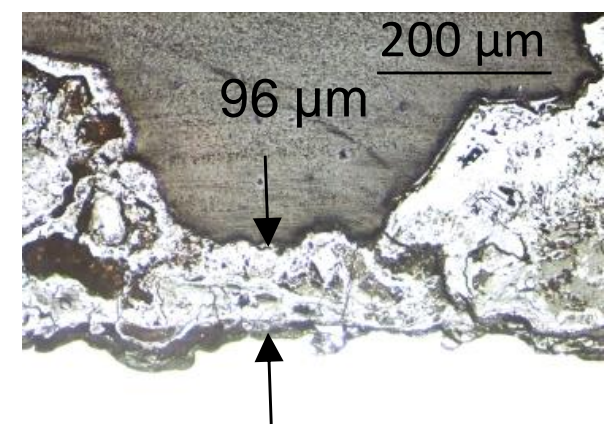

Figure 4.37: Optical Micrograph of CBPC Coating at Scribed Location. 


\subsubsection{Scanning Electron Microscopy (SEM) and Energy Dispersive X-ray}

\section{Spectroscopy}

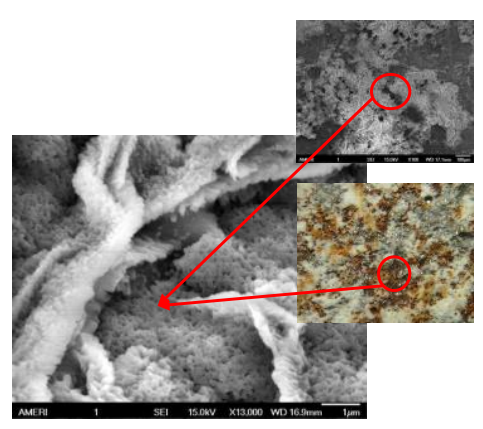

As-received

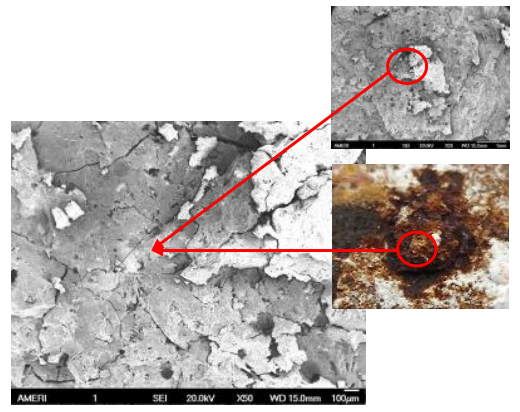

Beach Exposure

24-Month

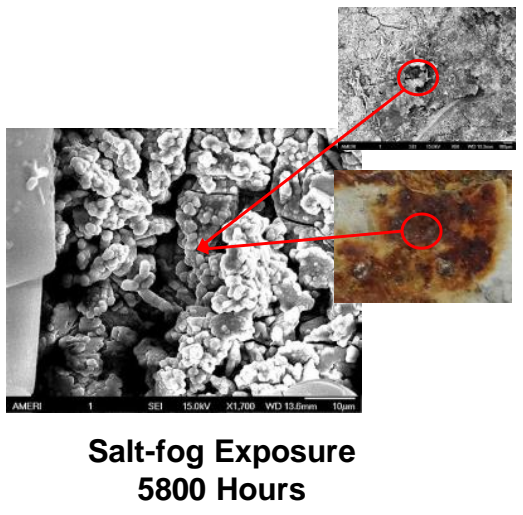

alt-fog Exposure 5800 Hours

Figure 4.38: SEM Picture on the Surface of the Coated Steel.

The SEM micrographs of surface morphology of as-received, beach and salt-fog exposed samples are represented in Figure 4.38. The bulk ceramic of the as-received sample was removed for coating substrate evaluation. Sporadic red spots were visually observed on the remnant coating substrate. One of the red spots of the remnant coating was magnified and the SEM micrograph showed the formation of hydrated product on the steel substrate. The same type of spread out iron hydrogen phosphate hydrate was visually identified over coating surface after 24 months of beach exposure and 5800 hours of salt-fog exposure. The SEM micrograph of those samples also showed significant coating degradation, especially the salt-fog exposed samples showed disintegration of ceramic compounds. Further, area scan was done over the 24-month beach exposed CBPC coating focused the hydrate product to identify its spatial distribution on coating substrate (Figure 4.39). There was a scattered existence of iron observed and this iron is related to formation of iron hydrogen phosphate layer. So, it can 
be opined that though there was an apparent protection of iron phosphate hydrate layer, it was not continuous to provide enhance protection of the steel substrate.

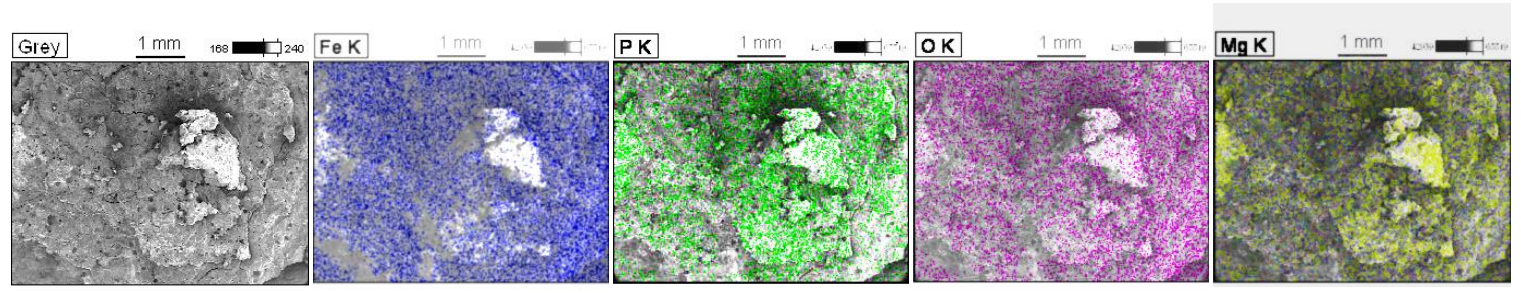

Figure 4.39: EDS Analysis for 24-month Beach Exposed Sample.

SEM imaging also done for cross-section of as-received and 5800 hours salt-fog exposed samples for direct comparison between the bulk properties (Figure 4.40). Larger pores are present in as-received condition as discussed earlies in optical microscopic evaluation section and due to the wide distribution of pores in the bulk coating, SEM imaging of exposed salt-fog samples also could not readily provide comparisons to distinguish coating degradation. EDS analysis (Figure 4.41) also made on those cross sections for further clarification of that hydrate layer which was identified in XRD and surface EDS analysis. Iron was identified $\sim 30 \mu \mathrm{m}$ from the base steel for as received samples along with the other coating constituents. The identified $\sim 20 \mu \mathrm{m}$ carbon layer adjacent to steel substrate was due to penetration of mounting epoxy into the degraded coating. The identified iron in the ceramic matrix was attributed for the formation of iron phosphate hydrate. More wide spread dispersion of iron was observed for 5800 hours salt-fog exposed samples due to the enhanced formation of iron phosphate hydrate for the presence of moisture through the degraded coating. 


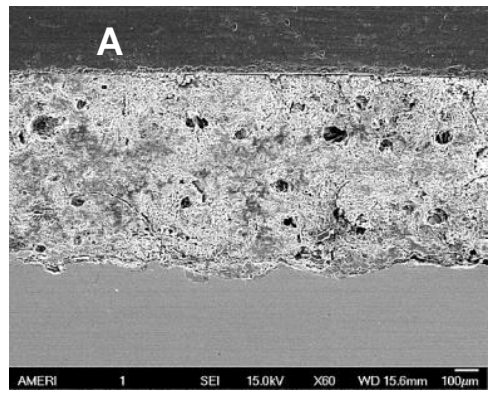

As-received

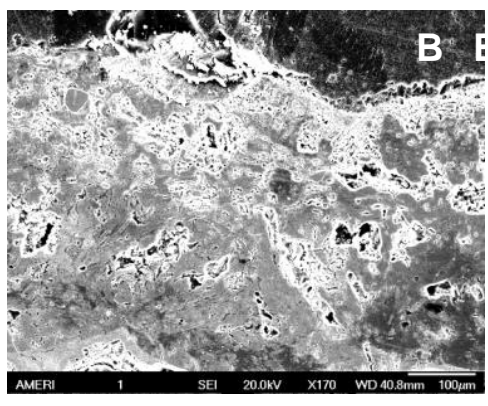

Salt-fog Exposure 5800 Hours

Figure 4.40: SEM Cross Section of CBPC Coating.

A) As-received. B) 5800 Hours Salt-fog Exposed.
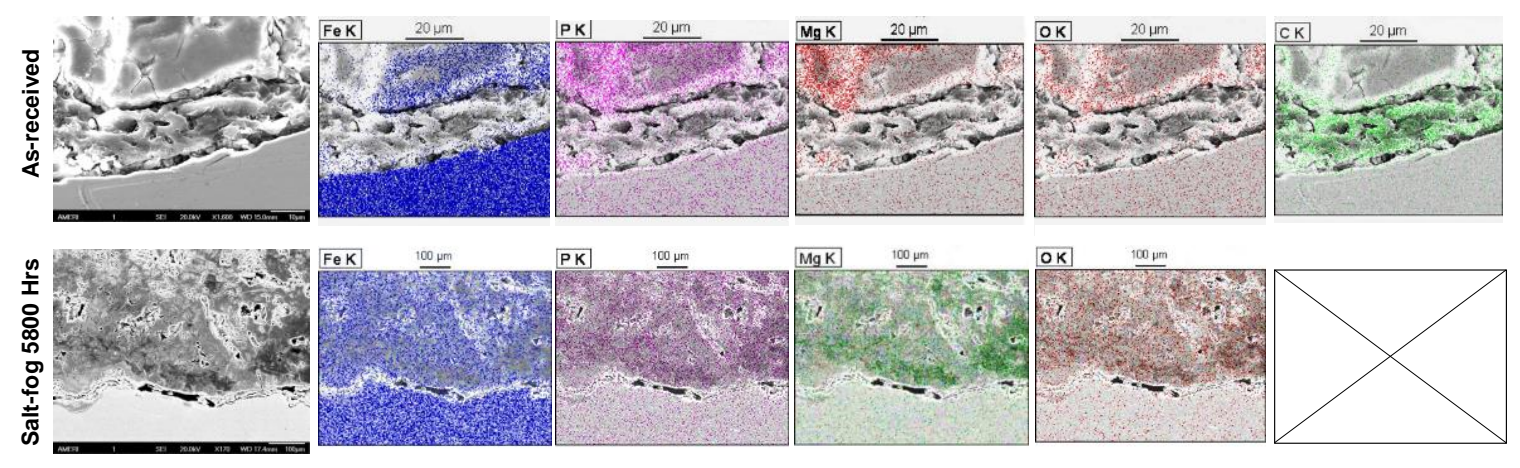

Figure 4.41: EDS Analysis on Cross Section of the Exposed Samples. 


\section{CHAPTER 5}

\section{DEGRADATION ASSESSMENT OF CBPC COATING BY ELECTROCHEMICAL IMPEDANCE SPECTROSCOPY}

Coatings can be degraded due to various environmental loads such as moisture, temperature, UV, etc. The environment supports chemical and electro-chemical reactions that can lead to degradation of the coating. Electrochemical impedance spectroscopy (EIS) has been used to characterize coating degradation for different materials including degradation of polymer coatings (Mertens et al., 1997). Dissemination of information on the applicability of EIS for ceramic coatings was not readily discovered by the author. Therefore, development of electrochemical techniques for assessment of ceramic coatings was necessary as part of the overall work on application of CBPC for structural steel applications. Resolved electrochemical parameters such as coating capacitance and pore resistance from electrochemical impedance spectroscopy (EIS) are related to moisture activity and defect geometry of the degraded coating. It was envisioned to assess the applicability of electrochemical techniques including EIS to identify and predict degradation modality and progression for CBPC coating in aggressive humid environment.

\subsection{Coating Capacitance Measurement to Characterize Coating Degradation}

Capacitance of the coating is a water sensitive measurement. Coating capacitance is expected to change during exposure due to moisture penetration through the coating. Thus, the degradation of the coating can be inferred by the change of coating capacitance. The capacitance is expressed by

$$
\mathrm{C}_{\mathrm{c}}=\frac{\varepsilon_{0} \varepsilon_{\mathrm{r}} \mathrm{A}}{\mathrm{d}}
$$


where:

$\mathrm{C}_{\mathrm{c}} \quad$ coating capacitance

$\varepsilon_{0} \quad$ permittivity of vacuum or the permittivity of free space $\left(8.854 \times 10^{-12}\right.$ F.m $\left.^{-1}\right)$

(Weast, 1984)

$\varepsilon_{\mathrm{r}} \quad$ relative permittivity or coating dielectric constant,

A coating surface area

d coating thickness.

The dielectric constant of water is $\sim 80$ at $20^{\circ} \mathrm{C}$ and is less than 10 for typical coating (polymer coating). The coating capacitance increases due to the water absorption (assuming the other constant coating geometric dimensions) and the volume fraction of water absorbed can also be estimated by Equation 5.2 (Brasher and Kingsbury, 1954).

$$
\mathrm{X}_{\mathrm{v}}=\frac{\log \left(\frac{\mathrm{C}}{\mathrm{C}_{\mathrm{o}}}\right)}{\log \left(\boldsymbol{\varepsilon}_{\mathrm{H}_{2} \mathrm{O}}\right)}
$$

where:

$\mathrm{X}_{\mathrm{v}} \quad$ volume fraction of absorbed water

$\mathrm{C}_{0} \quad$ capacitance before water absorption

C capacitance at specific time,

$\varepsilon_{\mathrm{H}_{2} \mathrm{O}} \quad$ dielectric constant of water

Coating capacitance is calculated by analyzing the impedance response with an equivalent circuit of the related systems. Due to testing artifacts, including coating heterogeneities and non-uniform current distribution the constant phase element (CPE) is commonly used to fit the impedance spectra. The impedance of CPE is 


$$
Z(C P E)=Y_{0}^{-1}(j \omega)^{-n}
$$

where:

$$
\begin{array}{ll}
\mathrm{Z}(\mathrm{CPE}) & \text { impedance of } \mathrm{CPE} \\
\mathrm{Y}_{0} & \text { pre-exponential term } \\
\mathrm{n} & \text { real number }(0<\mathrm{n}<1)
\end{array}
$$

The CPE element is useful in analog circuit fitting for systems that exhibit non-ideal capacitive behavior. However, the resolved parameter does not directly characterize capacitance. In ideal condition, when $n=1$ the capacitance can be directly calculated from the impedance of CPE. That implies that the CPE element behaves as ideal capacitor at $\mathrm{n}=1$. Most of the electrochemical system shows deviation of $\mathrm{n}$ value from unity. So, to calculate the capacitance of a CPE system it needs to transfer the pre-exponential term, $\mathrm{Y}_{0}$ to capacitance, $\mathrm{C}$ by a logical mathematical expression.

\subsubsection{Conversion Technique ( $Y_{0}$ to C) by Van Westing}

The conversion of Yo to C was first described by E. Van Westing in 1992. He proposed that at a given frequency $\omega$, the imaginary part of the impedance of the CPE $\left(\mathrm{Z}_{\mathrm{CPE}}\right)$ and the impedance of the fitted capacitance $(\mathrm{Zc})$ is equal.

$$
\begin{gathered}
\operatorname{Im}\left(Z_{C P E}\right)=Z c \\
\operatorname{Im}\left(\frac{1}{Y_{0}(j \omega)^{n}}\right)=\frac{1}{j \omega C}
\end{gathered}
$$

where:

$$
\begin{array}{ll}
\text { C } & \text { capacitance } \\
\text { Yo } & \text { pre-exponential term } \\
\omega & \text { radial frequency }
\end{array}
$$


n real number $(0<\mathrm{n}<1)$

Solving for $(\mathrm{jw})^{-\mathrm{n}}$, the formula can be expressed as

$$
(j \omega)^{-n}=\omega^{-n}\left(\cos \left(-\frac{n \pi}{2}\right)+j \sin \left(-\frac{n \pi}{2}\right)\right)
$$

Then the final relation between $\mathrm{n}$ and $\mathrm{C}$ was determined as

$$
\mathrm{C}=\frac{\mathrm{Yo}(\omega)^{\mathrm{n}-1}}{\sin \left(\frac{n \pi}{2}\right)}
$$

\subsubsection{Conversion Technique ( $\mathrm{Y}_{\mathrm{o}}$ to $\mathrm{C}$ ) by Hsu and Mansfeld}

Hsu and Mansfeld proposed a conversion equation in 2001. The work by Hsu and Mansfeld is based on the fact that at the frequency corresponding to the maximum imaginary impedance, there is no dependence of the CPE $n$ parameter for the real part of the total impedance. Therefore, the impedance of an ideal capacitance $\mathrm{Zc}=(2 \pi \mathrm{fC})^{-1}$ equals the impedance of the CPE at that frequency. This can be represented by

$$
\begin{gathered}
|Z|^{2}=\frac{1}{Y_{o}^{2}\left(\omega_{m}^{\prime \prime}\right)^{2}}=\frac{1}{\left(\omega_{m}^{\prime \prime}\right)^{2} C^{2}} \\
C=Y o\left(\omega_{m}^{\prime \prime}\right)^{n-1}
\end{gathered}
$$

where:

$$
\begin{aligned}
& \mathrm{C} \quad \text { capacitance } \\
& \mathrm{Y}_{\mathrm{o}} \quad \text { pre-exponential term } \\
& \omega^{\prime \prime} \mathrm{m} \quad \text { radial frequency at maximum imaginary impedance } \\
& \mathrm{n} \quad \text { real number }(0<\mathrm{n}<1)
\end{aligned}
$$

Hsu and Mansfeld applied the proposed equation for a simple Randle circuit and compared the results with Van Westing proposed equation. Comparatively, accurate results were observed by the proposed equation of Hsu and Mansfeld. For better 
understanding, the model was elaborated in this dissertation for a wide range of $\mathrm{n}$ value in the following section.

\subsubsection{Comparison between Van Westing and (Hsu and Mansfeld) Approach for}

\section{Single CPE}

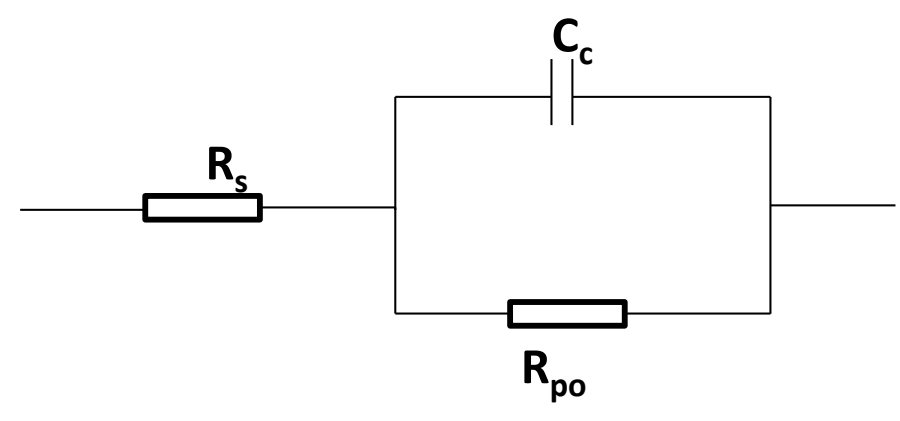

\section{Figure 5.1: Equivalent Circuit for Single CPE.}

Hsu and Mansfeld proposed a model for one CPE element where a parallel combination of $R_{p o}$ and $C_{c}$ is in series with $R_{s}$. The model was described for $n$ values from 1 to 0.8 . The model was further considered for the $n$ values from 1 to 0.5 in the work here. The assigned values for the simulation parameters were $R_{s}=1 \Omega, R_{p o}=1000 \Omega$ and $\mathrm{C}_{\mathrm{c}}=1 \mathrm{X} 10^{-5} \mathrm{~F}$ for $\mathrm{n}=1$. To fit the model with the pre-defined resistance values with different $\mathrm{n}$ value other than 1 , the pre-exponential term $\mathrm{Y}_{\mathrm{oc}}$ required calibration. The simulated and fitted values are represented in Table 5.1 with their corresponding $\mathrm{n}$ values. The Bode and Nyquist plot are represented in Figure 5.2a and 5.2b for the fitted capacitance with constant resistance. The frequency dependence of the imaginary and real part of impedenace is also represented in Figure 5.3a and Figure 5.3b, respectively. The imaginary part of the impedance has the maximum value at frequency $\mathrm{f}=17.28 \mathrm{~Hz}$, and at that frequency, the real part of the impedance was $500 \Omega$ regardless of the change 
of $\mathrm{n}$ value. It was evident that there is no frequency dependence on the real part of the impedance at that frequency. Hence the conversion equation is based on the fact that at the frequency of maximum imaginary impedance the real part of the impedance is independent of $\mathrm{n}$ value. At that frequency, the real part of impedance is equal to maximum imaginary part of impedance for $n=1$. The conversion of Yo to $\mathrm{C}$ was done by following equation 5.7. For comparison, the conversion was also done by following the Van Westing equation.

The results are presented in Table 5.1. The coating capacitance was $1 \times 10^{-5} \mathrm{~F}$. The resolved coating capacitance from curve fitting was $0.938 \times 10^{-5} \mathrm{~F}, 0.979 \times 10^{-5} \mathrm{~F}, 0.931 \times 10^{-}$ ${ }^{5} \mathrm{~F}, 0.920 \times 10^{-5} \mathrm{~F}, 0.959 \times 10^{-5} \mathrm{~F}$ respectively for $\mathrm{n}$ value $0.9,0.8,0.7,0.6$ and 0.5 by Hsu and Mansfeld approach and, by Van Westing approach was $0.950 \times 10^{-5} \mathrm{~F}, 1.030 \times 10^{-5} \mathrm{~F}$, $1.045 \times 10^{-5} \mathrm{~F}, 1.137 \times 10^{-5} \mathrm{~F}, 1.357 \times 10^{-5} \mathrm{~F}$. Comparable results were observed by both conversion technique at higher $\mathrm{n}$ values but the Hsu and Mansfeld technique gave more accurate results for lower $\mathrm{n}$ values. As shown in chapter 4, EIS response for CBPC in aqueous solution typically showed an apparent suppressed semi-circle at high frequencies typically between $(1 \mathrm{~Hz}$ to $1000 \mathrm{~Hz})$. The resolved CPE n parameter was 0.5 to 0.6 . In order to determine suitability of applying of those techniques, Hsu and Mansfeld approach was reanalyzed for systems with lower CPE $\mathrm{n}$ values. It was envisioned to apply the proposed equation by Hsu and Mansfeld to elucidate degradation of CBPC coating system. In the experimental work for CBPC, the resolved $\mathrm{n}$ value was typically between 0.5 to 0.6 . 

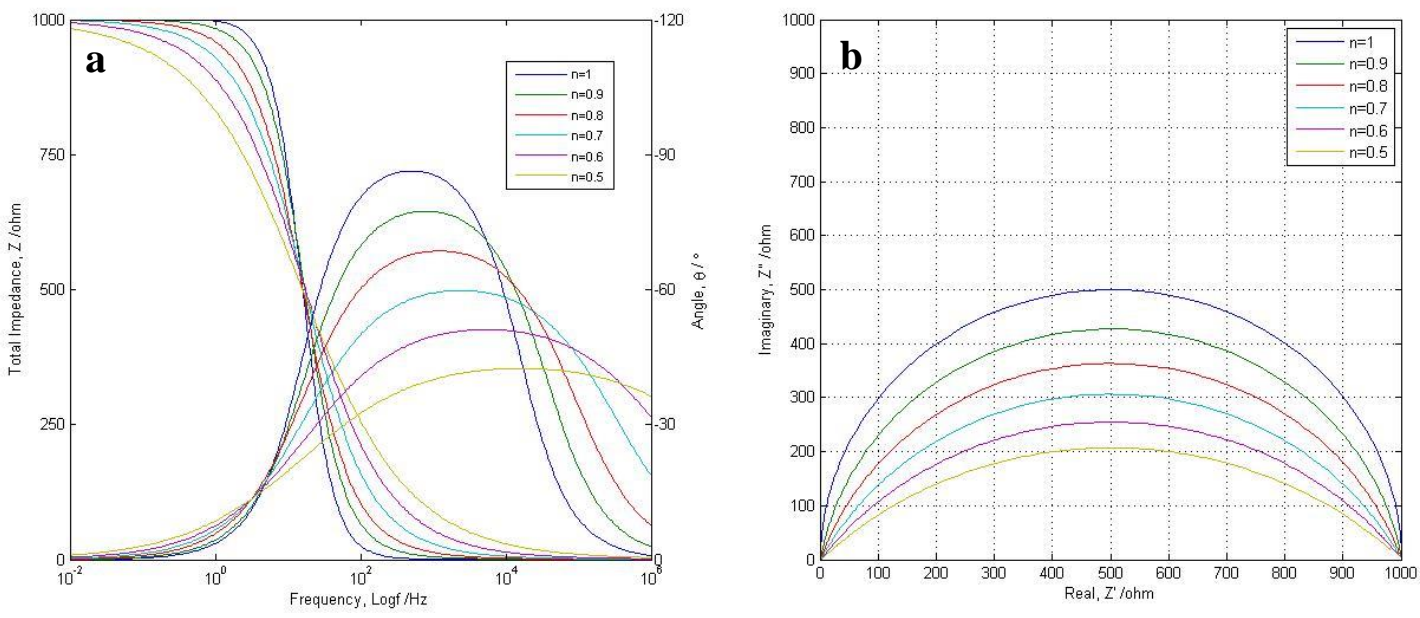

Figure 5.2: Single CPE Impedance.

a) Bode Plot b) Nyquist Plot.
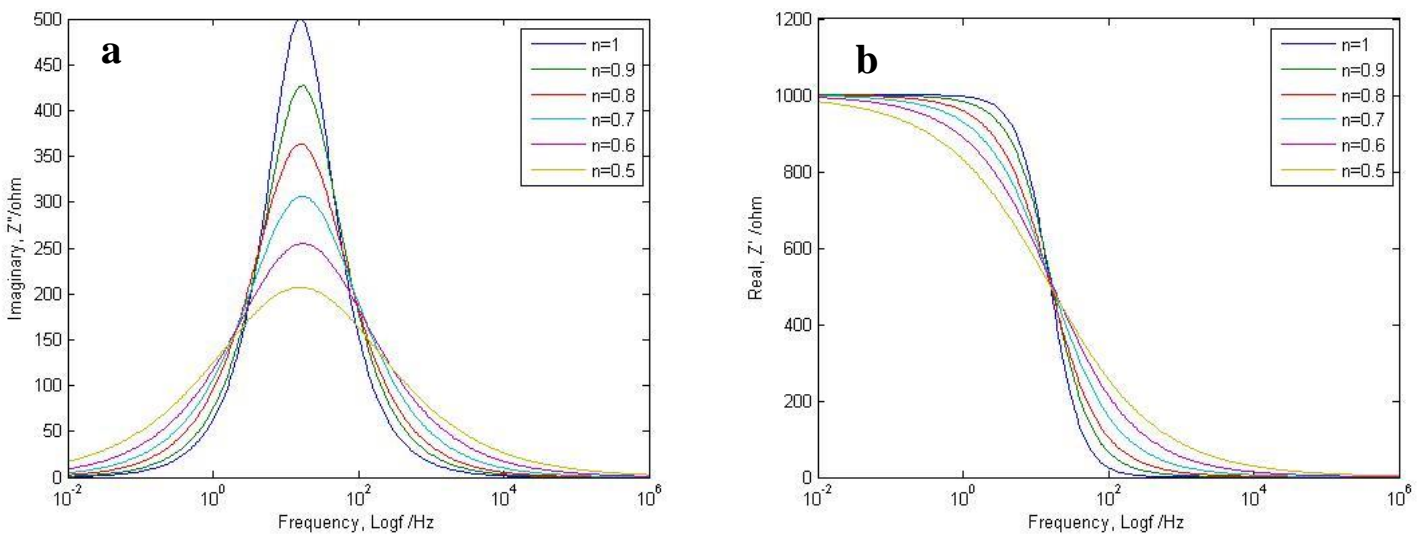

Figure 5.3: Frequency Dependence of Single CPE Impedance.

a) Imaginary, Z" b) Real, Z'. 
Table 5.1: Calculation of C from Yo for Single CPE

\begin{tabular}{|c|c|c|c|c|}
\hline \multirow[b]{2}{*}{$\mathrm{n}$} & \multirow[b]{2}{*}{ Parameter Condition } & Capacitance & $\begin{array}{c}\text { Hsu and } \\
\text { Mansfield }\end{array}$ & Van Westing \\
\hline & & $\mathrm{Y}_{0}\left(\mathrm{~s}^{\mathrm{n}} / \Omega\right)$ & $\begin{array}{c}\mathrm{C}=\mathrm{Y}_{0}\left(\omega^{\prime \prime}\right)^{\mathrm{n}-1} \\
(\mathrm{~F})\end{array}$ & $C=\frac{\operatorname{Yo}(\omega)^{n-1}}{\operatorname{Sin}\left(\frac{n \pi}{2}\right)}$ \\
\hline \multirow{2}{*}{1} & Simulation Parameter & $1 \times 10^{-5}$ & - & - \\
\hline & Fit Parameter & $1 \times 10^{-5}$ & $1 \times 10^{-5}$ & $1 \times 10^{-5}$ \\
\hline \multirow{2}{*}{0.9} & Simulation Parameter & $1 \times 10^{-5}$ & - & - \\
\hline & Fit Parameter & $1.5 \times 10^{-5}$ & $0.938 \times 10^{-5}$ & $0.950 \times 10^{-5}$ \\
\hline \multirow{2}{*}{0.8} & Simulation Parameter & $1 \times 10^{-5}$ & - & - \\
\hline & Fit Parameter & $2.5 \times 10^{-5}$ & $0.979 \times 10^{-5}$ & $1.030 \times 10^{-5}$ \\
\hline \multirow{2}{*}{0.7} & Simulation Parameter & $1 \times 10^{-5}$ & - & - \\
\hline & Fit Parameter & $3.8 \times 10^{-5}$ & $0.931 \times 10^{-5}$ & $1.045 \times 10-5$ \\
\hline \multirow{2}{*}{0.6} & Simulation Parameter & $1 \times 10^{-5}$ & - & - \\
\hline & Fit Parameter & $6 \times 10^{-5}$ & $0.920 \times 10^{-5}$ & $1.137 \times 10^{-5}$ \\
\hline \multirow{2}{*}{0.5} & Simulation Parameter & $1 \times 10^{-5}$ & - & - \\
\hline & Fit Parameter & $1 \times 10^{-4}$ & $0.959 \times 10^{-5}$ & $1.357 \times 10^{-5}$ \\
\hline
\end{tabular}

\subsubsection{Conversion Approach ( $\mathrm{Y}_{0}$ to C) for Double CPE}

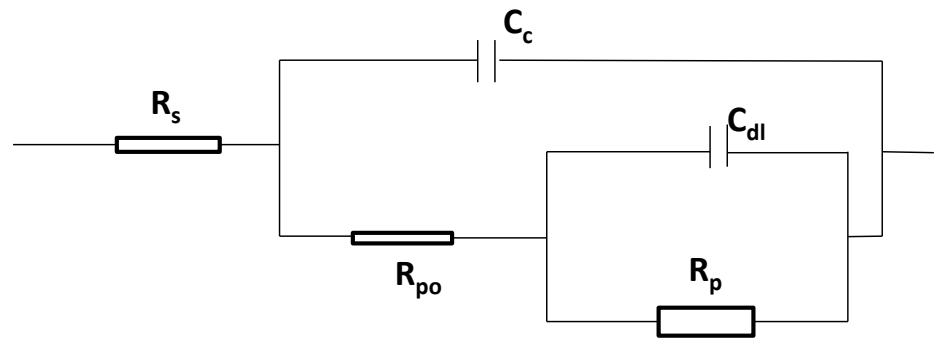

Figure 5.4: Equivalent Circuit for Double CPE. 
The work by Hsu and Mansfeld on basic electrical parameters can be idealized by theRandle circuit. However, more complex systems, such as with coatings and other system complications are part of many engineering systems. The impedance response of those systems would directly introduce difficulties in interpretation of the impedance spectrum. It was envisioned that similar approaches to determine coating capacitance for degraded CBPC coating systems to evaluate the degradation process. When an intact coating is in contact with the electrolyte, the electrolyte enters the pore of that coating. The pore resistance, Rpo changes with the passage of electrolyte intrusion. The entire system is represented as an equivalent circuit analog as shown in the Figure 5.4 where Rs is the solution resistance and $\mathrm{Cc}$ is coating capacitance. A new phase is included with this equivalent circuit where oxidation reaction takes place at the metal electrolyte interface as shown in the Figure 5.2. This circuit adds a double layer capacitance, $\mathrm{C}_{\mathrm{dl}}$ proportional to the active metallic area in contact with the electrolyte and electric element, $R_{P}$ is the polarization resistance. The capacitance does not act as a pure capacitor due to surface roughness and other physical properties. Thus a CPE element was introduced instead of C where Yo, pre-exponential term and n, real number. The model is developed for the frequency range from $0.001 \mathrm{~Hz}$ to $1 \times 10^{8} \mathrm{~Hz}, \mathrm{Rs}=1 \Omega, \mathrm{Rpo}=100 \Omega$ and $\mathrm{Rp}=1000 \Omega$. The model was developed for $\mathrm{n}$ value 1 to 0.5 . The Bode and Nyquist plot are represented in Figure 5.5a and 5.5b. The two CPE responses were clearly identified in this frequency range. The high frequency region $(>100 \mathrm{~Hz})$ represents the coating property and low frequency $(<100 \mathrm{hz})$ represents the coating-substrate interface property. The impedance spectrum shifted to lower impedance value with decreasing $\mathrm{n}$ value where the resistive part of the model was assumed constant. Thus the pre-exponential term is calibrated to fit 
the spectrum as presented in Table 5.2. The frequency dependence of imaginary and real part is presented in Figure 5.6a and 5.6b. The frequency dependence of two CPE systems satisfied the basic principle of Hsu and Mansfeld single CPE approach. The intention of the approach was to characterize the pore degradation of the coating. Thus, the discussion here will be concentrated for high frequency CPE response only, though the model was also fitted for low frequency CPE response.

The imaginary part of the impedance has the maximum value at frequency $f=$ $1.563 \times 10^{6} \mathrm{~Hz}$ and at that frequency the real part of the impedance was $55 \Omega$ regardless of the change of $n$ value. So there is no frequency dependence on the real part of the impedance at that frequency. The conversion equation of Hsu and Mansfeld can be extended for systems that can be characterized by two nested parallel combinations of $\mathrm{CPE}$ and resistance elements based on the fact that at the frequency of maximum imaginary impedance, the real part of the impedance is independent of $n$ value. At that frequency the real impedance is equal to imaginary impedance for $n=1$. Hence the conversion of Yo to $\mathrm{C}$ is

$$
\mathrm{C}=\mathrm{Yo}\left(\omega^{\prime \prime}\right)^{\mathrm{n}-1}
$$

Resolved coating capacitance values from simulations of coated steel impedance were calculated by using this conversion equation and are presented in Table 5.2. The real coating capacitance is $1 \times 10^{-9} \mathrm{~F}$ and the calculated coating capacitance is $0.9994 \times 10^{-9} \mathrm{~F}$, $0.9988 \times 10^{-9} \mathrm{~F}, 0.9983 \times 10^{-9} \mathrm{~F}, 0.9578 \times 10^{-9} \mathrm{~F}, 0.989 \times 10^{-9} \mathrm{~F}$ respectively for $\mathrm{n}$ value $1,0.9$, 0.8, 0.7, 0.6 and 0.5 . The findings would suggest that similar conversion techniques may be adapted for coating systems. 

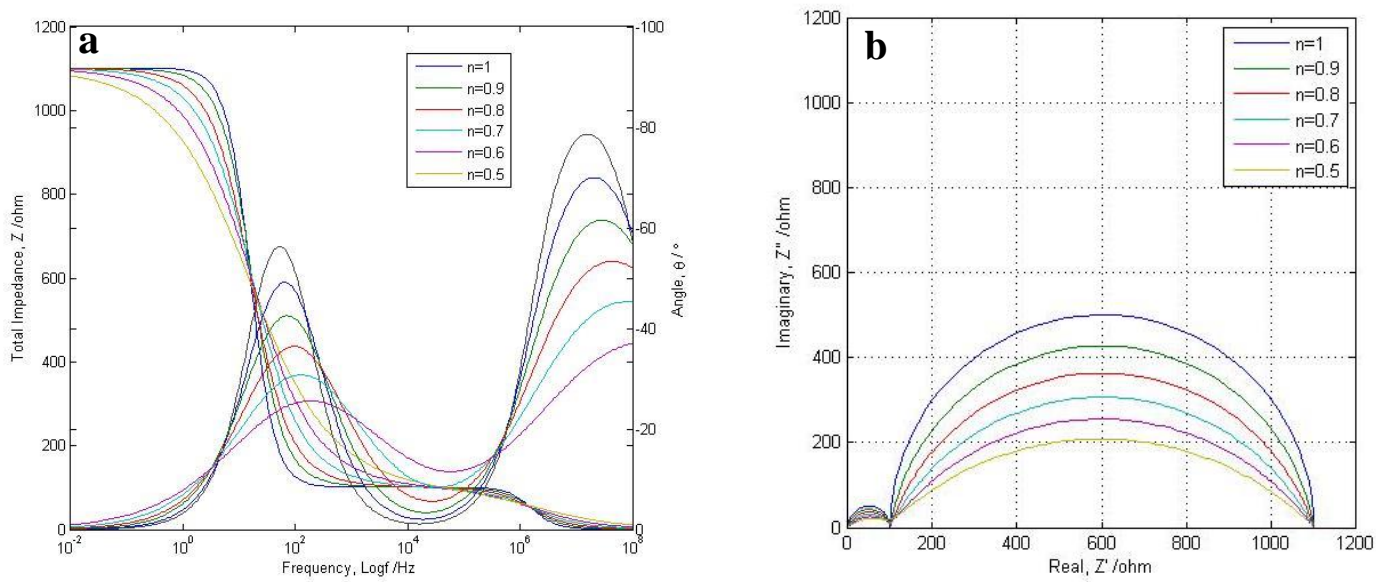

Figure 5.5: Double CPE Impedance.

a) Bode Plot b) Nyquist Plot.
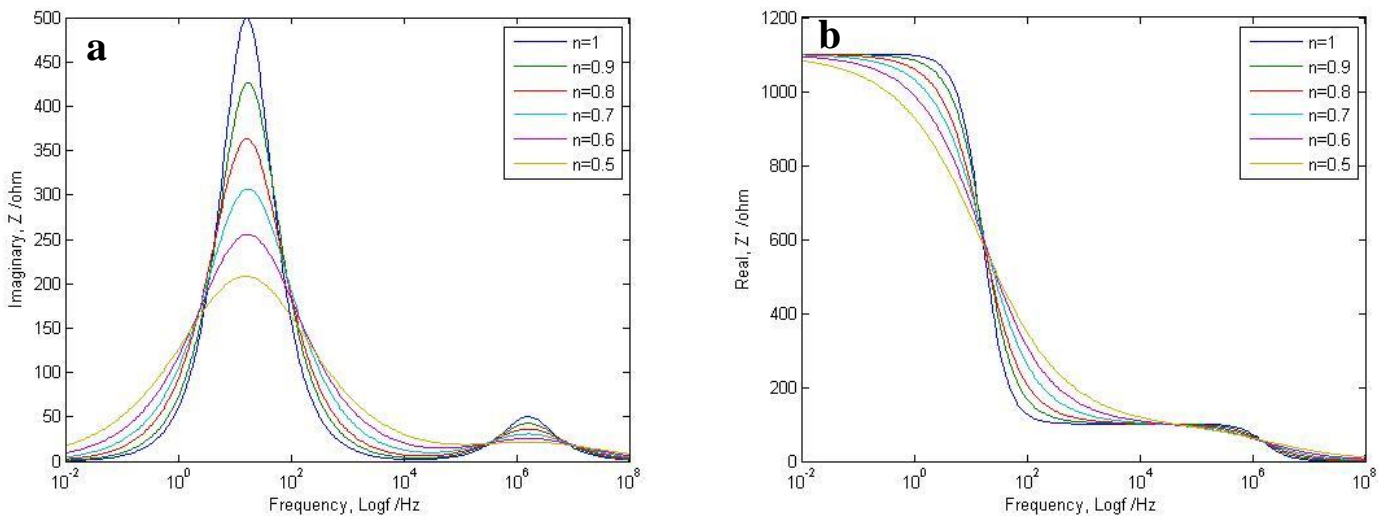

Figure 5.6: Frequency Dependence of Double CPE Impedance.

a) Imaginary, $Z^{\prime \prime}$ b) Real, $Z^{\prime}$. 
Table 5.2: Calculation of $\mathrm{C}$ from Yo for Double CPE

\begin{tabular}{|c|c|c|c|c|}
\hline \multirow{2}{*}{$\begin{array}{l}\mathrm{n}_{\mathrm{m}} \\
\& \\
\mathrm{n}_{\mathrm{c}}\end{array}$} & \multirow[t]{2}{*}{ Parameter Condition } & $\begin{array}{c}\text { Coating } \\
\text { Capacitance }\end{array}$ & $\begin{array}{c}\text { Interface } \\
\text { Capacitance }\end{array}$ & $\begin{array}{c}\text { Calculated } \\
\text { Coating } \\
\text { Capacitance } \\
\end{array}$ \\
\hline & & $\mathrm{Y}_{0 \mathrm{C}}\left(\mathrm{s}^{\mathrm{n}} / \Omega\right)$ & $\mathrm{Y}_{0}\left(\mathrm{~s}^{\mathrm{n}} / \Omega\right)$ & $\mathrm{C}=\mathrm{Y}_{0}\left(\omega^{\prime \prime}\right)^{\mathrm{n}-1}(\mathrm{~F})$ \\
\hline \multirow[b]{2}{*}{1} & Simulation Parameter & $1 \times 10^{-9}$ & $1 X 10^{-5}$ & - \\
\hline & Fit Parameter & $1 \times 10^{-9}$ & $1 \times 10^{-5}$ & $1 \times 10^{-9}$ \\
\hline \multirow[b]{2}{*}{0.9} & Simulation Parameter & $1 X 10^{-9}$ & $1 \times 10^{-5}$ & - \\
\hline & Fit Parameter & $5 \times 10^{-9}$ & $1.5 \times 10^{-5}$ & $0.9994 \times 10^{-9}$ \\
\hline \multirow{2}{*}{0.8} & Simulation Parameter & $1 X 10^{-9}$ & $1 X 10^{-5}$ & - \\
\hline & Fit Parameter & $2.5 \times 10^{-8}$ & $2.5 \times 10^{-5}$ & $0.9988 \times 10^{-9}$ \\
\hline \multirow[b]{2}{*}{0.7} & Simulation Parameter & $1 \times 10^{-9}$ & $1 \times 10^{-5}$ & - \\
\hline & Fit Parameter & $1.25 \times 10^{-7}$ & $3.8 \times 10^{-5}$ & $0.9983 \times 10^{-9}$ \\
\hline \multirow[b]{2}{*}{0.6} & Simulation Parameter & $1 \times 10^{-9}$ & $1 \times 10^{-5}$ & - \\
\hline & Fit Parameter & $6 \times 10^{-7}$ & $6.1 \times 10^{-5}$ & $0.9578 \times 10^{-9}$ \\
\hline \multirow[b]{2}{*}{0.5} & Simulation Parameter & $1 X 10^{-9}$ & $1 \times 10^{-5}$ & - \\
\hline & Fit Parameter & $3.1 \times 10^{-6}$ & $1 \times 10^{-4}$ & $0.989 \times 10^{-9}$ \\
\hline
\end{tabular}

\subsubsection{Methodology to Measure the Capacitance of CBPC Coating}

CBPC coated steel coupons were exposed to 2-day alternate wet and dry exposure for up to 30 days (cumulative 15 days in wet condition and 15 days in dry condition). The samples were submerged in distilled water (with and without $3.5 \%$ sodium chloride solution) to simulate the presence of accumulated runoff and pooled drainage water during the wet cycle and stored in a controlled humidity chamber $\left(\sim 75^{\circ} \mathrm{F}\right.$ temperature and $<20 \%$ relative humidity) during the dry cycle. Activated titanium was used as 
temporary reference and counter electrodes. The activated titanium reference electrode was calibrated with a saturated calomel reference electrode (SCE). EIS testing was made at the $\mathrm{OCP}$ condition with $10 \mathrm{mV} \mathrm{AC}$ perturbation voltage at frequencies from $1 \mathrm{MHz}$ to $1 \mathrm{~Hz}$ to ideally capture the responses associated with a bulk coating. Then the response of the EIS spectrum was interpreted by equivalent circuit fitting related to physical system. Non-ideal capacitive behavior and other factors due to heterogeneities including nonuniform current distribution in the coating and metal-electrolyte interface were in part represented by constant phase elements. Then the pre-exponential term of CPE was converted to coating capacitance by the developed model for double CPE system. The capacitive value of the CBPC coating was expected to give indication about the water absorption behavior related to degradation process.

\subsubsection{Application of Conversion Technique (Yo to C) for CBPC System}

The developed conversion technique was introduced to CBPC coating system. The experimental impedance spectrum was tested for a frequency range from $1 \mathrm{~Hz}$ to $1 \times 10^{6} \mathrm{~Hz}$. The impedance response was analyzed by commercially available software to obtain a best fit of the impedance parameters assuming that the electrical circuit analog shown in Figure X can be representative of the CBPC coating. The evaluated parameters included solution resistance, $\mathrm{Rs}=1.66 \Omega$, pore resistance, $\mathrm{Rpo}=0.588 \Omega$, coating preexponential, Yoc $=9.11 \times 10-2 \mathrm{~s} / \Omega$, Yom $=9.11 \times 10-2 \mathrm{~s}^{\mathrm{n}} / \Omega, \mathrm{n}_{\mathrm{c}}=0.565, \mathrm{n}_{\mathrm{m}}=0.565$.

Then, a numerical simulation of the impedance behavior, keeping all values constant to the resolved values except for the coating CPE component, was made to identify modulation the coating pre-exponential term for different $n$ values. The simulation was first run for $\mathrm{n}=1$ and $\mathrm{n}=0.565$. In Figure 5.7a, the high-frequency 
impedance characteristic to coatings was much smaller than the low frequency interfacial impedance. Nevertheless, a crest in the imaginary impedance was present in the frequency range greater than $1 \mathrm{~Hz}$. At that frequency range the coating spectrum is visible and a peak value was identified at $\sim 11 \mathrm{~Hz}$ for $n=0.565$ as shown in the Figure $5.7 \mathrm{~b}$. The capacitance $\mathrm{C}$ was calibrated for $\mathrm{n}=1$ to match the frequency of high imaginary part. The model was also run for $n=0.7$ and 0.9 and calibrated the pre-exponential value to match that frequency. Then the frequency dependence of real part was plotted as shown in the Figure 5.8. As expected there was no frequency dependence of the real part at frequency $\sim 11.58 \mathrm{~Hz}$. Hence, the transformation formula is applicable for CBPC coating system. The coating capacitance, $\mathrm{C}=1.8 \times 10^{-2} \mathrm{~F}$ was observed at $\mathrm{n}=1$ (Table 5.3). The apparent capacitance was calculated to be $\sim 1.8 \times 10^{-2} \mathrm{~F}$ for other $\mathrm{n}$ values and was is in close agreement with the expected values as shown in Table 5.3.
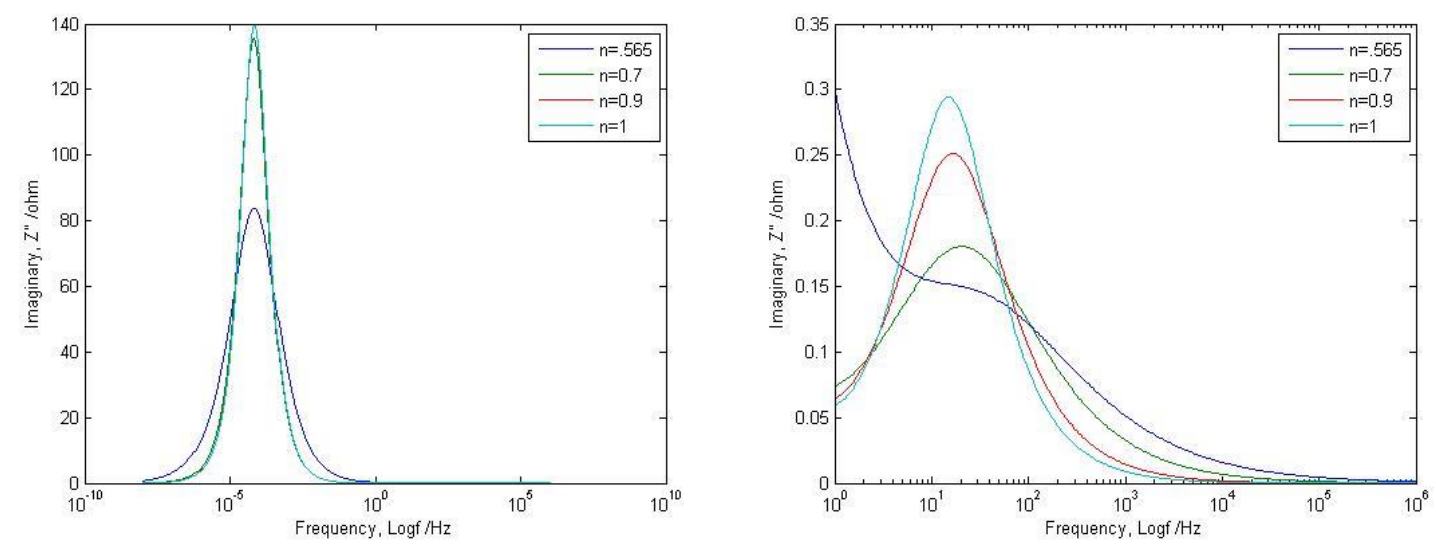

Figure 5.7 Frequency Dependence of Impedance for CBPC Coating. a) Frequency Dependence of $Z^{\prime \prime}\left(10^{-8} \mathrm{~Hz}-10^{6} \mathrm{~Hz}\right)$ b) Frequency Dependence of $Z^{\prime \prime}(1 \mathrm{~Hz}$ $\left.10^{6} \mathrm{~Hz}\right)$. 


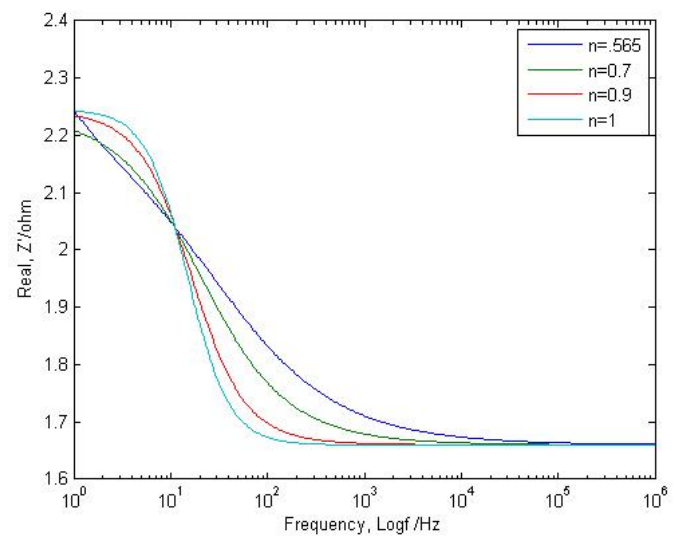

Figure 5.8: Frequency Dependence of Real Part of Impedance, $Z^{\prime}$ for CBPC Coating.

Table 5.3: Calculation of $\mathrm{C}$ from Yo for CBPC

\begin{tabular}{|c|c|c|c|}
\hline \multirow{2}{*}{$\mathrm{n}_{\mathrm{m}} \& \mathrm{n}_{\mathrm{c}}$} & Parameter Condition & Coating Capacitance & $\begin{array}{c}\text { Calculated Coating } \\
\text { Capacitance }\end{array}$ \\
\cline { 3 - 4 } & & $\mathrm{Y}_{0 \mathrm{C}}\left(\mathrm{s}^{\mathrm{n}} / \Omega\right)$ & $\mathrm{C}=\mathrm{Y}_{0}\left(\omega^{\prime \prime}\right)^{\mathrm{n}-1}(\mathrm{~F})$ \\
\hline \multirow{2}{*}{1} & Simulation Parameter & $1.8 \times 10^{-2}$ & - \\
\cline { 2 - 4 } & Fit Parameter & $1.8 \times 10^{-2}$ & $1.8 \times 10^{-2}$ \\
\hline \multirow{2}{*}{0.9} & Simulation Parameter & $1.8 \times 10^{-2}$ & - \\
\cline { 2 - 4 } & Fit Parameter & $2.6 \times 10^{-2}$ & $1.6934 \times 10^{-2}$ \\
\hline \multirow{2}{*}{0.7} & Simulation Parameter & $1.8 \times 10^{-2}$ & $1.5613 \mathrm{X}^{-2}$ \\
\cline { 2 - 4 } & Fit Parameter & $5.65 \times 10^{-2}$ & - \\
\hline \multirow{2}{*}{0.565} & Simulation Parameter & $1.8 \times 10^{-2}$ & $1.4111 \mathrm{X}^{-2}$ \\
\cline { 2 - 4 } & $\begin{array}{c}\text { Fit Parameter } \\
\text { (Actual fit value) }\end{array}$ & $9.11 \times 10^{-2}$ & \\
\hline
\end{tabular}

\subsubsection{CBPC Coating Capacitance and Water Absorption Capacity}

The capacitance of CBPC coating with and without chloride was calculated by using the developed model. The frequency at the peak imaginary part impedance was 
used for calculation of capacitance of the coating. The initial coating capacitance was $\sim 1 \times 10^{-5} \mathrm{~F}$ for non-chloride solution and $1 \times 10^{-3} \mathrm{~F}$ for chloride solution. The capacitance increased during the first 10 days of testing and then remained stables for the rest of the test period. The change in capacitive value can be explained by the water penetration during initial condition and the coating was apparently saturated with water within ten days. The dielectric constant of the electrolyte was also calculated for the initial and final day of testing. An expected increasing trend for the dielectric constant was observed although the resolved magnitude did not well characterize the water absorption for the assumed ideal geometry (Figure 5.10). The contributing factor for the discrepant results may include the apparent roughness and porosity of the CBPC ceramic. However, to support the argument of the coating degradation from its capacitive behavior, water absorption of CBPC coating was calculated by following the equation 5.2 (Figure 5.11). The coating reached the maximum water saturation level for the poor barrier protection offered by CBPC coating.

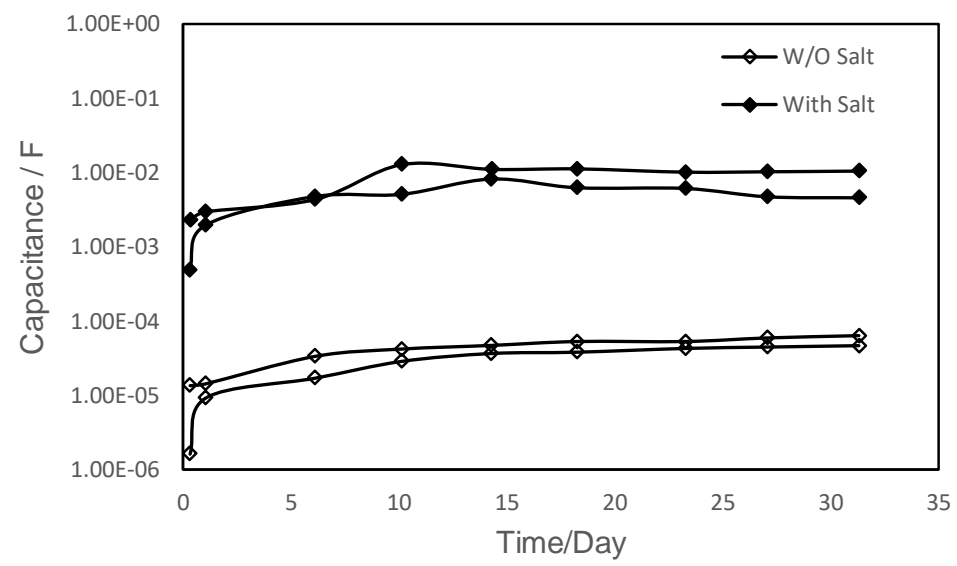

Figure 5.9: CBPC Coating Capacitance. 


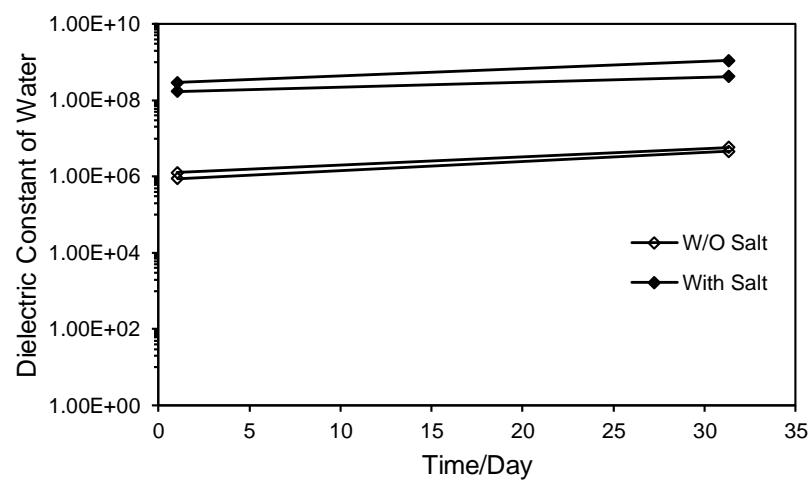

Figure 5:10 Dielectric Constant of Electrolyte.

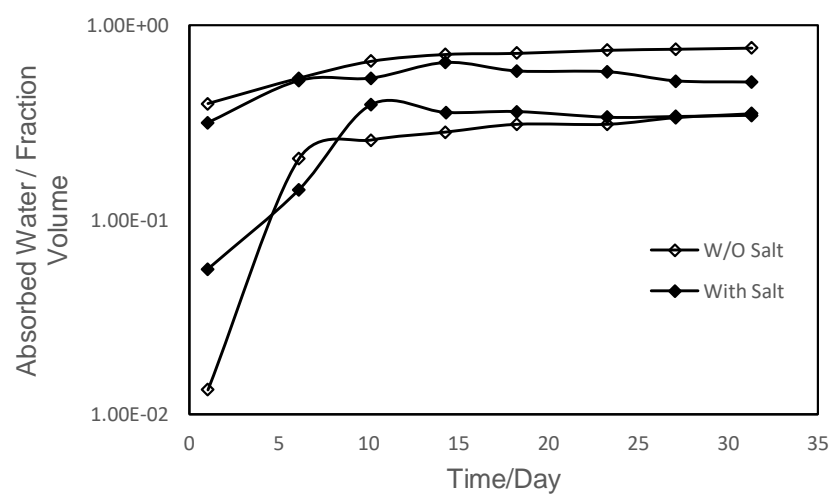

Figure 5.11: Water Absorption of CBPC Coating.

\subsection{Calculation of Coating Defect Area from Coating Pore Resistance}

The coating pore resistance is related to coating defects such as holidays, cracks or holes which are assumed to be filled up by electrolyte (Haruyama et al., 1987). Thus, the resistance of the pore is a function of the resistivity of the electrolyte filling the pores and the geometry of the pores as shown in the Equation 5.11. This implies that the coating pore resistance decreases with the increase of coating defect. Thus, the interpreted pore resistance was intended to capture the delamination of the CBPC coating during exposure.

$$
\mathrm{Rpo}=\frac{\rho \mathrm{d}}{\mathrm{Apo}}
$$


Where:

$$
\begin{array}{ll}
\mathrm{R}_{\mathrm{po}} & \text { coating pore resistance }(\Omega) \\
\mathrm{A}_{\text {po }} & \text { coating pore area }\left(\mathrm{cm}^{2}\right) \\
\rho & \text { resistivity }(\Omega-\mathrm{cm}) \\
\mathrm{d} & \text { coating thickness }(\mathrm{cm})
\end{array}
$$

\subsubsection{Methodology}

CBPC coated steel coupons were exposed to 3-day alternate wet and dry exposure for up to 45 days (cumulative 24 days in wet condition and 21 days in dry condition). The samples were submerged in distilled water to simulate the presence of accumulated runoff and pooled drainage water during the wet cycle and stored in a controlled humidity chamber $\left(\sim 122^{\circ} \mathrm{F}\right.$ temperature and $<5 \%$ relative humidity) during the dry cycle. Test cells were made for the wet cycle to accommodate reference and auxiliary electrodes required for EIS measurement. EIS testing was made at the OCP condition with $10 \mathrm{mV}$ AC perturbation voltage at frequencies from $1 \mathrm{MHz}$ to $1 \mathrm{~Hz}$ to ideally capture the responses associated with a bulk coating. New electrolytes were used for each electrochemical measurement to maintain the constant resistivity. Coating thickness was measured at the end of each dry cycle and coating pore resistance was also calculated for each cycle by fitting the impedance spectrum with an equivalent circuit. The aim of the test was to capture the coating degradation during exposure considering the coating pore area, coating pore resistance and coating thickness.

\subsubsection{Assessment of the Coating Degradation by Pore Resistance}

The variation of the coating thickness, coating pore resistance and calculated pore area with time are present in Figure 5.12 and Figure 5.13. The coating thickness 
decreased for both of the samples but the coating pore resistance showed an inverse relation with coating pore area. The coating pore resistance was calculated by following Equation 5.11 where resistivity was assumed as constant. Generally coating pores are distributed through coating thickness. So, n number of pores are assumed to be distributed through the CBPC coating surface. Then the combined pore resistance Rpo in equation 5.9 can be rewritten by considering parallel combination as

$$
\begin{aligned}
& R p o=\frac{R p o}{n} \\
& R p o=\frac{\rho d}{n A p o}
\end{aligned}
$$

where:

$$
\begin{array}{ll}
\text { Rpo } & \text { total coating pore resistance }(\Omega) \\
\text { Rpo' } & \text { coating pore resistance for single pore }(\Omega) \\
\text { Apo } & \text { coating pore area for a single pore }\left(\mathrm{cm}^{2}\right) \\
\rho & \text { resistivity }(\Omega-\mathrm{cm}) \\
\text { d } & \text { coating thickness }(\mathrm{cm}) \\
\mathrm{n} & \text { number of pores }
\end{array}
$$
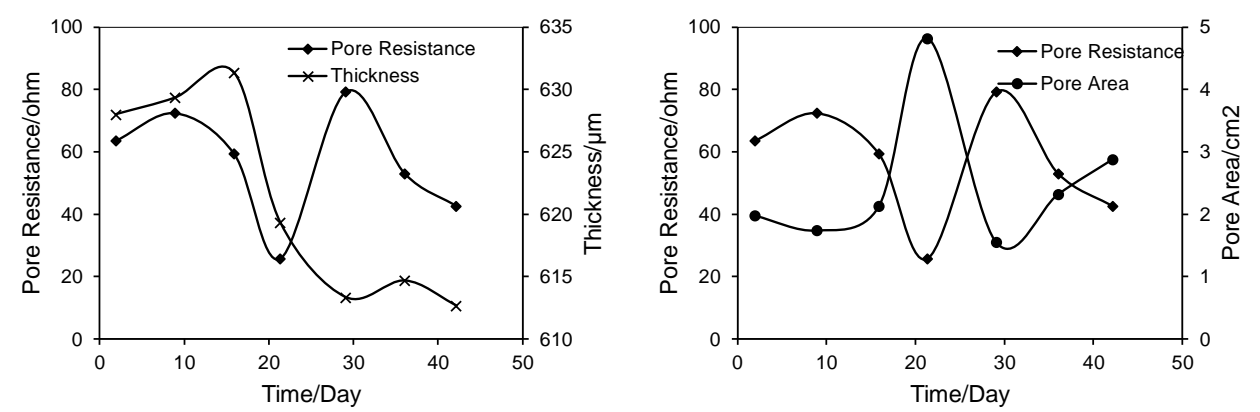

Figure 5.12: Variation of Coating Pore Resistance and Coating Thickness with Time (Sample 1). 

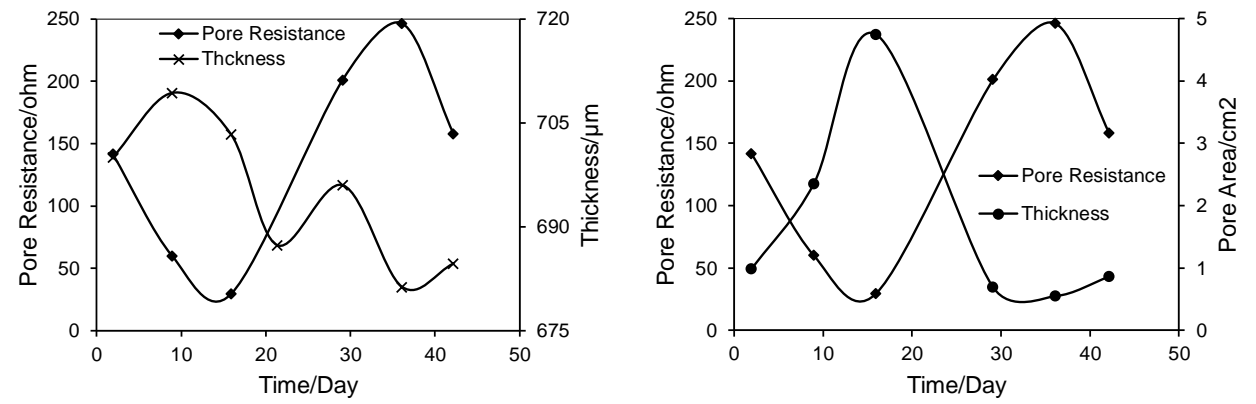

Figure 5.13: Variation of Coating Pore Resistance and Coating Pore Area with Time (Sample 2).

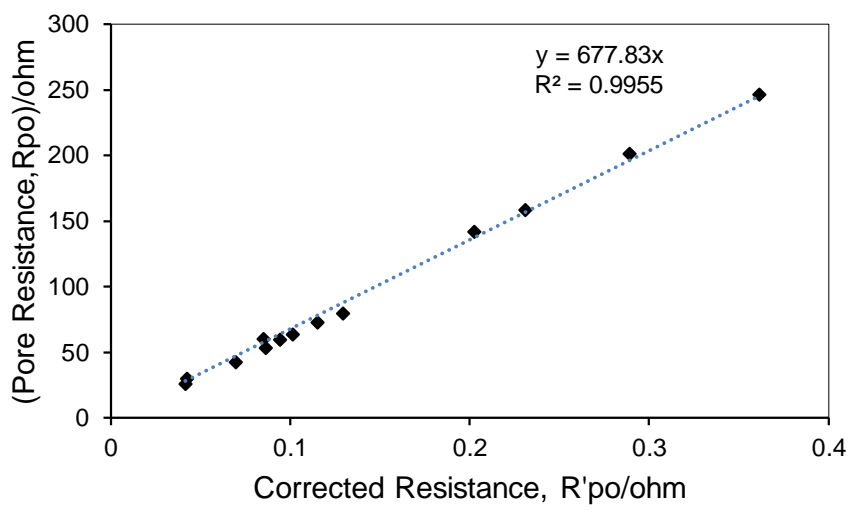

Figure 5.14: Correction Factor for Coating Pore Resistance

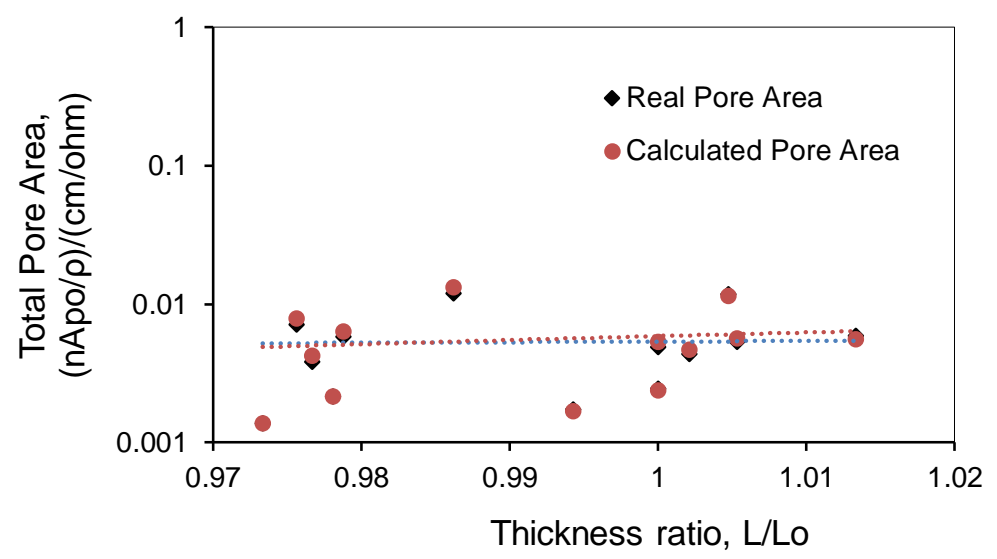

Figure 5.15: Calculation of Coating Pore Area

For the variability of coating pore resistance with coating thickness, a correction factor was introduced for calculated pore resistance to determine the pore area of the CBPC 
coating regardless of the thickness measurement (Figure 5.14). The ratio of the coating pore resistance to thickness $(\mathrm{Rpo} / \mathrm{L})$ was plotted against pore resistance, Rpo. The coating pore resistance was normalized for thickness change and represented as a correction factor. Thus, for similar CBPC coating systems, the coating pore area can be calculated from the correction factor by following the equation 5.14.

$$
\mathrm{nApo}=\frac{\rho}{\mathrm{R} \text { 'po }}
$$

To verify the simplified formula, the coating pore area calculated from measured data was compared with the pore area by simplified formula as shown in the figure 5.15. The coating pore area calculated by the simplified formula was in good agreement with the resolved areas calculated incorporating the actual measured coating thickness data. It is important to note that there was no significant change observed in pore area measurement during the duration of test, though the MIP data showed deterioration of the pore geometry by the large pore size distribution. The discrepancy of the result was thought to be the apparent distribution of the pore in the ceramic and formation of the hydrated product. The MIP data was based on the volumetric measurement of an arbitrary part of the exposed volume but the pore resistance from the EIS was the resistivity of the interconnected pores on the coplanar surface between the exposed ceramic and steel substrate. Greater material loss occurred near the exposed surface than compared to the adjacent steel substrate location. The MIP measurement could capture that resolution of spatial distribution of pore geometry near exposed surface for its volumetric measurement where EIS was unable to capture that spatial distribution. Further, the electrolytic path for the EIS measurement could be hindered by formation of hydrated 
product at the steel substrate. The apparent indicated constant porosity by EIS measurement of the CBPC provides indication of near similar exposed steel area despite of the bulk changes of the coating pore geometry.

The resolved capacitance and pore resistance from EIS measurement indicated the coating degradation during exposure though the denotation of interpreted results are different from traditional interpretation of coating degradation. Further evaluation of CBPC coating is necessary to successfully implement the EIS technique to quantify the coating degradation related to the other geometric property and electro-chemical behavior. 


\section{CHAPTER 6}

\section{PROPOSED DEGRADATION MECHANISIM OF CBPC COATING}

Much of the results and discussion presented earlier alluded to the difficulty in analyzing the data due to the inherent large variability of the coating thickness in the asreceived condition. Nevertheless, the findings lead to commonalities from the outdoor, accelerated immersion, salt-fog tests and electro-chemical test, where a sequence of steps for coating degradation can be proposed.

Though some discrepant results observed for thickness and pull-off strength measurements during earlier exposure, general consistency of results in increment of thickness and reduction of pull-off strength is identified after long term exposure. For environments with constant high humidity and moisture content (such as in the extreme case of the salt-fog environment), major pull-off strength reduction can occur regardless of significant thickness change. This suggests that the ceramic coating degrades by internal deterioration rather than only surface weathering in high moisture conditions. It is improtant to note that bulk coating anomaly was observed even in as received condition. The presented results and discussion indicated that the CBPC coating experienced initial degradation due to the alternate wet and dry environmental exposures as shown by the visual surface defects and the leaching of magnesium and phosphorus in solution. As shown by coating thickness measurements after exposure, it was apparent that later reaction of coating constituents may occur with the formation of hydrates of magnesium and phosphates. The x-ray diffraction of the exposed samples proved that argument of hydrate formation. Such reactions may include reactions such as (Wagh, 2004) 


$$
\mathrm{MgO}+\mathrm{Mg}\left(\mathrm{H}_{2} \mathrm{PO}_{4}\right)_{2} \cdot 2 \mathrm{H}_{2} \mathrm{O}=2 \mathrm{MgHPO}_{4} \cdot 3 \mathrm{H}_{2} \mathrm{O}
$$

In chloride solutions, such reactions were less favorable. In any case, the weakening of the bulk material may be related to the exposure of moisture to these constituent components especially at the outer coating layers where the material may be less compact. Visual observations after testing showed discoloration of the outer surface layer that has been associated with magnesium phosphate hydrate in preliminary testing. It is posed that these reactions near the coating surface may not be able to form compact layers with cohesive integrity that would thus lead to the surface defects described earlier. MIP testing indicated that there remains a network of small pores in the as-received condition and exposed conditions and that some fraction of pores was enlarged during testing. It was thought that the network of fine pores is related to the stronger CBPC hydration products and the changes in porosity was due to further reactions of the constituent materials. The apparent porous nature of the coating would allow better transport of moisture and other chemical species. The availability of moisture within the coating would lead to degradation and significant cohesive strength loss. Observations of coating degradation in immersed conditions, where the ceramic became exfoliated from the substrate in flakes, further corroborates this finding. Interesting results relating to the intentional defect (scribed) sites exposing the substrate were observed. Corrosion at the defect sites on samples placed in outdoor and salt-fog exposure did not increase with time yet significant undercoating surface oxidation (similar to non-scribed samples) occurred throughout the samples. The electro-chemical testing of the non-scribed and scribed samples sowed identical behavior of electrochemical nature during testing. That findings also corroborate the apparent porous nature of the CBPC coating. The apparent constant 
to somewhat increasing trend of pore resistance also gave the indication about the differential porosity within the thickness and formation of hydration product that was susceptible for pore blocking. Earlier testing also indicated that reaction with the steel substrate may lead to formation of a possible beneficial intermediate layer of iron hydrogen phosphate hydrate that was identified by XRD. There was a general increase in thickness of that hydrated layer observed with longer exposure time. The enhanced porosity could facilitate moisture to produce the intermediate hydrate product by reacting with the steel substrate. Such reactions may include reactions such as (Wagh, 2004)

$$
2 \mathrm{Fe}_{3}\left(\mathrm{PO}_{4}\right)_{2}+8 \mathrm{H}_{3} \mathrm{PO}_{4}+1.5 \mathrm{O}_{2}+21 \mathrm{H}_{2} \mathrm{O}=6\left(\mathrm{FePO}_{4} \cdot \mathrm{H}_{3} \mathrm{PO}_{4} .4 \mathrm{H}_{2} \mathrm{O}\right)
$$

It was apparent that the layer here formed in relation to apparent significant corrosion of the steel substrate. The steel consumption at the blister site under the hydrate layer is disconcerting as there are apparent conditions where coating corrosion mitigation is compromised.

The degradation process can be summarized in following steps

Step 1: Initial degradation of barrier ceramic by alternate wet and dry cycle and interaction with moisture.

Step 2: The degradation of barrier ceramic and characteristics porosity of the CBPC coating facilitates moisture within the coating.

Step 3: The coating constituent further reacts and form magnesium phosphate hydrate with presence of moisture for the formation of intermediate product instead of phosphate ceramic during application.

Step 4: The coating constituents also (phosphorus and magnesium) leaches out for its water solubility and enhances the porosity. 
Step 5: The enhanced porosity further facilitates moisture to coating substrate and iron corrosion initiates at steel substrate.

Step 6: The apparent formation of iron corrosion product reacted with phosphate compounds to form iron phosphate hydrate.

It is noted again that the material used in testing was intended to be prepared and coated in accordance to manufacturer best practices, but indications of significant sample variability were observed. As with any test program with provided test materials, the findings described are solely based on the testing results for the materials received, and may not necessarily reflect material behavior due to any changes by the materials providers. Also, the outdoor exposure periods used here were rather short to fully identify long term behavior, and accelerated tests in salt-fog and solution immersion were aggressive and not necessarily representative of field conditions. However, the findings from this study were meant to provide indicators of major material incompatibility with environments relevant to highway bridges. As such, the scope of the work was broad and did not focus on any particular application or environment. 


\section{CHAPTER 7}

\section{CONCLUSION}

The CBPC coating was exposed in outdoor and salt-fog environment to access the integrity of coating system in humid and aggressive marine bridge environment. Electro chemical tests were also done in wet and alternate wet and dry condition to get advanced information about the degradation mechanism of CBPC coating. The findings of those test results are summarized in the following paragraphs

CBPC coating degraded in moist environmental condition. The degradation was in the form of scouring and chalking on coating surface. That compromises the barrier protection for long-term durability of the steel bridges. So, bridge locations with high moisture presence should be avoided to reduce CBPC coating degradation.

Poor coating adhesive and cohesive strengths were observed in as-received and exposed conditions. Major pull-off strength reduction can occur regardless of significant thickness change during exposure. This indicates that the ceramic coating degrades by internal deterioration rather than only surface weathering in high moisture conditions.

The CBPC forms during the application of acid phosphate and magnesium hydroxide at $\mathrm{pH}$ 3-4 but the apparent deficiency in reaction, hydration product of magnesium form along with phosphate ceramic and some coating constituents remains unreactive. Hence, subsequent reactions of those coating constituent materials occur during the exposure to moisture, which further accelerate the degradation process.

The reaction of the unreacted coating constituents formed different forms of hydrates and leaches out the magnesium and phosphorus compounds from the CBPC matrix at 
moist condition. That resulted a porous CBPC coating and facilitate more moisture within the coating to accelerate bulk ceramic degradation.

Under coating corrosion of the steel substrate occurred for the availability of moisture at the steel substrate and the corrosion product reacted with the coating constituent to form apparent protective iron phosphate hydrate. The developed phosphate hydrate was not continuous. Therefore, the corrosion mitigation by phosphate hydrate may not be well manifested. The steel consumption under the hydrate layer is alarming as there are apparent conditions where coating corrosion mitigation is compromised in the long run.

In chloride solution, extended undercoating surface hydration product formed in non-scribed samples, and the oxide product was within the exposed steel of scribed regions may be for the possible beneficial cathodic prevention which needs to be further investigated.

Scribed and non-scribed samples had similar active OCP condition, which indicated the poor barrier property of the CBPC coating. Further, high corrosion rate in salt solution is possible indicative of steel substrate corrosion in marine environment.

EIS analog circuit curve fitting of constant phase element can be used to determine capacitive behavior of porous CBPC coating. Numerical simulation for Yo to C conversion has shown satisfactory for condition of greater impedance dispersion (as low as $\mathrm{n}=0.5$ ) and did not appear to convolute the Yo to $\mathrm{C}$ conversion.

Water sensitive response of CBPC coating was identified by EIS measurement. The deduced capacitive response of the samples indicates early saturation with water in very short exposure. Also, pore resistance measurements from immersion testing did not show 
a major decreasing trend with time, but rather a constant to somewhat increasing trend with time. So, the resolved impedance coating parameters give some indication of pore activity but distinct trends with time or exposure environment cannot be captured by only EIS measurement for CBPC coating.

MIP testing along with EIS measurement can give more advanced information about pore characteristics related to coating degradation process. The results indicated that there remains a network of small pores in the as-received condition and exposed conditions and that some fraction of pores is enlarged during testing due to further reactions of the constituent materials.

A calibration factor was suggested to quantify the delaminated coating area. Results were consistent with MIP data indicating confluence of pore defects. 


\section{REFERENCES}

ArmorGalv.( 2013). Environmental friendly thermal diffusion zinc. Retrieved May 27, 2013 from http://www.armorgalv.com/armorgalv/ArmorGalv_HOME.html

ASTM A 1059/A 1059 M. (2008). Standard Specification for Zinc Alloy ThermoDiffusion Coatings (TDC) on Steel Fasteners, Hardware, and Other Products1. ASTM Book of Standards.

ASTM G 7M-11. (2011). Standard practice for atmospheric environmental exposure testing of nonmetallic materials. ASTM Book of Standards.

ASTM B 117. Standard Practice for Operating Salt Spray (Fog) Apparatus. ASTM Book of Standards.

Balasubramaniam, R. (2000). On the corrosion resistance of the Delhi iron pillar. Corrosion Science 42, 2119

Balasubramaniam, R. (2000). Characterization of Delhi Iron Pillar Rust by X-ray Diffraction, Fourier Transform Infrared Spectroscopy and Mossbauer Spectroscopy. Corrosion Science 42, 2092.

Barsoukov, E., \& Macdonald, J. R.(2005). Impedance spectroscopy: theory, experiment, and applications ( $2^{\text {nd }}$ ed.). Hoboken: Wiley Inter science.

Bell, J.L., Driemeyer, P. E., \& Kriven, W. M.(2009). Formation of ceramics from metakaolin-based geopolymers. part ii: k-based geopolymer. The University of Illinois at Urbana-Champaign, 607-615.

Bernecki, T., Clement, K., Cox, E. Kogler, R., Lovelance, C., Peart, J., and Verma, I. (1997, January). Bridge maintenance coatings. FHWA Study Tour for Bridge Maintenance Coatings.

Brasher, D. M., and Kingsbury, A. H. (1954). Electrical measurements in the study of immersed paint coatings on metal. I. Comparison between capacitance and gravimetric 
methods of estimating water uptake. Journal of chemical technology and biotechnology. 4,62 .

Brigham, S. (2009, March). Understanding and Use of Glass Flake.

Calla, E. \& Modi S. C. (2000). Long life corrosion protection of steel by zinc-aluminum coating formed by thermal spray process. Corrosion its Mitigation and Preventive Maintenance, CORCON - 2000. Mumbai, India.

Castro, P., Saguiés, A. A., Moreno, E. I., Maldonado, L., \& Genescá, J. (1992).

Characterization of activated titanium solid reference electrodes for corrosion testing of steel in concrete. Corrosion Science, 52 (8), 609-617.

Chang, L.M. and Georgy, M. (1999). Metallization of steel bridges: research and practice. Indiana DOT and Purdue University. (Report No. FHWA/IN/JTRP-98/21). West Lafayette, IN.

Chang and chung (1999, May). Steel bridge protection policy, Volume 2. Prepared by Purdue University for Indiana Department of Transportation. (Report No. FHWA/IN/JTRP-98/21).

Chong, S.L. and Yao, Y. (2006). Are Two Coats as Effective as Three? Federal Highway Administration (Report No. FHWA-HRT-2006-006).

Chang, L., Zayed, T., \& Fricker, J.D.(1999). Steel bridge protection policy: Evaluation of bridge coating system for INDOT steel bridges. Indiana DOT and Purdue University. West Lafayette, IN. (Report No. FHWA/IN/JTRP-98/21-II).

Dallin, G.W. (2012, August). Continuous hot dip galvanizing - process and products. Galvo info center. Retrieved September 15, 2014 from www.galvinfo.com

Duxson, P., Provis, J. L., Lukey, G. C., Mallicoat, S. W., Kriven, W. M., Deventer, J. S. J. V. (2005) Understanding the relationship between geopolymer composition, microstructure and mechanical properties. Colloids and Surfaces A: Physiochem. Eng.,269, 47-58. 
El-Mahdy, G. A., Nishikata, A., \& Tsuru, T. (2000). AC impedance study on corrosion of 55\% Al-Zn alloy-coated steel under thin electrolyte layers. Corrosion Science.

42(9), 1509-1521.

FDOT. (2013). Evaluation of ArmorGalv® under salt fog exposure and partial immersion in saltwater. Retrieved May 2013 from http://www.armorgalv.com/armorgalv/Downloads_files/Florida\%20DOT\%20Armorgalv \%20evaluation\%20Final.pdf

Federal Highway Administration. (2006, September/October). Are two coats as effective as three? (Report No. FHWA-HRT-2006-006), 70 (2).

Federal Highway Administration. (2011, June). Performance evaluation of one-coat systems for new steel bridges. (Report No. FHWA-HRT-11-046).

Federal Highway Administration. (2012, November). 100-Year coating study. (Repost No. FHWA-HRT-12-044).

Federal Highway Administration. (1997, July/August). Steel bridge coating research, 61(1). Retrieved September 15, 2014 from http://www.fhwa.dot.gov/publications/publicroads/97july/brdgct.cfm

Fontana, M., \& Greene, N.(1986). Corrosion Engineering (3rd ed.). : McGraw Hill.

Haruyama, S., Asari, M., \& Tsuru, T. (1987). Corrosion protection by organic coatings. The Electrochemical Society, 87(2), 197.

He, P., Jia, D., Wang, M., Zhou, Y. (2011). Thermal Evolution and Crystallization Kinetics of Potassium-based geopolymer. Ceramic International, 37, 59-63.

Grundmeier, G., Schmidt, W., \& Stratmann, M. (2000). Corrosion protection by organic coatings: electrochemical mechanism and novel methods of investigation. Electrochemical Acta, 45(15-16), 2515-2533. 
Hsu, C. H., \& Mansfeld, F. Technical Note: Concerning the conversion of the constant phase element parameter $\mathrm{Y}_{0}$ into a capacitance. Corrosion Science, 57 (9), 747-748.

Isakaev, E. K., Gusev,V.M., Mordynskii, V. B., Sidorova, E. V., \& Maksimov,A. A.(2010). Dynamic thermal diffusion galvanizing of components, analysis of the process and features of technology. Chemical and Petroleum Engineering, 46(11-12), 774-781.

Jeong, S. Y., \& Wagh, A. S.(2002). Chemically bonded phosphate ceramics: cementing the gap between ceramics and cements. Materials Technology, 2.

Jones, D. A. (1996). Principle and preservation of corrosion. ( $2^{\text {nd }}$ ed.). : Prentice Hall Kodumuri, P. \& Lee, S. K. (2012, November). Federal Highway Administration 100Year Coating Study. Federal Highway Administration. (Repost No. FHWA-HRT-12044).

Kalendova, A. (2003, June). Effects of particle sizes and shapes of zinc metal on the properties of anticorrosive coatings. Progress in Organic Coatings, 46 (4), 324-332.

Kline, E. (2009, November). Durable bridge coatings. Modern Steel Construction, AISC.

Koger, R.A., Brydl, D., \& Highsmith, C. (1998). Recent FHWA experience in testing and implementing metallized coatings for steel bridges. Corrosion-98. Paper 499 NACE Int. Houston, TX.

Kim, D., Lai, H.T., Chilingar, G.V., \& Yen, T.F. (2006). Geopolymer formation and its unique properties, Environ. Geol, 51 (1), 103-111.

Lau, K., \& Sagues, A. A.(2009). Corrosion of epoxy - and polymer/zinc-coated rebar in simulated concrete pore solution. Corrosion, 65 (10), 681-694.

McCafferty, E. (2010). Introduction to corrosion science. Springer New York Dordrecht Heidelberg London, 127.

Materials Performance. (2011, December). Inorganic ceramic coating shows resistance to corrosion. 
Mahdavian, M., \& Attar, M. M. (2006). Another approach in analysis of paint coatings with eis measurement: phase angle at high frequencies. Corrosion Science, 48(12), 41524157.

Marder, A. R.(2000). The metallurgy of zinc-coated steel. Progress in materials Science, 45 (3), 191-271.

Mertns, S. F., Xhoffer, C., Cooman, B. C. De. And Temmerman, E. (1997). Short-term deterioration of polymer-coated 55\% Al-Zn-Part 1: Behavior of thin polymer films. Corrosion Science, 53(5), 381- 388.

Mittal, K. L. (1983). Adhesion Aspects of Polymeric Coatings. New York: Plenum Press.

Molnár \& Liszi, J. (2001, September). Protective properties of zinc-rich paints. Joint International Meeting - the 200th Meeting of the Electrochemical Society, Inc. and the 52nd Annual Meeting of the International Society of Electrochemistry - San Francisco, California.

Mraz, L., \& Lesay,J.(2009). Problems with reliability and safety of hot dip galvanized steel structures. Soldagem Insp. São Paulo, 14 (2), 184-190.

Murray, J. N. (1997). Electrochemical test methods for evaluating organic coatings on metals: An update. part iii: multiple test parameter measurements. Progress in Organic Coating, 31 (4), 375-391.

Myers. et al. (2010, October). Structural steel coating for corrosion mitigation, Prepared by Missouri University of Science and Technology, Rolla, Missouri \& University of Missouri-Columbia, Missouri, for Missouri Department of Transportation.(Report No. OR11-006).

O'Dea, V., Brown, C., \& Dallen, A. (2016). Pull-Off Adhesion Strength Testing of Lining Systems on Concrete. J. Prot. Coat. Linings, 33 (), 64.

Orazem, M. and Tribollet, B. (2008). Electrochemical Impedance spectroscopy, Hoboken, NJ: Wiley Interscience. 
Rashidi, N., Alavi-Soltani, \& S., Asmatulu, R. (2007). Crevice corrosion theory, mechanisms and prevention methods. Proceedings of the 3rd Annual GRASP Symposium, 215-216.

Seneviratne, A.M.G., Sergi, G., \& Page, C.L. (2000). Performance characteristics of surface coatings applied to concrete for control of reinforcement corrosion. Construction and Building Materials, 14(01), 55-59.

Song, G. L. and Atrens, A. (2003). Understanding Magnesium Corrosion-A Framework for improved Alloy Performance. Advanced Engineering Materials 5, 837-858.

Vetter, K. (1967). Electrochemical Kinetics: Theoretical and Experimental Aspects. New York, NY: Academic Press.

Virmani, Y. P., \& Payer, J. H. (2002). Corrosion costs and preventive strategies in the United States. Federal Highway Administration. (Report\# FHWA-RD-01-156). Retrieved September 15, 2014 from http://events.nace.org/publicaffairs/images_cocorr/ccsupp.pdf

Wagh, A.S. and Jeong, S.Y. (2003). Chemically bonded phosphate ceramics: i, a dissolution model of formation. Journal of American Ceramic Society, 86 (11), 18381844.

Wagh, A.S. (2004). Chemically Bonded Phosphate Ceramics- Twenty-first Century Materials with Diverse Applications. Amsterdam, The Netherlands: Elsevier Ltd.

Wagh, A.S. (2005). Chemically bonded phosphate ceramic-A novel class of geopolymers. Proceedings of the $106^{\text {th }}$ Annual Meeting of the American Ceramic Society, 107-118.

Weast, R. C. (1984). Handbook of Chemistry and Physics (64 ${ }^{\text {th }}$ ed.): CRC Press

Westing, E. V. (1992). Determination of coating performance with impedance measurements. $\mathrm{PhD}$ thesis. Technical University of Deift. 
Xin, Y., Huo, K., Tao, H., Tang, G. and Chu, P. K. Influence of Aggressive Ions on the Degradation Behavior of biomedical magnesium alloy in Physiological Environment," Acta Biomaterialia 4, p. 2008-2015 (2008).

Yao, Y., Kodumuri, P., \& Lee, S.K. (2011, June). Performance evaluation of one-coat systems for new steel bridges. Federal Highway Administration. (Report No. FHWAHRT-11-046).

Yadav, A. P., Katayama, H., Noda, K., Masuda, H., nishikanta, A., \& Tsuru, T. (2007). Effect of Fe-Zn alloy layer on the corrosion resistance of galvanized seek ub chloride containing environments. Corrosion Science, 49, 3716-3731.

Yeomans, S. R. (2004). Galvanized Steel Reinforcement in Concrete: An Overview. Amsterdam, The Netherlands: Elsevier Science.

Zhang, X. G. (1996).Corrosion and electro chemistry of zinc. New York: Plenum Press.

Zhmurkin, D. (2009, July). Corrosion resistance of bolt coatings. Tyco Electronics. 
Appendix A -Sample Picture 


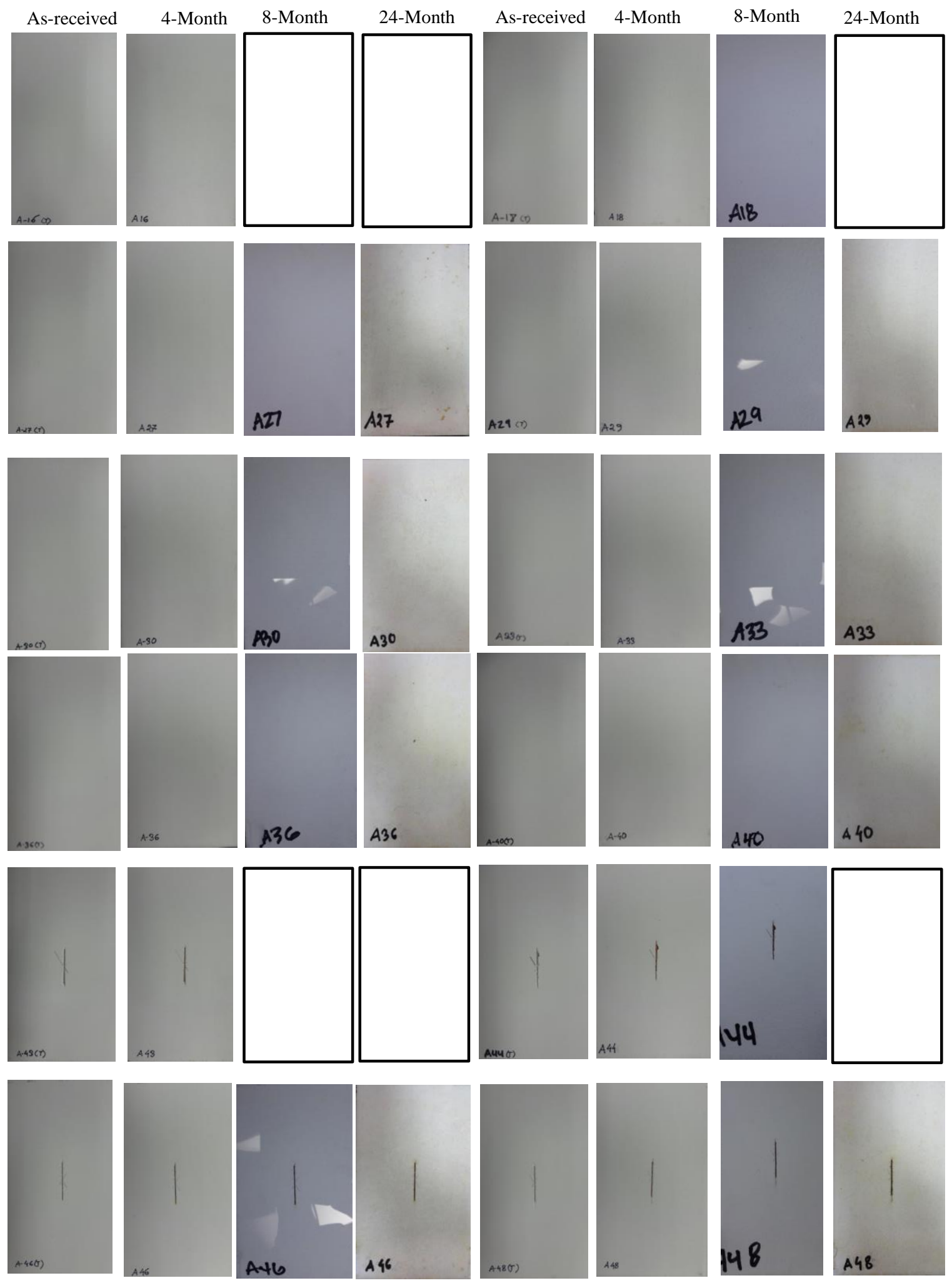

Figure A1: CBPC Samples Exposed at Inland Test Site 


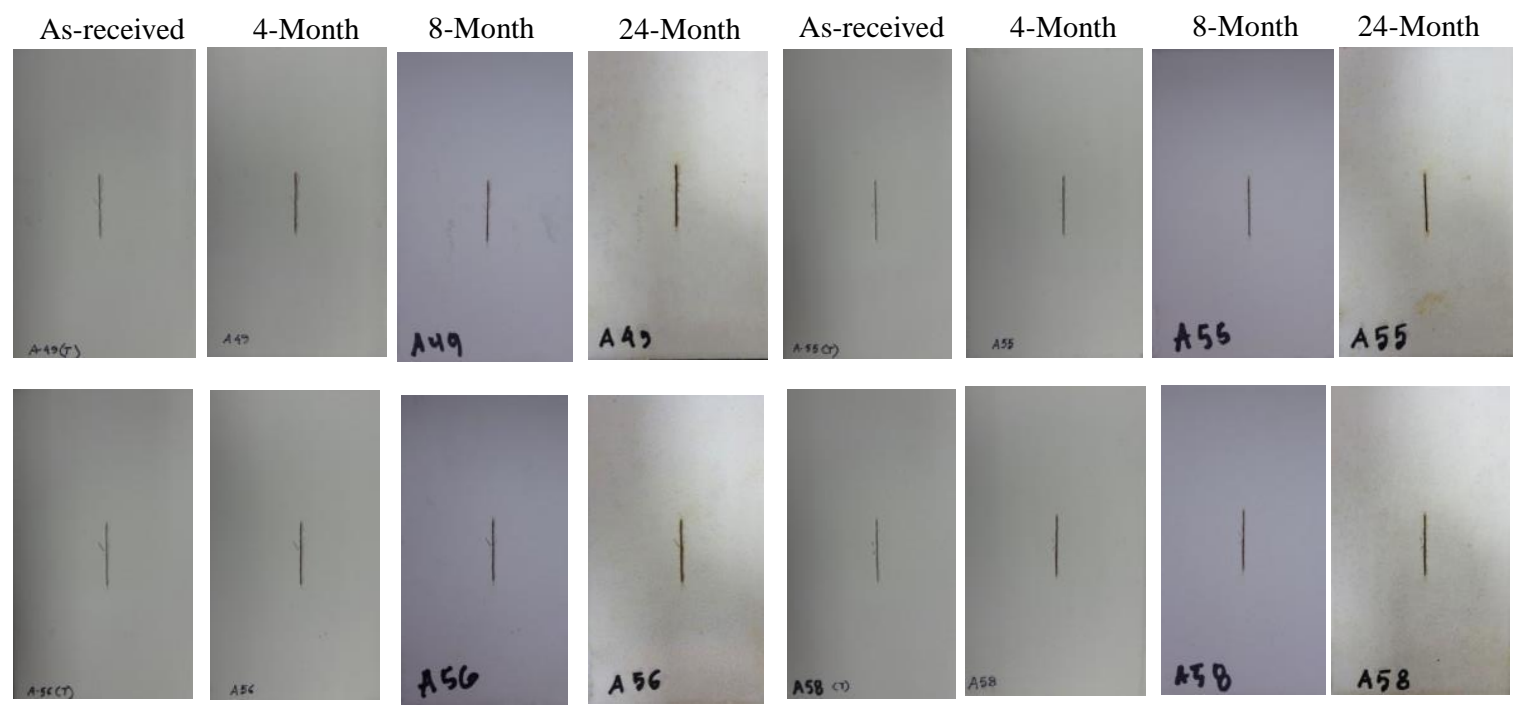

Continuation of Figure A1: CBPC Samples Exposed at Inland Test Site

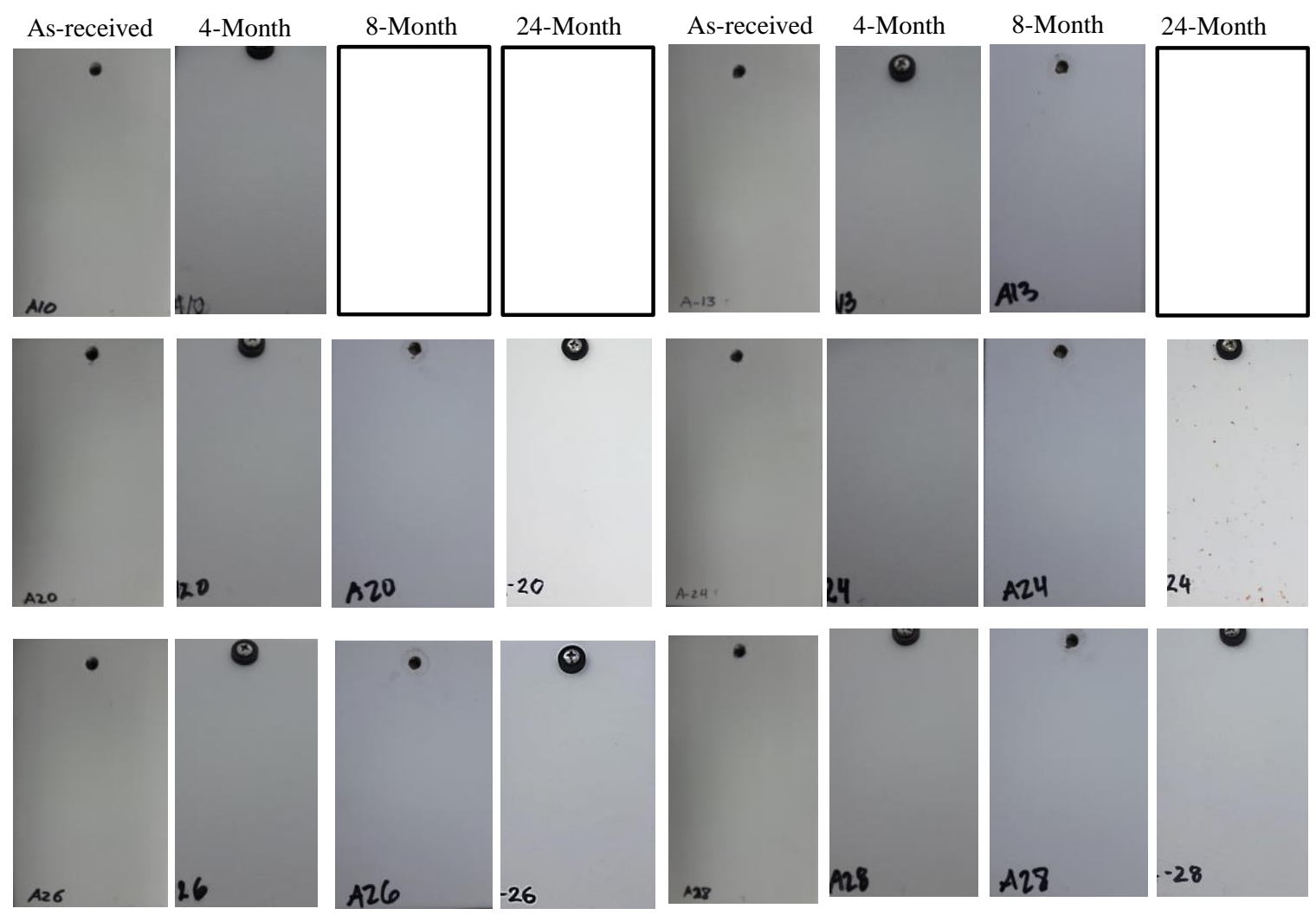

Figure A2: CBPC Samples Exposed at Beach Test Site 


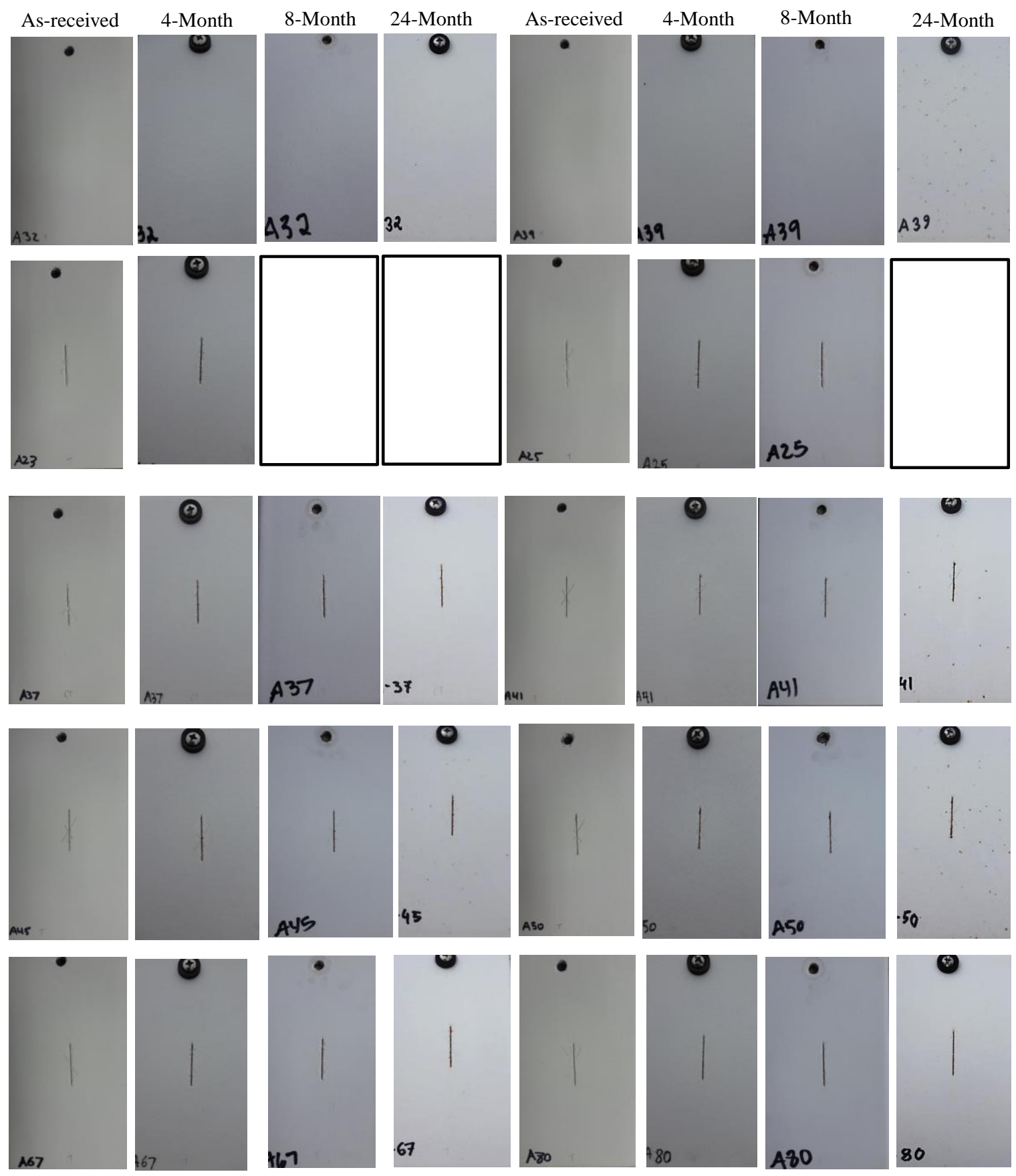

Continuation of Figure A2: CBPC Samples Exposed at Beach Test Site 


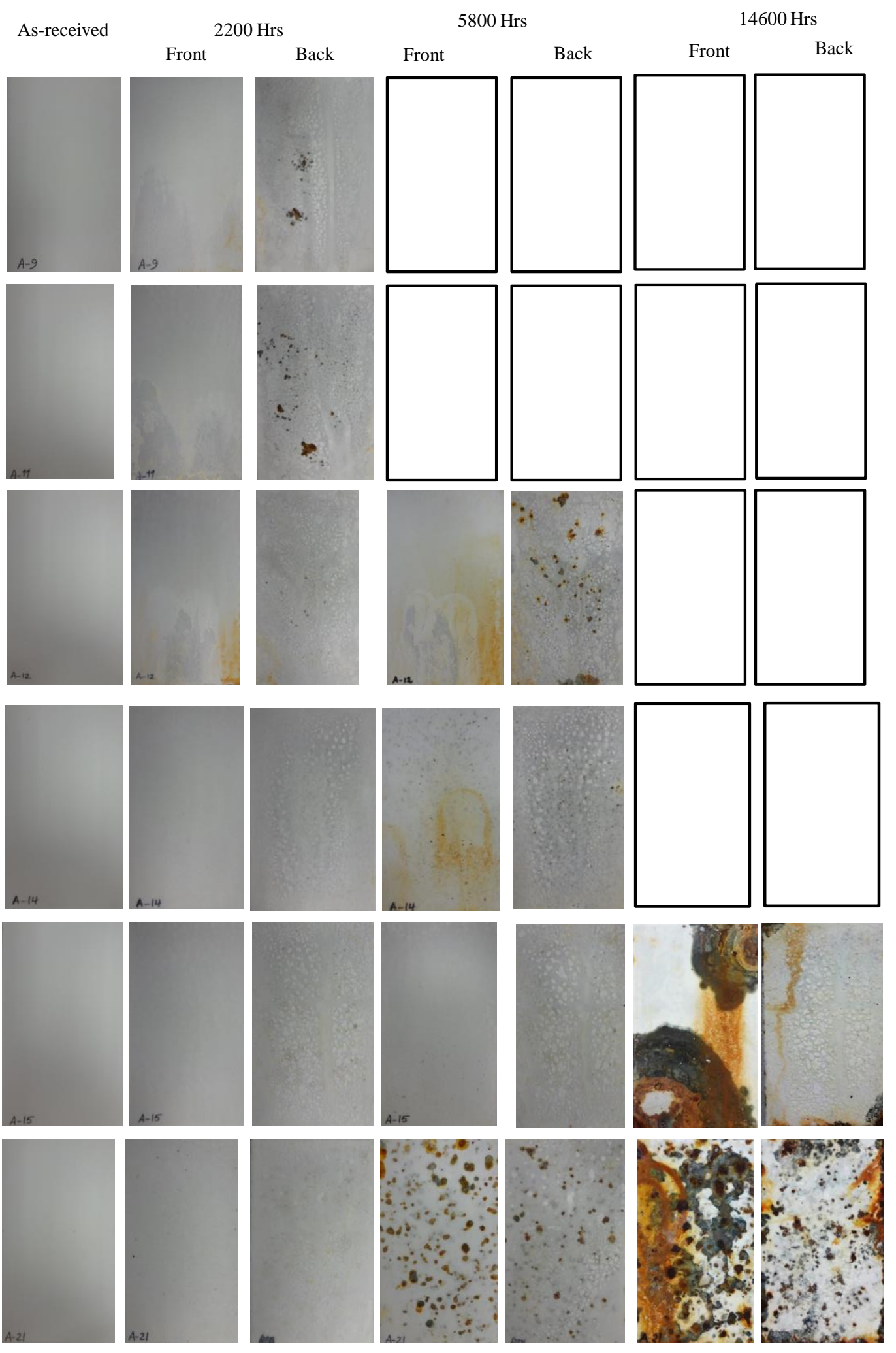

Figure A3: CBPC Samples Exposed at Salt-Fog 


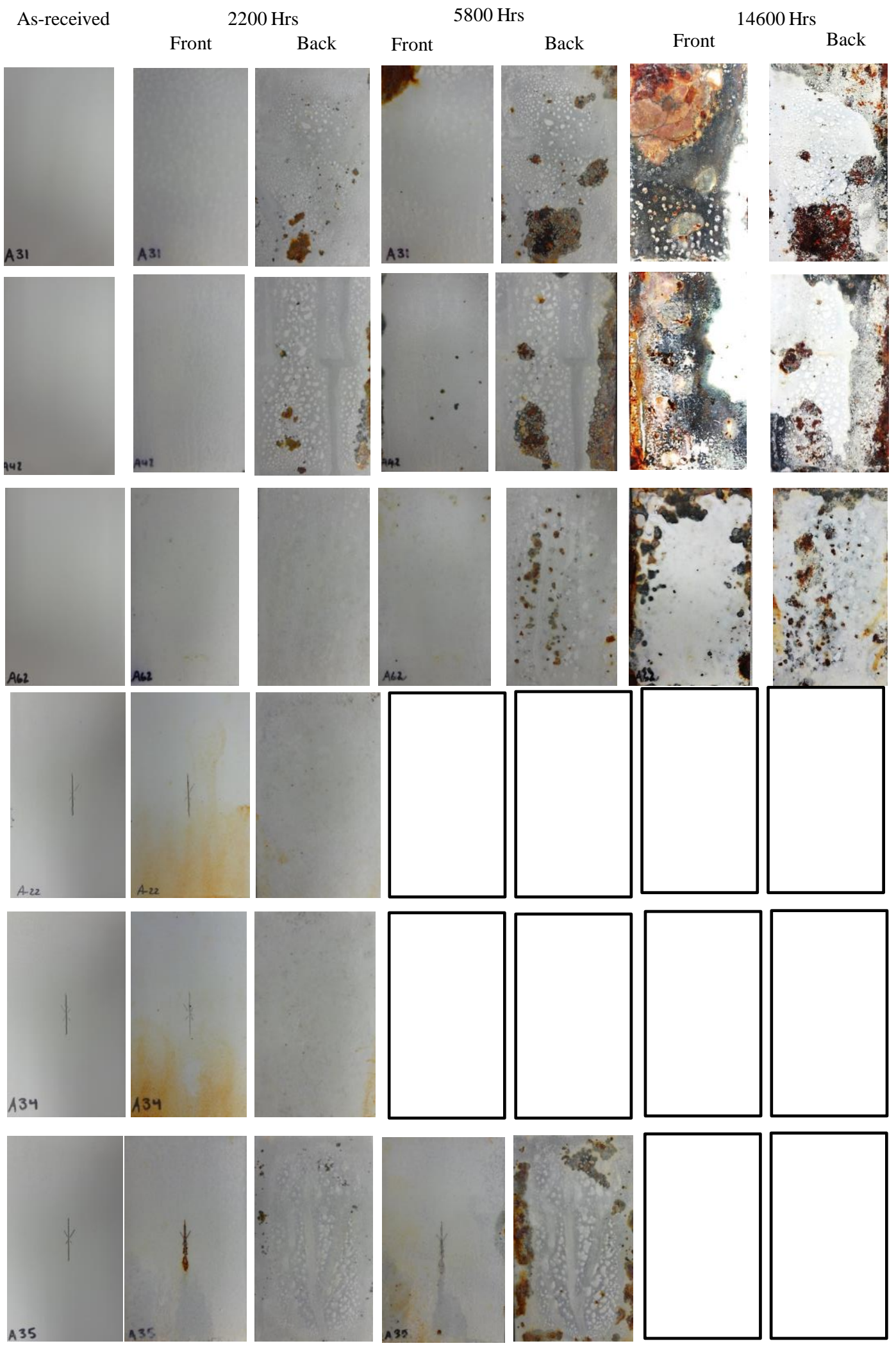

Continuation of Figure A3: CBPC Samples Exposed at Salt-Fog 


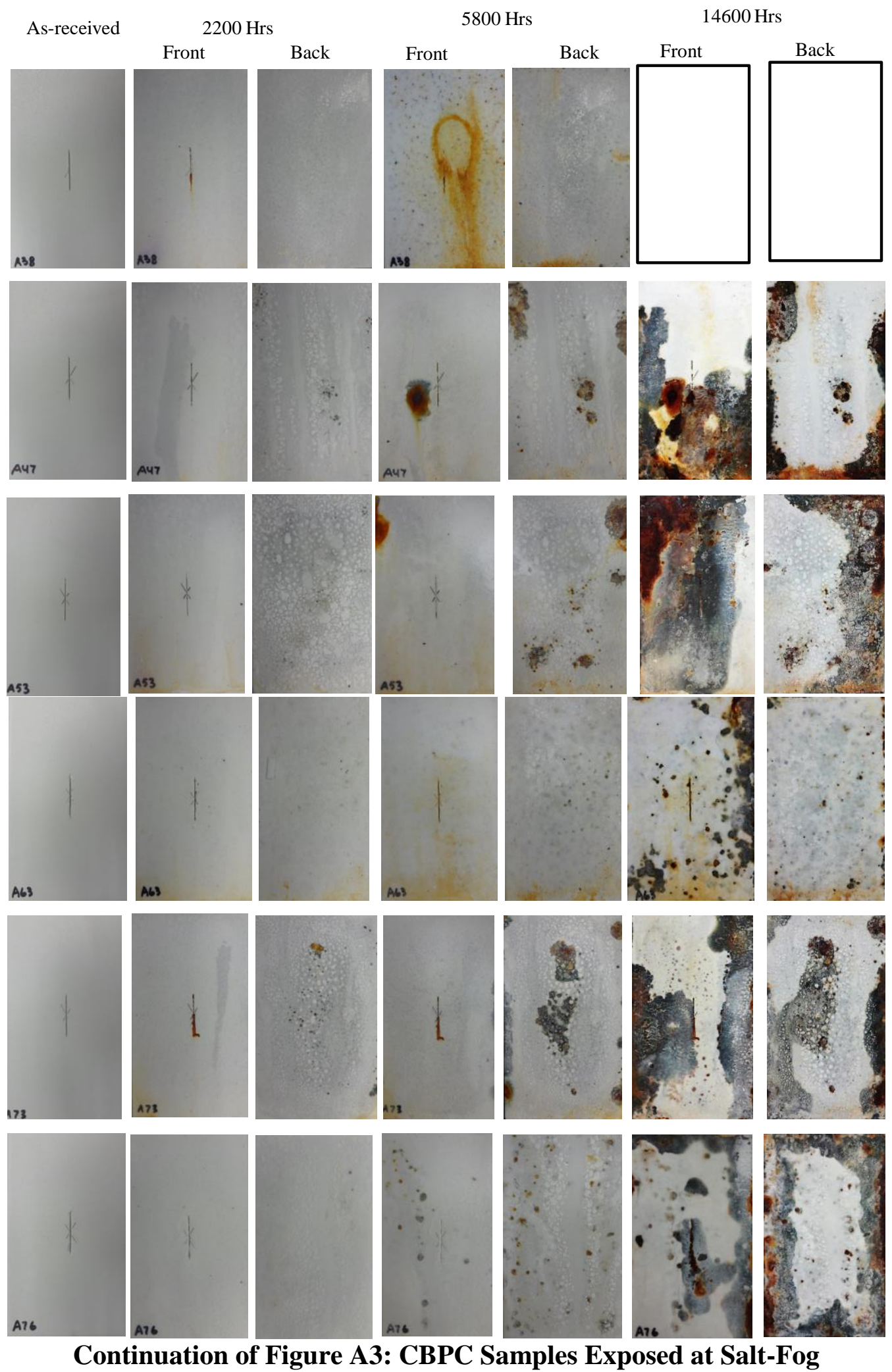



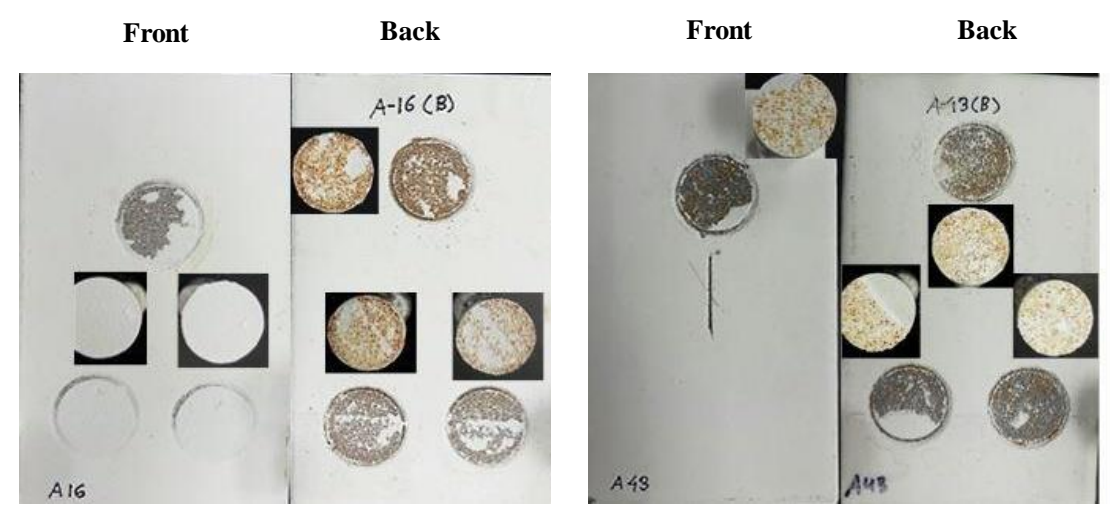

Figure A4: Exposed Substrate after Pull-off Strength of Inland Samples after 4Month
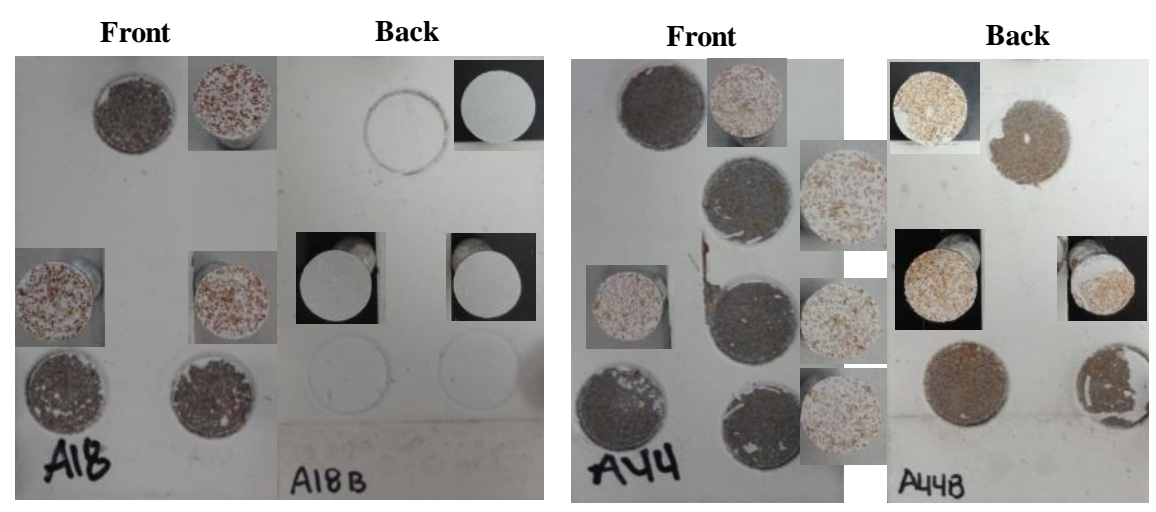

Figure A5: Exposed Substrate after Pull-off Strength of Inland Samples after 8Month

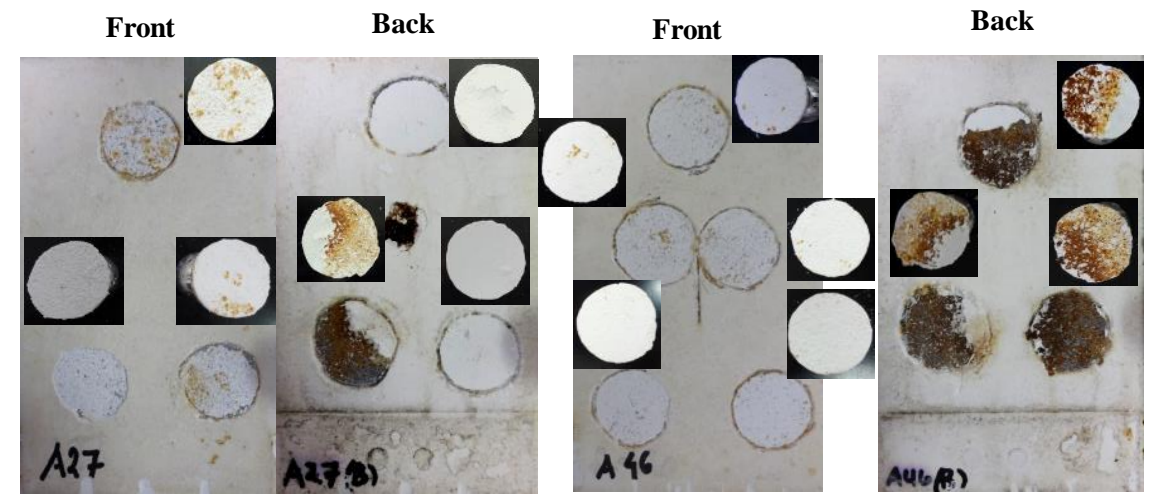

Figure A6: Exposed Substrate after Pull-off Strength of Inland Samples after 24Month 

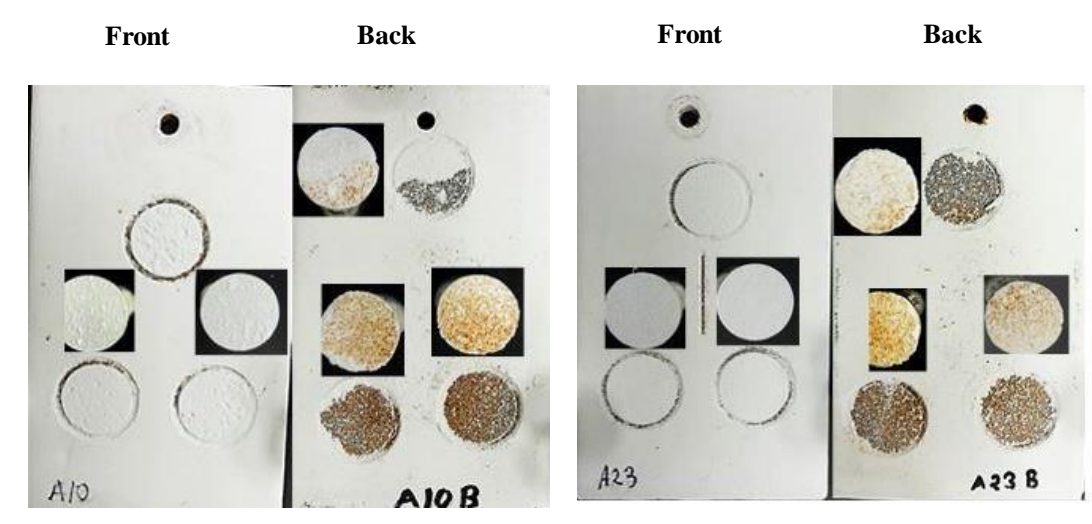

Figure A7: Exposed Substrate after Pull-off Strength of Beach Samples after 4Month
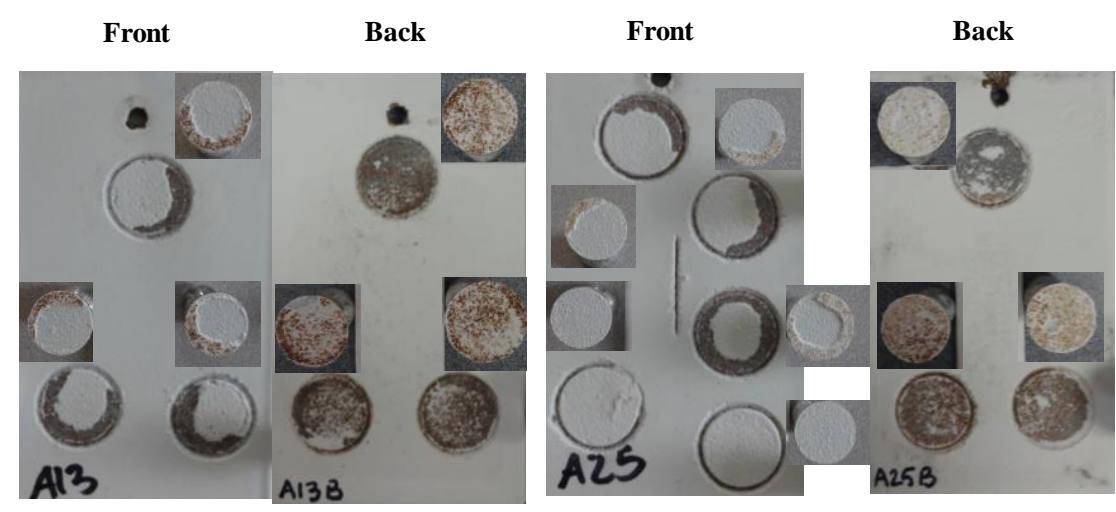

Figure A8: Exposed Substrate after Pull-off Strength of Beach Samples after 8Month

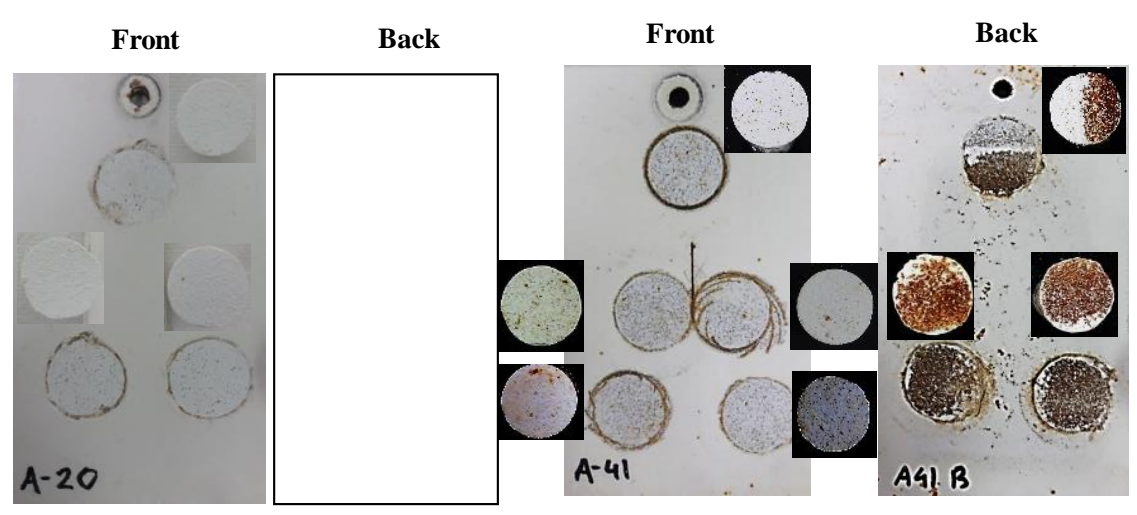

Figure A9: Exposed Substrate after Pull-off Strength of Beach Samples after 24Month 


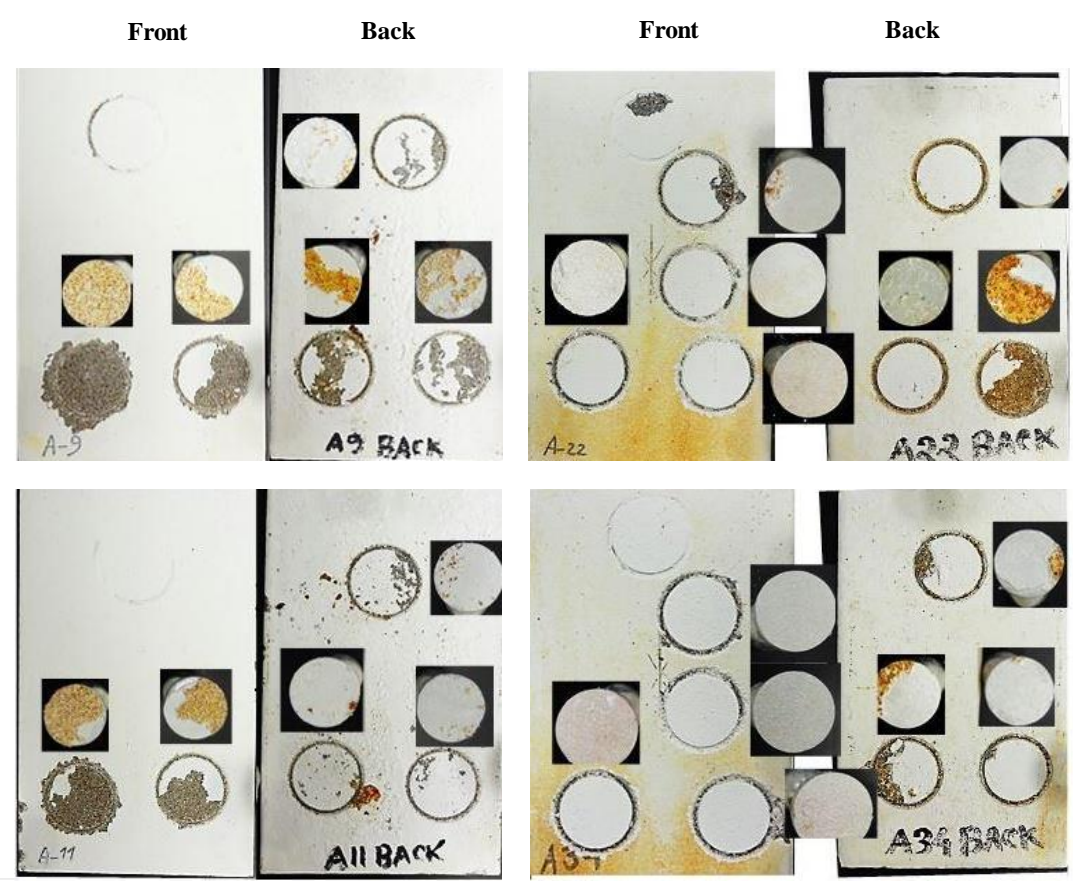

Figure A10: Exposed Substrate after Pull-off Strength of Salt-Fog Samples after 2200- Hours

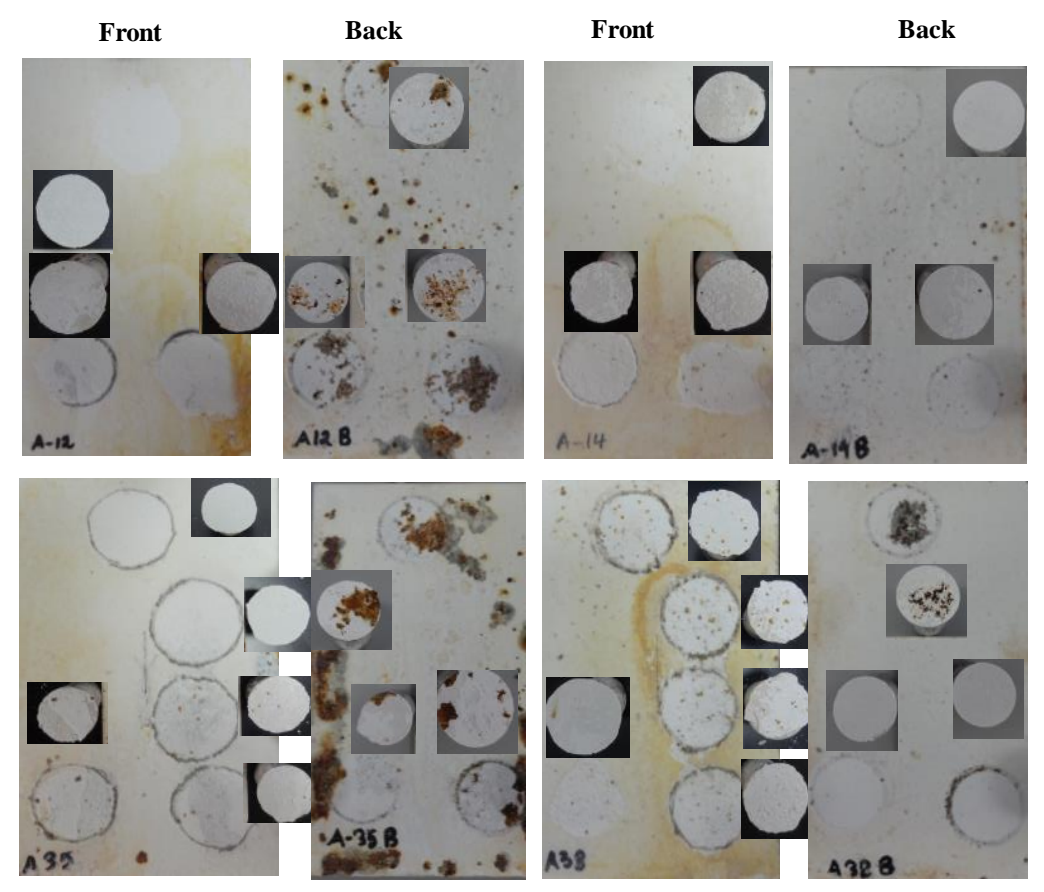

Figure A11: Exposed Substrate after Pull-off Strength of Salt-Fog Samples after 5800- Hours 


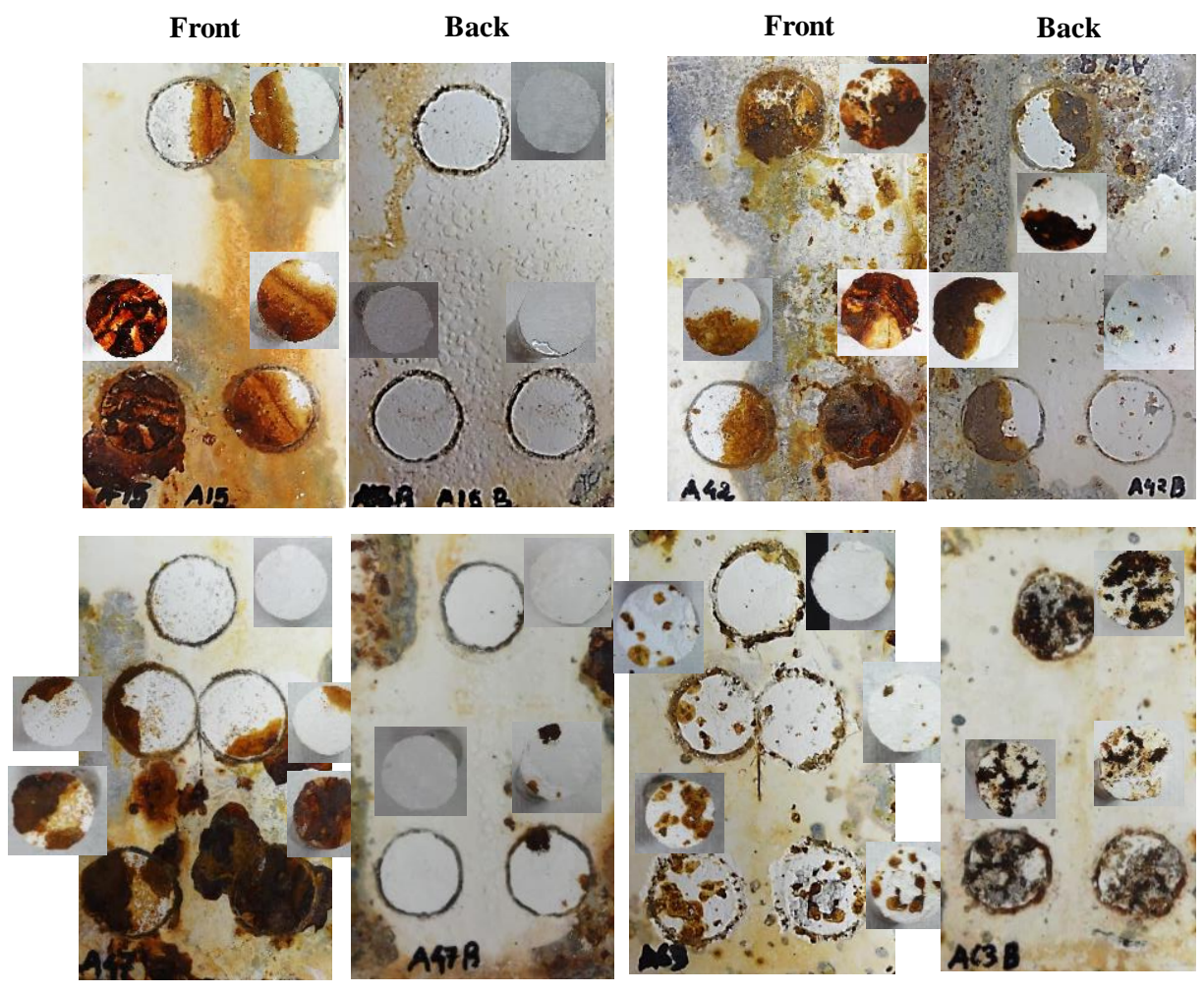

Figure A12: Exposed Substrate after Pull-off Strength of Salt-Fog Samples after 14600-Hours 
Appendix B -Copyright Release 
Date: 04/14/2017

Name: Md Ahsan Sabbir Title: Graduate Research Assistant

Company ('Publisher'): Florida International University

Address: 10555 West Flagler, Miaml, FL-33174

Tel: 7867156139

Email: msabb004giflu.edu

Publication Media: Check the applicable Box:

П MagazinedJournal ("Periodical"):

Issue:

$\sqcup$ Web ste URL ("Web Site"):

Circle the source: Materials Performance CORROSION Standards PaperiArticle Title: Update on Corrosion Performance of CBPC Coatings in Aggressive Bridge Environment

Authors: M. A. Sabbir, S. F. Fancy, K. Lau and D. DeFord

(Work") Conference Paper No, Y Year: 9593/2017

NACE Intemational ("NACE') hereby grants to "Publisher" the right to publish the Work utilizing the Publication Media elected above. To the extent the Publication Media is a Perlodical, the publication night is limited to publication in the specific issue identified above of the Periodical identfied above and this right shall automatically termingte upon the date of lasue of the particular issue of the Periodical, whether or not such Work is actually published. To the extent the Publication Media is a Web Site, the publication right is limited to publication at the specific Web Site identifled above. Any right granted herein is a limited. non-transferable, non-exclusive right. No other rights in the Work are grented herein. The Publisher agrees to hold NACE harmless and indemnify NACE against any and all legal action and expenses arising out of the Publisher's use and editing of NACE material.

Notwithstanding the forecoing. Publisher may edft or ctherwise modify the Work as reasonably necessary to accommodate the style and size requirements of the specific publication so long as the published Work that will appear in the Publication remains substantially similar to the originalWork. Any such permitted edit or modification shall maintain the integrity of the overall original Work.

Publisher shal obtain a copy of the original Work dirsctly from NACE International and shall not utilize copies of the Work from other sources, including the author(s). Publisher shall include on the published version of the Work the names of all authors listed on the original Work.

The Publisher shal include the following applicable Copyright notation with any publication of the Work:

A. Conference Paper

Reproduced with permission from NACE International, Houston, TX. All rights reserved. Author(s), Paper NUMBER presented at CORROSIONYEAR, Cly, State, 1 NACE International FIRST YEAR OF PUBLICATION.

B. Journal Article

Reproduced with permission from NACE International, Houston, TX. All rights reserved. Author(s) name, Article tille, Journal tite, Vol. no., Issue no, and publication year. NACE Intemational FIRST YEAR OF PUBLICATION.

C. Magazine Article

Reproduced with permission from NACE International, Houston, TX. All rights reserved. Author(B) name, Article title, Magazine title, Vol. no., Issue no., and publication year, E NACE Intemational FIRST YEAR OF PUBLICATION. 


\section{Standards}

STANDARDSITECHNICAL COMMITTEE REPORT NAME. O NACE Intemational YEAR. All rights resenved by NACE. Reprinted with permission. NACE standards are revised periodically, Users are cautioned to obtein the latest edition; information in an outdated version of the standard may not be accurate.

- Modifications to Notations: Oner reference wording can be used, but must be approved by NACE in writing in advance.

As between NACE and Publisher, Publisher acknowledges that NACE owns all fights in the Works. Publisher shal not be entilied to any compensation for its efforts in promoting the Work.

THE WORK IS PROVIDED "AS IS." ALL EXPRESS OR IMPLIED COVENANTS, CONDITIONS, REPRESENTATIONS OR WARRANTIES, INCLUDING ANY IMPLIED WARRANTY OF MERCHANTABILITY OR FITNESS FOR A PARTICULAR PURPOSE OR CONDITIONS OF ACCURACY, COMPLETENESS OR QUALITY AND THOSE ARISING BY STATUTE OR OTHERWISE IN LAW, ARE HEREBY DISCLAIMED.

IN NO EVENT WILL NACE BE LIABLE FOR ANY DIRECT, INDIRECT, PUNITIVE, SPECIAL, INCIDENTAL OR CONSEQUENTIAL DAMAGES IN CONNECTION WITH OR RELATED TO THIS AGREEMENT IINCLUDING LOSS OF PROFITS, USE, DATA, OR OTHER ECONOMIC ADVANTAGE), HOWSOEVER ARISING,

This Agreement and the rights granted herein may be terminated immediately by NACE upon breach of this Agreement by Publisher. Unless earlier terminated, this Agreement and the rights granted herein will automatically terminate 6 months from the Date set forth above. If the Work has not been published within that time period, a new Agreement must be obtained.

Publisher may not, directly or indirectly, sell, assign. sublicense, lease, rent, distribute, or otherwise transfer this Agreement or any rights granted herein, without the prior written consant of NACE

If any provision of this Agreement is found to be unenforceable, then this Agreement shall be deemed to be amended by modifying such provision to the extent necessary to make it legsl and enforcesble while preserving its intent. The remainder of this Agreement shall not be affected by such modification.

This Agreement does not create, and shall not be construed to create, any employer-employee, foint venture or partnership relationship between the partics. No officer, employee, agent, servant or independent contractor of either party shall at any time be deemed to be an employee, servant, agent or contractor of any other party for any purpose whatsoever.

This Agreement shall be govemed by, and construed and enforced in accordance with, the laws of the State of Texas, withou regard to the choice of law provisions of that State.

This Agreement shall only be effective if signed by authorized representalives of both parties. This Agreement constiutes the entire Agreement between the parties with respect to the subject matter of this Agreement. Any change, modification or waiver heresto must be in writing and signed by authorized represertatives of both parties.

Other Terms \& Conditions:

Publisher hereby requests permission to publish the psperlarticle described above and agrees to comply with all Terms and Concitions listed above.

Request submitted by:

Md Ahsan Sabbir

Printed Name

Graduate Research Assistant Title

\section{Signature}

$04 / 14 / 2017$

Date

Request agreed to by:

Md Ahsan Sabbir

Lead Author Printod Name

Graduate Research Assistant

\section{Lead Author Tsle}

Lead Author Signatur

$04 / 14 / 2017$

Date
Request approved by NACE:

Daniela Freeman

Printed Name

Audience Development Manager

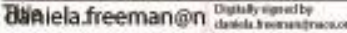

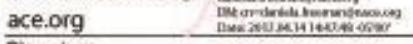

Signature

4/14/2017

Date
Third partes requeeting permission to use NACE arficles FM_PUB_05

Revised 07/20/2015 
VITA

MD AHSAN SABBIR

EDUCATION

$2012-2017$

Ph. D., Civil Engineering

Department of Civil and Environmental Engineering

Florida International University,

Miami, Florida

2008 - $2011 \quad$ M.Sc., Structural Engineering

Bangladesh University of Engineering and Technology,

Dhaka, Bangladesh

$2001-2007 \quad$ B.Sc., Civil Engineering

Bangladesh University of Engineering and Technology,

Dhaka, Bangladesh

\section{PUBLICATIONS AND PRESENTATIONS}

Sabbir, M. A., Fancy, S. F., Lau, K. and DeFord, D. "Update on Corrosion Performance of CBPC Coatings in Aggressive Bridge Environment." Paper No 9593. NACE

Corrosion 2017. New Orleans/ March 26-March 302017.

Fancy, S. F., Sabbir, M. A., Lau, K. and DeFord, D. "Durability of Nano-Coating for Marine Highway Bridge Application.” Paper No 9539. NACE Corrosion 2017. New Orleans/ March 26-March 302017.

Sabbir, M. A., Fancy, S. F., Lau, K. and DeFord, D. "Characterizing Bulk Porosity of CBPC Coating in Aggressive Bridge Exposure.” SSPC. Tampa/ January 30-February 2 2017.

Fancy, S. F., Sabbir, M. A., Boan, M. E., Lau, K. and DeFord, D. "Coating Response to Cathodic Polarization of a Nanoparticle Enriched Epoxy Primer in Aqueous Solution." SSPC. Tampa/ January 30-February 22017.

Sabbir, M. A., Lau, K. and DeFord, D. "Update on Corrosion Performance of TDG Coatings in Aggressive Bridge Environment.” Paper No RISK16-8755.NACE Corrosion Risk Management Conference. Houston / May 23-25 2016.

Sabbir, M. A., Lau, K. and DeFord, D. "Assessment of the CBPC Coating in Wet Exposure.” SSPC. San Antonio/ January 18-21 2016. 
Sabbir, M. A. Lau, K. and DeFord, D. "Corrosion Performance of TDG Coatings for Marine Bridge Application.” Paper No 5942. NACE Corrosion/2015. pp. 15

Sabbir, M. A. and Lau, K. Final Report to FDOT. "Corrosion Evaluation of Novel Coatings for Steel Components of Highway Bridges.” BDV29 977-02. March 2015

Sabbir, M. A. Presentation at Graduate Student Appreciation Week 2016. Florida International University, Miami, FL. March 2016.

Sabbir, M. A., Lau, K. and DeFord, D. Presentation at NACE Concrete Coatings Conference. Philadelphia, PA. May 2014.

Sabbir, M. A., Lau, K. and DeFord, D. Presentation at Anna Maria Workshop XIV, Holmes Beach, FL. November 2013. 